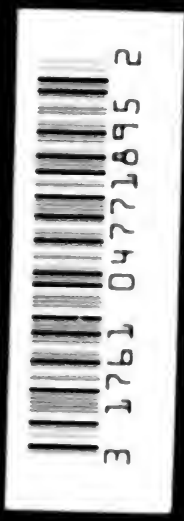


Digitized by the Internet Archive in 2007 with funding from

Microsoft Corporation 


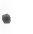
$\checkmark$ 


\section{STATISTICS IN BUSINESS}




\section{Me Graw-Fill Book Ca the PUDLISHERS OF DOOKS FOR}

Coal Age - Electric Rallway Journal Electrical World $\nabla$ Engineering News-Record American Machinist $\nabla$ Ingenieria Internacional Engineering 8 Mining Journal $\nabla$ Power Chemical \& Metallurgical! Engineering Electrical Merchandising 


\section{STATISTICS \\ IN \\ BUSINESS}

\section{THEIR ANALYSIS, CHARTING AND USE}

BY

HORACE SECRIS'T, PH. D.

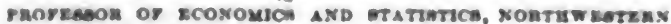

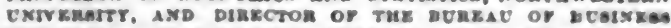

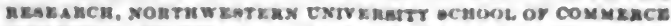

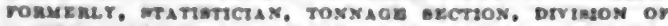

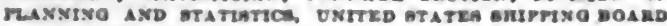
A CTHOA: AN INTHODLCTION TO ETATUTHCAL METHOD

First Edrtion

SECOND IMPkEssion
162933.

$8 \cdot 6 \cdot 21$.

McGRAW-HILL BOOK COMPANY, INc.

NEW YORK: 239 WEST 39TH STREET

LONDON: 6 \& 8 BOUVERIE ST.. E. C. 4

1920 
Copyright, 1920, bX the

McGraw-Hill Book Company, Inc. 
To

M. A. S.

H. A. S.

L. H. S. 



\section{PREFACE}

This volume has been prepared primarily for business executives, although it is hoped that it will be of use in Schools of Commerce. It aims to present briefly and concretely the reasons why statistics should be used in business analysis, and to illustrate how and with what effect they may be applied in the solution of business problems.

The volume is not intended to be a treatise on statistics. Its purpose is to serve as a handbook for executives and others in responsible positions in the application of business statistics to problems which currently arise. To this end, the discussion is of a practical character - especial attention being given to the use of graphs and charts. Both good and bad statistical usages are developed by means of illustrations, and rules are formulated which will serve to guide executives at each step in business analysis by means of statistics.

The treatment is intentionally brief. What is most needed, in the writer's judgment, is a terse, concrete discussion of statistics in business which executives will read, and which will serve to suggest the place which statistics should have as a controlling factor in business planning. This need, this book endeavors to meet.

The writer is indebted to his colleagues, Professors Walter K. Smart and Franklin Bliss Snyder, for carefully reading the manuscript, and to Professor Homer B. Vanderblue and Mr. A. W. T. Ogilvie for helpful suggestions concerning the applications of statistics in business.

\section{Horace Secrist.}

NoRTHWEsters UNiversitY,

December 15, 1919. 



\section{CONTENTS}

Canten Paus

I. Modern Business and Fact Amalysis. . . . . I

II. The Facts of Business . . . . . . . 5

III. Recognizing and Securing the Facts. . . 26

IV. Classifying and Tabulating the Facts ... 41

V. Presenting the Facto-Graphics. . . . . 55

VI. Summarizing the Facto-Averages and Other Means . . . . . . . . 97

VII. Comparison and the Establishment of Business

Principles and Standards. . . . . . 124

INDkx. . . . . . . . . . . . 131 



\section{STATISTICS IN BUSINESS}

THEIR ANALYSIS, CHARTING AND USE

\section{CHAPTER I}

\section{MODERN BUSINESS AND FACT ANALYSIS}

Business, as known to the producer, to the consumer, and to the public generally, is personified in the merchant, the banker, the manufacturer, the farmer. Representatives of each class may be known personally, but as a whole, business is seen as the impersonal organizations and relations upon which production, distribution, and exchange depend.

Some businesses are small, some are large. Some are the result of almost world-wide activity and foresight, while some are of local significance and of limited outlook. Whatever their size, or the extent of their activities or influence, they are the operating units through which the wants of mankind are satisfied. They are individual, partnership, and corporate enterprises. To some, they represent accumulated wealth operating only as profit makers; to others, they are primarily service units, providing the necessities, the comforts, and luxuries of life. They are coopperative organizations, through which modern complex society, by the use of natural resources, labor, and inventive genius, not only satisfies its wants, but also expresses its creative faculties. To the business man, 
as such, they are the organized machinery for making profits; to the public, as consumer, they are the means of satisfying wants.

Viewed from either angle, such business units rest on coöperation, trust, confidence, and good-will. Society as a whole, and as classified groups, realizes its economic life through them. This has always been so, but the type of the modern business is different from the ancient. Modern industrial life is complex, the units are relatively large, the classes dealing with them diverse, and the relations between them impersonal. Some of them must meet world competition; others, only that which is local. But they must all deal with an increasingly discriminating public, and with an intensified competition. Competition applies to price, service, and cost. Costs extend to a whole world of commodities, and service is drawn from ever extending areas, and from an increasingly independent labor market. Prices are governed by local and by national conditions, and the standards of service are progressively severe and exacting. Modern business cannot ignore these facts, nor blindly meet the issues which they raise. The day of chance gains and treasure trove is passing, if it is not past. The possession and use of facts in business today spell the difference between success and failure. No longer is it enough to trust to luck and to rule-of-thumb methods. Economic and business judgments must be based on facts, properly analyzed and interpreted. Appeal to force of custom and long continued practice no longer suffices as a basis for an economic program, or business judgment. Ours is the age of the concrete. The reasons for success or failure must be sought in 
realities. A fool's paradise in business brings with it its just reward.

So strongly has the need for classified knowledge come to be felt by successful business during the last two decades that a true accounting is today considered not only desirable, but indispensable in industry. There are some who still say, "We keep no accounts, we are successful business men," but this tribe is fast becoming extinct. Accounting has clarified the occasion for profit and for loss, and accurately stated the amount. Business has aimed to be intelligent as to past operation; it has only here and there begun to be scientific as to policy and future activity. A strict accounting serves to meet the problems internally; statistics or fact analysis will meet them generally.

Now, fact analysis is nothing but an application of scientific method. What does it imply? Scientific method in industry means recognizing facts and acting in the light of their interpretation. It means taking note of small differences, seeking for the similarities and basic truths which govern business and industrial relations, and being guided by them. It means foresight, rather than hindsight; planning rather than customary behavior. It means innovation and change, if an impersonal analysis of the facts suggests them. It means fearlessness and respect for facts.

Scientific analysis of business and industrial problems requires, first, a point of view, and second, a method. The point of view is an unconditional demand for the truth; the method is (1) intelligent observation; (2) impartial analysis; (3) logical inference; and (4) sincere application of the conclusion reached to the problem to which the facts and obser- 
vation apply. Business facts are numerous and increasingly complex; they are ever changing in content and application. To know them requires keen observation; to secure them, organization; and to apply them, determination and business integrity. There is a science of business and industry, the underlying facts and principles of which can be determined, and they must be applied, if planning and foresight are to take the place of guessing and rule-of-thumb action.

Business and industry need facts, but most of all they need analysis of facts and application of them to current problems. Business will not run on, but down, on the momentum of customary action. Fresh and continuous analysis of facts is indispensable. The need is for an appreciation of facts, an ability to observe truthfully the conditions which produce them, and a determination logically to use them in such a way that they will serve as rules for business guidance. 


\section{CHAPTER II}

\section{THE FACTS OF BUSINESS}

What the facts of business are which need to be recognized, understood, and applied to business problems, it is the purpose of this chapter to answer. But first, the nature of a "fact" must be considered. The facts which can be used scientifically in business and industry, must be commensurable. They must be stated, enumerated, or estimated according to suitable standards of accuracy; they must be collected systematically for a definite purpose, and must be capable of being used comparatively. They are the raw material upon which positive conclusions are to be based, and, therefore, must be definite, measurable quantities.

When they exist ready for use, they must be scrutinized and their meaning understood. When they do not exist ready at hand, they must be collected or secured with these thoughts in mind. How they may be secured and the tests to which they must be subjected, it is the purpose of the following chapter to explain. It is the purpose of this chapter to describe briefly the kinds of facts by which business and industry must be positively guided.

Business and industry may be classified according to the functions which are performed. From this angle, the producing, selling, marketing, transporting, 
and credit-making services are significant. For instance, industry is designed for production purposes. Raw materials, finished and partly finished commodities, find their way into the great maw of organized industry, to be turned out as finished products, ready for consumption, or as partly finished products, to be turned back again into industry, and subjected to further alterations, combinations, or changes. Transportation, selling, marketing, and credit extending are all incidental to production and preliminary to final consumption.

What detailed facts must be known about these processes, if they are to be intelligently conducted? Socialists and others characterize competitive industry as wasteful, meaningless, and anarchistic in many of its processes, and the criticism to a large degree is valid. In a given plant, purpose and order may obtain, but within industry as a whole, chaos may reign. How can private industry meet the challenge of its opponents, and justify itself through the application of scientific methods?

Production implies the creation of commodities and services in response to, or in anticipation of, demand. It requires continuous and uninterrupted additions of capital, wide and certain markets, an uninterrupted flow of raw materials, and a contented and industrious labor force. In order for production to be conducted intelligently, the contingencies affecting any and all of these factors must be definitely known and discounted. If iron or steel constitutes the basic raw material upon which an industry depends, the peculiarities of its production, the sources from which it is drawn, its price determining factors, transportation 
difficulties and facilities, and its relationship to credit conditions must be appreciated. These can hardly be known in detail by a single producer for a single supplier, but as reflected in that indefinite, yet very real, thing known as the market, they are determinable. There are capital, labor, and credit markets, and these the business man should know and be able to interpret. Moreover, the conditions governing transportation and consumption are patent to those who have eyes to see and understanding to appreciate. The producer, like others in the intricate organization of business and industry, must realize the fact that economic life expresses itself in the basic facts of crop production, credit extensions, business failure, capital formation, labor satisfaction and distrust. The view of the forest, however, must not be confounded with that of the trees. The view points must be complementary. This is no less true for other types of business than it is for the producer.

A more intimate view of some business functions in relation to fact analysis will be of interest. Why are goods, either as raw material or as finished products, imported? How does the imported compare with the domestic product in relation to price, certainty of supply, costs in transportation, ease in handling? How does it stand in relation to substitutes and competitive conditions? Why push export sales? Are home markets exhausted, or has the point of diminishing returns been reached? Is the foreign consumer known as well as the domestic; are there race prejudices, national peculiarities and trade customs, which must be overcome? Have these been measured, and their significance considered in the action taken? 
Have the facts been determined in shaping the policy, or is the line of action the customary or convenient one? "Look and see," is the perpetual injunction with which industry must ever comply.

But "seeing" is discriminating. To those who are business blind, markets, price policies and labor appear as homogeneous phenomena to be treated by fixed formulæ. The solution of problems is thought to be automatic. To those who really look and "see," all business problems break up into numerous phases, each requiring different treatment as principles of psychology, social and labor theories, etc., are involved.

But business and industry may also be looked at from another angle. In both, the facts of labor, for instance, must be known. What wages are paid, and why? What are the living conditions in industry? Do they tend to foster a spirit of confidence and goodwill, or to play upon and accentuate industrial ill-will? What are the sources and race characteristics of the labor force, and how are these related to questions of strikes, unrest, sabotage, unemployment, accidents, labor turn-over? Is only labor power secured when a changed policy would guarantee labor interest? Is industrial good-will or ill-will, capitalized?

Other facts, bearing as intimately as those connected with labor on the success of industry, must be surveyed and used. Capitalistic or machine methods made modern large-scale industry possible, and business is becoming increasingly capitalistic; yet the possibilities of machine production, involving roundabout, time-consuming, but prolific processes, are only faintly realized. How often today is the introduction into industry of capitalistic devices accompa- 
nied by an application of scientific method, in order to test their fitness, usefulness, and cost? The hit-andmiss, rule-of-thumb method triumphs in all but the largest andwmost enterprising industries. The small, struggling, wasteful, and planless business still endures. A long-time point of view, accompanied by observation and experimentation on the economies of particular capital devices, is not the rule. It should be, however, and undoubtedly will be as soon as the business man becomes keenly alive to the logic of facts and the significance of planning in industry.

Moreover, capital is the result of saving, and takes the form of capital goods, only through investment. Does the modern business man know the investment market? The public is not a homogeneous mass which absorbs so many loans or exudes a certain capital fund. It is composed of discriminating and differentiating groups reacting differently to different conditions of credit, time, risk, and economic return. Moreover, the public does not respond uniformly toward all types of enterprise. To the conservative investor, mining stock is taboo; to the plunger, his forte. Public utility securities, under a given philosophy of regulation and the laws of certain states, may be considered as choice investments. Under different philosophy and laws they may be a drug on the market. Does the business man know the principles of investment, the technique of security issue, and the facts which give investment principles validity?

Again, is business cognizant of the facts, practices and policies which stimulate confidence and trust, and develop credit? Business today is almost synonymous with credit, reaching out into the fields where it flows 
and retreating where it refuses to go. What creates it, what measures it, what retains it? Only business self-analysis will suggest the answers. Failure to receive credit brings ruin. Of this any business is certain, yet knowing this, the conditions which support credit are ignored because of a frenzied rush for immediate profits and a disregard of underlying principles and their analysis.

The commanding single element in business is, of course, profit. Profit is the difference between costs assumed and prices realized. What are the determining factors in both? Every business man is perpetually straining with them, but how many study scientifically the underlying principles of price determination? Why are market prices fixed at the current levels? What relations exist between costs of production and prices, between retail and wholesale prices, between the prices of producers' and consumers' goods, between the prices of complementary goods, between the prices of goods produced under conditions of joint cost? What is the elasticity of a given market? What pressure will it stand? Is it equally elastic at all points, and for all goods? How high can a price be before it reduces sales; how low must it be to stimulate them? What latent buying power is there and where does it exist?

Rule-of-thumb methods and customary behavior will not answer these questions, but the application of scientific method will. Fact analysis in business and industry makes planning intelligent. It gives a substantial basis for constructive judgments. Business under such circumstances is not enshrouded by a halo of obscurities, nor fettered by a web of indefensible 
praciices. It is still conducted for profit; it still renders service, and appeals for industrial and popular good-will, but it has incorporated in itself the spirit of scientific method.

It is unnecessary to show how the need for fact analysis extends to other aspects of business. To the reader who has caught the meaning and spirit of scientific method, simply to enumerate a few of these will suffice to call his attention to its further application. Costs, prices, public restrictions, and scientific uses, all apply to land, both as a factor in production and as a marketable commodity. Values for taxes may differ from values for industrial uses. The principles governing rents and tax capitalization offer a broad field for business research. Are taxes shifted, and if so, what are the results due to cost, public discontent, and the distribution of economic burden? What are the relative advantages of land and capital goods under different conditions of business growth and decline; different conditions of costs of production and tax policies?

The results of business activities are revealed in the amount of profit; in industrial growth and decline; in the facilities for exchange; and in transportation and industrial and social well-being and discontent. Profits must be studied and the reality of them determined. Real, must not be confused with paper, profits. Profits must be thought of both from the short- and the long-time points of view. Failure adequately to provide for depreciation and obsolescence may give immediate gains but ultimate loss. What is a reasonable and conservative depreciation rate? Analysis of operation will determine. The rate, we 
may be sure, will be different for different properties and for different conditions of operation, but the amount cannot be divined in some occult manner, nor left as a "detail" to take care of itself.

The amount of profit and the business outlook may suggest retrenchment or development. Where shall it be made? Costs are not generally uniform, nor are profits the same on all goods produced or sold. The results of contraction or expansion may be satisfactory as to costs, but ruinous as to profits. The market may be spoiled by additional goods, and costs persist in spite of curtailed production.

Business, although competitive, is also coöperative. One producer satisfies the demand of another. Trade is more than economic rivalry. The gain to one is not a loss to the other. To satisfy economic wants is the goal of all industrial enterprise, and economy and the scientific point of view suggest that a spirit of live and let live should characterize industry. The truth must be known, whether it applies to questions of industrial technique, to matters of industrial relations, or to any other economic fact. The more broadly knowledge is disseminated, and the more general the scientific frame of mind becomes, the more nearly will economic waste and friction be dissipated and human welfare maintained.

Industrial growth today is determined by the business man. His responsibilities to society are large and his opportunities great. If he accepts the scientific approach to his problems, is fearless enough to scrap his prejudices, and at the same time constructive enough to observe the facts; if he reaches impartial conclusions on the basis of the facts, and then 
applies them honestly to his problems, one need have no fear in leaving the directive power in his hands. If he is timorous, cringing, intellectually inert, and oblivious to the facts of industry, then industrial society must be recreated.

An outline view of the facts with which the business executive must be familiar, and the meaning and application of which he must sympathetically understand, is given below. No attempt is made to contribute a complete catalog, nor to furnish a classification which will meet all of the needs of every business, but only to supply under classified heads the outstanding and basic facts of business.

LABON FACTs:

Wages, wage-rates and earnings.

Hours.

Union membership, and types.

Strikes and lockouts

Accidents.

Compensation, Industrial and Health Insurance.

Unemployment.

Turn-over.

Immigration.

Capital Facts:

Capitalization.

Resources.

Earnings.

Prodoction Facts:

Agricultural crops.

Raw materials extracted.

Manufactures.

Stocks on hand.

Popthation Facts:

Geographical distribution.

Occupations.

Earnings. 
Market Facts:

Money.

Banking.

Credit.

Trade.

Commodity prices.

Security prices.

Competition.

Failures.

Forecasting.

Land and Bullding Facts:

Land and building values.

Taxes.

Restrictions on use.

Transportation Facts:

Foreign rates and fares.

Foreign facilities.

Domestic rates and fares.

Domestic facilities.

Domestic control.

LAW AND PouICY FActs, as expressed through law and the activities of

State Railroad and Utility Com missions.

State Tax Commissions.

State Industrial Commissions.

Federal Trade Commission.

United States Department of Agriculture.

Unted States Geological Survey.

Interstate Commerce Commission.

United States Tariff Commission.

It is not enough, however, simply to appreciate that these facts have business significance. It is necessary to know where the data bearing on each of the various subjects may be secured, to know something of their peculiarities, and to be able to use them in connection with the problems which currently arise.

The following bibliographical comments have reference only to the major sources of business facts, and to 
some of the more evident criticisms which might be made of them. Both the sources and the cautions are significant more as a general than as a detailed statement.

\section{LABOR FACTS}

For business, as a whole, no single source of data on labor facts is superior to the publications of the United States Bureau of Labor Statistics, and no single publication of this bureau is more significant than the Monthly Labor Review. This publication contains literally a mine of information, discriminately collected and issued in such form as to meet many of the needs of business with respect to general and detailed labor facts.

Wage-rates and Earnings.-Particularly is the above publication significant in the presentation of wage and wage-rate data for the larger industries, and for union labor. The wage and wage-rate data are as nearly comparable as they can be made for different times and for different types of enterprises. They are supplied not only in the form of actual rates, in which distinction is made for regular, overtime, and specialized conditions, but are reduced to a comparative or index number basis, so as to be of service for historical comparisons. The publication does not regularly contain wage-rates for non-union labor. However, from time to time, wage data are given on non-union employees, and from them a comparative picture, at least for a few industries, may be secured.

Union Membership and Types.-The Monthly Labor Review, reports of the New York Industrial Commission, and the Annual Report of the Proceedings of 
the American Federation of Labor contain data on union membership, types of organization, union agreements, and other union activities.

Strikes and Lockouts.-Similarly, data on strikes and lockouts are published in the Monthly Labor Review. The data are secured, for the most part, from union secretaries and others who are in a position to know the facts, and are reduced to a comparable basis for important industries and for great industrial centers.

Accidents.-Statistics of industrial accidents are also published in the Monthly Labor Revicw, in a comprehensive way, through special studies growing out of the Bureau's surveys, and in compilations of accident experience, as reflected in hazardous industries. The steel industry has been given particular attention in this respect. Moreover, the Review regularly summarizes the legislation having to do with accidents and their compensation, with the rules governing the installation and use of safety devices, etc.

Compensation, Industrial and Health Insurance. The Monthly Labor Review regularly contains discussions of compensation, as well as industrial and health insurance, and gives the statistics that are significant on these subjects. The business man, in these days of liability for accidents and industrial disease, cannot afford to be unacquainted with these facts, as here summarized, and with the developments in these important industrial fields.

Unemployment.-From the standpoint of the individual, and of industry as a whole, unemployment is a serious problem. It represents an economic waste from the standpoint of the person unemployed, and 
is proof of industrial mal-adjustment for industry as a whole. Unemployment data, secured from the larger industrial centers and employers, and from union records, are periodically published in the Monthly Labor Review. They serve as a basis for measuring the state of the labor market and the source of labor supply. In this field, the publications of the New York Bureau of Labor and of the Massachusetts Industrial Commission, are significant.

Labor Turn-over.-Labor turn-over in industry is a problem to which the business executive is finding it necessary to give more of his attention. His success depends upon a stable and industrious labor force, and every attempt should be made to reduce the turn-over to a minimum. A high labor turn-over figure represents a loss to the employer, and a sacrifice of wages to the employee. Standards for measuring it and the experience of larger industries, are fully discussed in the Monthly Labor Review, and business executives should be acquainted with this treatment. Figures on labor turn-over are so susceptible of mis-interpretation, and what constitutes labor turn-over is so difficult of measurement in a form to be significant, that the service of the Bureau in digesting experience and establishing standards for the measurement, ought not to be overlooked.

Immigration.-The most important single source of data on immigration is the reports of the United States Bureau of Immigration. Immigrant labor has constituted, and will continue to constitute, an important element in our labor supply. The relationship of immigration to industrial development, to a fluctuating labor supply, to turn-over, and problems of manage- 
ment, is so vital that business executives must see this subject in its broader aspects, and attempt to measure its application to their problems as they arise. The facts on immigration are conveniently summarized in a useful form for business in the Monthly Labor Review.

\section{Capital Facts}

The sources of information on capital facts are numerous. At five-year intervals for industrial and manufacturing enterprises, the amount of capital employed is published in the reports of the United States Census Bureau. The data are only roughly accurate for separate industries, but are significant even in this form as measures of business activity.

Capitalization, as distinct from capital, is also reported for industrials, for railroads, and other types of corporations, in Moody's Manual, Poor's Manual, etc. The data from these sources are given for individual enterprises, rather than for industries as a whole, and business should be thoroughly familiar with them. Similarly, the capitalization of corporations and other forms of business enterprise, is given in annual reports, and in the financial prospectuses issued by investment houses at the time loans are made and securities underwritten.

Resources.-The resources of corporate and other enterprises are described in detail in such financial publications as Moody's Manual, Poor's Manual, etc. These publications should be on the desks of business executives and constantly referred to in matters affecting credits, investments, etc.

Earnings.-The earnings of industrial and other enterprises are, of course, the most single significant 
fact in relation to business promotion and success. Earnings, as reported, are often deceptive. So much depends upon the interpretation of the term, the conditions under which the figures are measured, and the periods to which they apply, that discrimination is needed in the interpretation of the figures supplied, no matter what the source of the data is. For these facts, in relation to industrial enterprises, not especially subject to public regulation, recourse must be had to financial journals, such as Bradstreet's and Dun's. For railroads and public utilities, where regulation by state or federal authority is the rule, and where uniform systems of accounts prevail, earnings as published may in a more accurate sense be considered authoritative.

\section{Production Facts}

Crops.-The United States Department of Agriculture regularly and periodically supplies facts concerning crop production, crop condition, crop prices, etc. Particularly worthy of mention as bearing on these problems, is the Monthly Crop Report. This report gives estimates for the main crops on acreage, prices, total production, acreage production, and similar subjects. Special reports are periodically made on crop production, and intensive studies are published from time to time on other important agricultural problems.

Raw Materials Extracted.-The primary source of information on extraction of raw materials, is the Geological Survey. The reports from this source cover oil, iron, coal, etc., and are prepared in coöperation with state geological surveys and producers of such commodities. Typical private publications hav- 
ing to do with metal and mineral products are The Iron Age; The Manufactures Record; The Metal Industry; Engineering and Mining Journal; Drugs, Oil and Paint; Coal Age.

Manufactures.-The United States Census Bureau is the primary source of information on manufactures. The reports cover capital invested, raw materials used, wages paid, number of employees, etc., for practically all of the important industries of the United States. A five-year census is taken, and reports are issued by industries and by states. From these data, bulletins are published at intervals so that it is possible to make an industrial picture of the country, and to measure the development which takes place in each of the industries covered. Many of the data are little better than carefully prepared estimates, but are of distinct service to business executives and others upon whom the problems of industry rest. Typical private publications dealing with manufactured products are India Rubber World; The Leather Manufacturer; Fiber and Fabric.

\section{Population Facts}

Geographical Distribution.-The geographical distribution of the population of the United States is shown in the reports of the United States Census Bureau at its decennial census. These data furnish measures of population concentration, migration, and growth, and, if carefully interpreted, may be used in estimating the buying power of different markets. Taken in connection with the Bureau's report on Occupations, and the reports of the Treasury Department on internal revenues and income taxes, and with the reports of the Bureau of Agriculture, these data may 
serve as a basis for sales and advertising campaigns, for the study of the localization of industry, and other industrial purposes. The data are only roughly accurate, but rough accuracy is all that is demanded in this case.

\section{Market Facts}

Money. - The facts concerning the circulation of money and the production of precious metals, are eontained in the federal government's reports issued by the Treasury Department, the Comptroller of the Currency, the Federal Reserve Board, etc.

Banking.-Data on banking activities are regularly issued by the Federal Reserve Board in its Bulletin, and by the different state bank commissioners, and are summarized conveniently for the business man in such private publications as The Commercial and Financial Chronicle; Dun's Review; Bradstreet's and The Annalist. The resources and liabilities of the United States banks are included in the reports of the Federal Reserve Board, and those of the state banks in the reports of the various state bank commissioners.

Credit.-Comprehensive facts concerning credit are to be had from the private publications named in the paragraph above, and in the daily press where market data on loans, interest rates, clearings, domestic and foreign exchange rates, etc., are published.

Trade.-The most satisfactory source of trade data is the Monthly Summary of Commerce and Finance, issued by the Department of Foreign and Domestic Commerce, Washington, D. C. In this publication, exports and imports are given in detail, both as to quantities and as to value. This publication, together with the daily and other reports of consular 
agents, should be a common source of information to which business men should turn for data on this phase of their business activities.

Commodity Prices.-Data on commodity prices are published regularly by the financial journals, such as Bradstreet's; The Annalist; etc., but are most conveniently and authoritatively compiled by the United States Bureau of Labor Statistics, and published in the Monthly Labor Review. This publication includes both wholesale and retail prices, and gives both the actual and relative prices for goods which enter into a consumer's budget, and into the process of production. This publication compiles both whoesale and retail price index numbers, and, as nearly as is possible, supplies a barometer of price condition and change for the United States. Commodity prices are also included in a great number of private publications, such as The Iron Age; Drugs, Oils and Paints; Fiber and Fabrics.

Security Prices.-Security prices of listed and unlisted securities, besides being reported in the daily press, are summarized at intervals in such publications as Bradstreet's; Dun's; The Annalist; The Economic World.

Failures.-Statistics of financial and industrial failures are reported regularly by Dun's Review, and these represent the best available figures for the country as a whole. Failures constitute a barometer of trade and business conditions, and are significant in business forecasts.

Forecasting.-Statistical data of a business character are used as a basis for business forecasting by the Babson Service, Brookmire Service, Moody Service and 
Harvard Committee on EconomicResearch. The chief merit of the services issued by the Babson, Brookmire, and Moody organizations consists, in the writer's judgment, in the great amount of data which are collected, and which are made convenient for business use, rather than in the forecast which is made. These services are open to criticism in the use which is made of the data, and in the assumptions which are made concerning business cycles; and should be used by the business man rather as a relative than as an absolute measure of business conditions and likely change. The service now being issued by the Harvard Committee on Economic Research is thoroughly scientific, and seems to possess distinct merits in actual forecasting.

Land and Building Facts. - Statistical facts of which the business man should be in possession concerning land and building values, taxation, and restrictions on their use, can be secured by a study of the reports of assessors, tax commissioners, and others having to do with taxation matters. Unfortunately, these facts are sometimes not available for business use, and in many instances are not prepared in such a way that they are of distinct service to business as issued. The main facts are available, however, even though they may require considerable interpretation and readjustment for particular uses.

\section{Transportatron Facts}

Domestic rates and fares for transportation service are regularly published, under the supervision of the federal government, by carriers and tariff associations. At the present time, the supervision is exercised by the Railroad Administration, and by the Interstate 
Commerce Commission, jointly. There is no occasion for the business man to be in doubt concerning transportation charges, since the law clearly requires that full publicity shall be given to them.

The reports of the Interstate Commerce Commission on freight and passenger movements, on wages and financial conditions of transportation companies, constitute a veritable mine of information, and under the newly provided accounting system, will be of even more distinct service than the reports have been in the past. The private publications which most fully cover transportation facts are the Railway Age Gazette, and Poor's Manual, and the reports of the Bureau of Railway Economics, Washington, D. C.

Law and Policy facts as Expressed Throvgir Law, and the Activities of State and Federal

Boards and Commissions

The results of the operations of public utility commissions, and other state and federal boards, are currently summarized in their annual reports. These reports, moreover, contain suggested laws, legal interpretations, restrictions, and methods of control, with which the business man should be familiar, and which are fundamental to his success. These commissions have to do with railroad and utility companies, tax methods and measures, industrial compensation, health and accident insurance, wages, trade activities, combinations, competition and business practices, tariffs, etc.

The attitude of the government toward types of business and the methods which are followed, should 
be known, so far as is humanly possible. No condition is so detrimental to business as uncertainty. Public opinion, so far as it has been crystallized, may often be read in these reports, and the business man must be familiar with them.

It is not intended, of course, that every business executive should be familiar with all of the facts suggested above, or the sources from which they may be secured, but it is necessary, in so far as the problems of his business extend into the fields mentioned, that these and other sources of information should be thoroughly known, and the data which they contain be fully understood.

Many of the facts which are needed by business, in order to approach its problems in a scientific manner, are available in such sources as those listed above; others are in process of collection; and others must be secured de novo. Where these facts are, how good they are, and the methods by which they may be secured, are discussed in the following chapter. 


\section{CHAPTER III}

\section{RECOGNIZING AND SECURING THE FACTS}

The statement was made in the beginning of the last chapter that a business fact, in order to be used as the basis for a business judgment, must, among other things, be definite and measurable. In this chapter this point of view is given definite application, and its importance illustrated by reference to concrete problems.

Every business, large or small, is daily confronted by a series of problems. Some of these are current, others are periodic. About the solution of them there is often a degree of uncertainty, which on the surface is baffling. Deeper down, however, many of them may, on investigation, be found to rest upon a relatively few major issues, and group themselves about a few basic facts. Their solution may in part be accomplished by a proper approach. The problems may, for instance, relate to the advisability of beginning a campaign of advertising, of increasing a labor force, of more thoroughly cultivating certain sales territory, as an alternative to lowering prices, or readjusting production methods, in view of increased wages and shorter hours. In what frame of mind must the busines man, no matter how large or how small a business he controls, meet them? What must be his attitude toward them? It cannot be one of inattention and disregard. Problems have a way of 
becoming cumulative, and to defer them, or to leave them to self-adjustment and self-settlement, is ruinous in the end.

Every business problem should be approached by an executive with:

First, a clear and certain respect for the truth; second, a desire to understand the facts and to apply them whole-heartedly toward a solution of the problems. The first involves a point of view; the second, a method of procedure.

The first two chapters have, we hope, established the necessity for the application of the scientific method to business problems. So much for the point of view. It can now be taken for granted, and the discussion proceed at once to the conditions which govern its application.

A business fact, statistical or otherwise, is always relative. "Success" is not absolute; neither is "failure." "Bumper" crops, "poor" trade, "bull" markets, "successful" advertising, "high" interest rates, and "steady" markets, are relative expressions. The statistical data which express them, although definite, are not to be interpreted in an absolute sense. The measurements are relative and must be appraised in connection with the problems and the conditions to which they apply. The relation between a problem and its measurement is reciprocal; the fact ought not to be divorced from the problem, and the problem cannot be understood without the fact. The following examples of statistical facts, considered in connection with concrete problems, will illustrate the meaning of this truth in business affairs.

A strike is a statistical fact. It is commensurable 
and may be stated numerically, as twenty during the year. But not all strikes are identical. They differ as to the number of laborers and others affected, size of industry involved, duration, grievance, temper of strikers, issues at stake, etc. The amount of gross sales in dollars is another statistical fact. But two sales experiences of equal gross amount may be different in every other respect. One may result from an intensive campaign of advertising among small towns in an old field; the other, from the practice of direct selling in virgin fields, with an entirely different sales organization.

An industrial accident, likewise, is a statistical fact, but its meaning is different for different industries, size and nationality of labor force, industrial hazard, conditions of operation, duration of exposure, etc. The experience of the industries of one state, as reflected in the number or result of accidents, is of little value in another state unless the basis of enumeration is uniform and the duration of exposure is expressed in a common unit. The same is equally true in comparing accident frequency and accident severity rates in two departments. Most of the statistics of labor turn-over, when removed from the particular plant or industry in which they are collected, are of little comparative value. Units of measurements are not abstract; they refer to definite and measurable things. A ton, for instance, is invariably a ton; but all tons, except as to weight, are not the same. The problem of enumeration is not so much that of counting the same thing, as it is of counting different things which are given the same general name; things which are equal to each other in name 
are often not so in use. Facts must be standardized, and standardization implies homogeneity; it suggests suitability to conditions required in the light of particular application. The meaning of a business fact is a function of the use to which it is put.

The point which is being made is that the meaning and use of business facts cannot be dissociated. The scientific method requires that problems be broken up into their various parts, that these be measured by homogeneous units, and that comparisons rest upon common qualities. Comparisons are invalid, and fact analysis useless for business purposes in the degree to which this truth is ignored.

The tests by which a fact may be appraised as a basis for a business judgment, are suggested by the uses to which they are to be put. If crude comparisons only are wanted, imperfect facts will suffice. Trade buoyancy may be measured for general purposes by the amount of exports, imports, or bank clearings, or by orders for steel or some other basic commodity. But individual business policies, and the way in which they should be adjusted to meet specific problems, can hardly be based upon such general figures. Not that it is unimportant in business to understand trade movements and to observe the fundamental tendencies in trade, finance, labor and production. All these are significant, but how fully an individual business may profit or suffer from them can be determined only by a business analysis of the particular problems with which it is concerned. A nicety of discrimination is required both in diagnosing particular business ailments and in prescribing the remedies for them. Only rarely can business 
judgments safely rest on crude approximations. Business is being conducted on narrow margins of profits. The source of profits, the responsiveness of customers to price policies, and the ways in which coöperation and interest on the part of labor may be secured can be determined only through business analysis. Analysis involves comparison, and comparison requires the establishment and use of standards. These can rarely be of a general character.

Without attempting here to set up standards for specific types of business facts, since each fact must be interpreted in connection with the problem to which it relates, it may be helpful to enumerate briefly the conditions which are of universal application.

As a basis for comparison and application of scientific method, statistical facts must, first, be homogeneous. Characteristics which are significant for the purposes for which the facts are to be used, should not be ignored. For instance, men and women should be differentiated in wage comparisons; town and city population, in developing sale campaigns; religious persuasions, frequently, in estimating buying power. To consider a market without distinguishing consumers' buying power, their personal peculiarities or their incomes would be equivalent to treating as homogeneous that which is clearly diversified. Differences of training, psychological behavior, standards of livelihood and tastes are all significant in shaping selling policies. People are homogeneous as to comparatively few characteristics. The business man who conceives of his problems scientifically will take note of all differences which are significant from the 
point of view from which he proceeds. Comparisons between the turn-over of goods may be misleading if this requirement is forgotten. The turn-over figure for one type of merchandise can not be accepted for another. The market price which would discourage sales in one field acts as no deterrent in another. Labor, too, is non-homogeneous. In a general labor turn-over figure are represented casual and responsible labor services. To replace some, costs are negligible; to replace others, costs are prohibitive. Comparisons must be made between things having common qualities, regard always being had to the purposes in mind. Violation of this principle leads to imperfect generalizations and false conclusions.

Second, statistical facts must be representative. Unrepresentative facts, due either to ignorance or to conscious design, are an uncertain basis upon which to base a business judgment. Where bias rules, the occasion for error exists. When the motive to deceive is present, little difficulty is encountered in making a case. Bias may be due to wilfully eliminating part of the facts, to basing conclusions on insufficient data, or to comparing periods or conditions that have nothing in common. Truth is desired, and every effort must be made to attain it. It is the function of the facts to reveal truth, not to conceal or distort it.

In market analysis by sampling, the question is always important: Are my samples representative or is there bias running through them due to selecting too narrow a territory, too small a group or too restricted a class? Statistical principles require that every sample must contain the characteristics of the group and that these be represented in proportion to their 
presence in the original data. Cast of living data selected from one economic strata will hardly suffice to determine a disputed wage adjustment for another group whose incomes are different. For instance, the amount and per cent. of expenditure for food for 12,096 white families in 92 industrial centers varies for each income group as follows: ${ }^{1}$

Table 1. - Amount and Per Cent. of Expenditures for food by INCOMn Groups

\begin{tabular}{|c|c|c|c|c|}
\hline \multirow{2}{*}{ Income groups } & \multirow{2}{*}{$\begin{array}{l}\text { Number of } \\
\text { families }\end{array}$} & \multirow{2}{*}{$\begin{array}{l}\text { Equivalent } \\
\text { adult males }\end{array}$} & \multicolumn{2}{|c|}{$\begin{array}{l}\text { Average yearly expenditure } \\
\text { for food }\end{array}$} \\
\hline & & & Amount & Per cent. \\
\hline Total & 12,096 & 3.33 & $\$ 548.50$ & 38.2 \\
\hline Under $\$ 900 \ldots$ & 332 & 2.89 & 371.61 & 44.1 \\
\hline$\$ 900$ to $1200 \ldots$ & 2,423 & 2.98 & 456.16 & 42.4 \\
\hline 1200 to $1500 \ldots$ & 3,959 & 3.16 & 515.55 & 39.6 \\
\hline 1500 to $1800 \ldots$ & 2,730 & 3.36 & 571.75 & 37.2 \\
\hline 1800 to $2100 \ldots$ & 1,594 & 3.62 & 626.52 & 35.7 \\
\hline 2100 to $2500 \ldots$ & 705 & 4.09 & 711.86 & 34.6 \\
\hline 2500 and over. . & 353 & 4.95 & 859.98 & 34.9 \\
\hline
\end{tabular}

And yet, is it not a common practice not only to ignore the relationship of expenditure to income, but also to identify expenditures for food, rent, clothing, etc., with the "cost of living" to any group irrespective of the standard which they maintain? How completely is the "cost of living" represented in the retail price changes of the 22 commodities used by the United States Bureau of Labor Statistics? "Cost of living" to whom? How representative of market con-

${ }^{1}$ Monthly Labor Review, United States Bureau of Labor Statistics, August, 1919, p. 118. 
ditions are the 25 wholesale price changes weekly shown by the New York Annalist?

Again, how nearly is the stock and bond market gauged by the average price of 25 industrial stocks or 25 railroad bonds? Are the selected securities representative, and what effect on the result comes from taking an average (arithmetic mean) when a large change in a single security may influence the result as much as minor changes in a number of securities? Moreover, what condition or personal interests are held in mind in deciding whether they are "representative?" Ought not the prices to be multiplied by the amount sold in order to be of interest to the speculator, and multiplied by the amount outstanding to be of significance to the stockholder?

Third, facts must fit the problem; they must be germane. Do the facts which you employ accurately describe your problem? Are they too narrow, or too broad; too restricted, or too general? Are your problems so peculiar that the facts of trade, labor and market conditions do not apply? Why? Can you demonstrate the lack of application, or are you hiding behind the old shibboleth, "my business is different?" Be square with yourself, and scientific toward the facts available. If they do not fit your business, prove it, and secure those that do. Ignorantly to select data at random to support a contention or to develop a business policy violates both aspects of scientific method. There is then neither intelligent observation of facts nor logical inference from them. Refer every fact to the condition which can produce it. Fourth, facts must be stable. They must relate to periods and conditions which are essentially uniform. 
Look for the norm in your business. Business judgments based on exceptions and on erratic conditions or periods are unstable. Distinguish between the short- and the long-time influences, and in analyzing your business difficulties, select the facts which apply to homogeneous conditions. Distinguish between the facts which measure transitory skirmishes and those which describe permanent tendencies. Business facts are constantly changing; some fluctuate rapidly, as prices of speculative securities; others are more stable, as, in normal time, the rate of Sterling exchange. Some changes are sporadic; others are periodic. When changes are frequent, measurements, to be representative, must be numerous, as for instance in studying piece-rates in the clothing trade. Where periodic changes occur, as in the movements of crops, in receipts of wheat at elevator terminals, or in the price of eggs, measurements should cover a complete cycle.

Fifth, both the facts themselves, and the conditions of the measurement, must be comparable. "Like can only be compared with like." Shifting conditions of measurement, and changing units, cannot be tolerated. Use the same measuring stick and apply it in the same way throughout all measurements. Profits are not comparable from period to period, when definitions change and the base upon which they are determined shifts. Be consistent in measuring your business successes and failures, and logical in the interpretation of them.

Sixth, facts must be accurate. Accuracy is affected by the conditions under which facts are reported and collected. If they are not understood, or if their col- 
lection incites distrust, and arouses suspicion or the desire to protect oneself, inaccuracy creeps in. To what extent, this is true, is often difficult, if not impossible, to determine. Moreover, facts may be correctly reported, but the report be inaccurate because they have been wrongly determined. Occupations, for instance, are confused in the absence of standardized nomenclature, and the real cause of occupational death is often not revealed because of amateurish diagnosis, or desire to conceal the truth. Moreover, facts may be inaccurate, because accuracy is impossible to attain. The wages of farm labor, or the acreage of corn harvested within the United States, can only be estimated. Estimates are all that are desired, and they are all that are published. Business executives and others must treat them as estimates, and be cognizant of the conditions under which they are made. Against the imputation of gullibility, the executive must always be capable of defending himself.

The facts of business for the most part grow out of daily routine operations. Some are collected by business organizations for their own use, some by trade publications, and still others by governmental agencies. What the significant facts are, which are hidden away in routine reports, or systematically collected, it is the function of the business man to know; how they apply to his problem, it is his duty to understand.

In studying business facts, the executive must apply both general and specific tests of worth and application. In searching his own records for them, he must classify his problems and apply the facts which are germane. While business units operate primarily for 
profit, and only secondarily, if at all, as statistical laboratories in the production of facts, yet the relation between fact analysis and business success is so close that it cannot be ignored. Statistical and research departments cannot become a part of every business undertaking, but there is no business so small that it cannot duplicate in a small but effective way the attitude of mind suggested by these special departments. This attitude is one of business curiosity and intellectual integrity toward problems as they arise.

The attitude of the executive toward his business affairs must be, Why? Where is the logical justification of the action taken? Does custom dominate the contents of my records, my reports, my office organization, my advertising, the treatment of my labor force? How do I stand with my competitor, in the matter of costs and services? Are the resources of my organization fully employed? How might I use my office, sales, and production records to decrease costs, to analyze my markets, experiment with prices, increase my capital, and decrease my labor turn-over? Is my business a "going" concern, and where is it "going?"

Business analysis-the application of scientific method-in commercial enterprise, will answer such queries, and suggest such positive action as the following: How can I extend my market? (Describe your present market in terms of its possibilities.) Is my sales record the best? (Establish a standard of "best.") What are my selling costs?

(Define costs accurately and defend the amount.) What share of the business in my line am I getting? (Measure and 
localize the buying power available.) Are my salesmen the best? (Establish a standard of salesmanship and realize it in your own organization.) Are the reports of my salesmen filled with business meaning, or are they perfunctory? (Submit them to critical inspection, and make yourself defend them.)

A business, to be successful, must have standards and be critical of them; it must eliminate the dry rot which unconsciously accumulates, and accept the truth, that progress means change, but change only as the result of conscious, purposeful choice. Beware of innovations as such - the gold bricks of successbut welcome and cultivate improvement through positive change.

The facts which are needed for the solution of many business problems exist in whole, or in part, in the daily records which are kept. When they are not currently collected, they must be secured. It may be necessary in large establishments to create separate departments to secure and interpret them; in others it may require nothing more than the interest and talents of a single individual. Business does not hesitate to adopt the specialized machinery of production; it must not hesitate to install suitable machinery for the collection and interpretation of business facts. To determine what these are, where they are, how they may be collected, what they mean, and how they may be applied in the solution of business problems, constitute the essence of fact analysis.

A serious weakness of business is to allow the problem of office organization, accounting readjustments, etc., to drift. In many instances, the changes and modifications which are essential to secure 
economy and to increase output are not known. This may be due to wilful ignorance, or more often, probably, among smaller business units, to lack of facilities for keeping in touch with modern developments and progress touching these matters. The latter condition, by means of advertising and other educational methods, will sooner or later be dispelled for all but a fraction of establishments. There is not so much hope, however, for the wilfully ignorantfor the individual who "knows it all," and at the same time knows little or nothing beyond the routine of his daily grind. Concerning this individual, hope lies primarily not in education, but in elimination. Sooner or later he must give way. His goods and services, coming at too great a cost, are lost to the market, and justly so. Competition slowly forces him out, but only after the social costs have become intolerable. He or his like reappears, however, because of the unequal advantages under which industry is carried on-there is a sort of perpetual handicap for some running throughout all industry. It may, however, be lessened by business self-analysis. Where the disposition to make this analysis does not exist, and where the justification for not making it is sought in a self-centered complacency, the problem is hopeless.

More often, however, lack of progress is due not so much to wilful ignorance as it is to the absence of a scientific approach to business problems. An executive may be open to suggestion; he may be willing to adopt labor- and time-saving devices, and may have caught the social point of view respecting problems of labor. He may also approach market problems from the standpoints of psychology and of the new 
competition and upon the basis of analysis of population and occupational data. But still there may be something lacking in his attitude-something that is vital to the application of the scientific method. What too many progressive business executives fail to realize is that the scientific method, or fact analysis, is not to be applied sporadically; is not to be applied here and neglected there; begun and then allowed to lapse. For an execulive to appreciate the meaning of fact analysis is not enough. He must create and maintain an organization to apply it. It must become a religion not only to him, but to the othars in his industry as well. Simply to order sales to be analyzed, or a new acounting control to be established, without at the same time providing the ways in which it shall be done, and allowing for all of the consequences which will follow, is only to catch a glimpse of the meaning of scientific method. Glimpses alone are not enough; conviction is what is needed, and this must be general and felt by all those on whom responsibilities rest. The lesser officials, the department managers, and even the workers themselves, are the ones who are in a position to see the need for fact analysis; and, if convinced of its services, can be of inestimable service to the management in suggesting improvements to be made and in observing the results of the changes introduced. The technique of scientific method will have to be applied by the expert, but he should have not only the sympathy but also the coöperation of all those in whom any responsibility rests. An espritde corps is indispensable.

Scientific method has been defined as a state of mind, and this is probably a true characterization if 
the condition is added, that the point of view it represents is consistent in seeking the truth and being guided by facts not at one time, in one place or under one condition, and ignoring them when it becomes advantageous, or when they are difficult to determine, but in all places, at all times, and under all conditions. Cost accountants, statisticians, and industrial engineers, in the study of business, are continually finding conditions which are deplorable; where every principle of scientific method is violated, and where businesses are running on without cost figures, depreciation reserves, sales analysis, and comparative and basic operating data. A remedy is sought at the hands of the expert, but only for certain specific ills, and not for a complete constitutional treatment. Changes are introduced with fear and hesitancy, doubt characterizing every innovation.

This is not the spirit of scientific method. To the fact analysist, facts are facts. They are welcomed for the truth they contain. The attitude toward them and toward the changes which they make imperative, is positive, receptive, and open minded; not negative, doubtful and hesitant. It is not a little truth, but the whole truth, which is wanted. Nothing is too sacred, too old, nor too customary to be challenged. Truth from whatever source is sought out and welcomed, and applied to problems as they arise. 


\section{CHAPTER IV}

\section{CLASSIFYING AND TABULATING THE FACTS}

Business analysis involves the classification of facts, the application of them to business problems, and the formation of business judgments. The methods of classifying facts and of presenting them in tabular form are treated in this chapter. The following chapter is concerned with the principles and rules of graphic presentation.

Business phenomena and the data bearing upon them must be classified. Business judgments which call for more than nominal consideration, are made on the basis of some sort of analysis. The pros and cons are considered, given their appropriate weight, and a final determination made. Decisions must be reached and actions taken. Upon what basis are decisions made? How soberly are the facts considered; is their use scientific?

Classification consists in separating facts according to a definite plan, into groups, according to certain characteristics, and of placing them in tables, and in graphic or other form, for the purpose of presentation. It presupposes a definite knowledge of the purpose for which facts are studied, and the manner of presentation depends upon the ease with which data, as classified, may be understood. Sometimes tabulation suffices, and is easily understood. In other cases, some form of graphic expression is indispensable. 
The advantages of clearly defined and logically constructed tabulation forms are many. Tables systematize data and show the order of arrangement. They make it possible to show group relations and bring out comparisons. They facilitate addition and summarization, and avoid the necessity of repeating headings and of duplicating items. In short, they are a means of recording in permanent form the analysis that is made through classification and of placing in juxtaposition things that are similar and should be compared. How true this is may be seen by comparing the following methods of showing the number of occupational deaths among cotton mill operatives in Fall River, 1905-1912.

"The recorded number of male operative decedents in Fall River for the eight-year period (1905-1912) was 915. Of these 233 . . were found not to have been cotton-mill operatives, while 207, who on their death certificates were assigned to other occupations, were really cotton-mill operatives at the time of their death. The real number of male operative decedents, therefore, was 889 , the group as recorded having been larger by 26 than the facts justified.

Table 2.-Occupational Deatho-Cotton-mill Operatives in Fall River for Period, 1905-1912

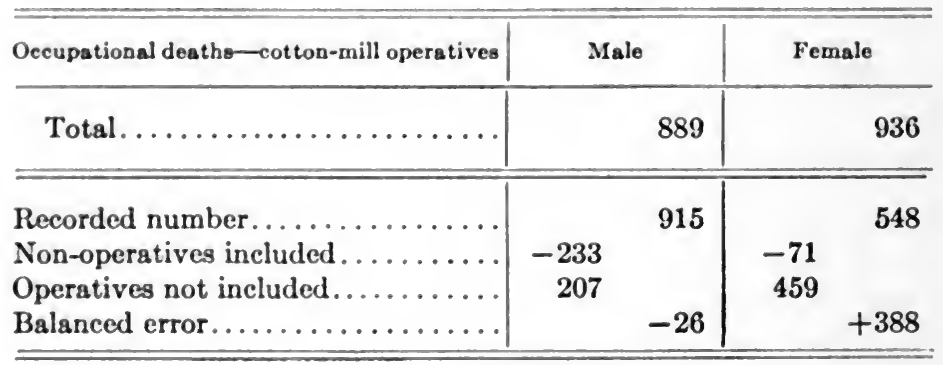


"On the other hand the recorded number of fernale operative decedents in Fall River for the eight-year period was 548. Of these 71 . . were found not to have been cotton-mill operativen, while 459, who were recorded either as having other occupations or no occupation at all, proved on investigation to have been really cotton-mill operatives. This gives a total of 930 decedent female operatives." '

In order to tabulate statistical data, they must generally be prepared for this purpose. Sometimes the units can be transferred directly into prepared tables from reports, memoranda, and such sources. In most instances, however, they have to be transcribed, rearranged, combined, coded, etc., before this process begins. Whether taken from secondary sources, or collected from business records, they are still raw material, and consistency in classification is indispensable. The identity of the facts included must be as complete as possible. A table is no better than the classification that it expresses.

In tabulating statistical data, strive for simplicity. Make tables simple in outline and their purpose evident. Avoid too complex tabular arrangements, and place in immediate relationship the facts which are to be compared. The order in which the data appear should be natural, emphatic, and convincing.

The following table shows the form in which the municipal offerings of a Chicago investment house were distributed to the public. The investor is probably most interested in the "net" return-notice the order in which the issues are listed. The purpose of the arrangement is clear.

- Monthly Revieve, United States Bureau of Labor Statistics, July, 1917, pp. 7-8. 
TABLE 3.-BONds for SAFE INVEstMenT

\begin{tabular}{|c|c|c|c|c|c|}
\hline Amount & Name of isuue & Rate & Maturity & $\begin{array}{c}\text { Price } \\
\text { and } \\
\text { intereat }\end{array}$ & $\begin{array}{l}\text { Netting } \\
\text { about }\end{array}$ \\
\hline$\$ 30,000$ & Buffalo, N. Y., Registered... & 436 & Nov. 2,1934 & 102.78 & 4.25 \\
\hline 60.000 & Camden County, N.J. & 5 & Aug. 1, 1925 & 103.10 & 4.10 \\
\hline 20,000 & New York City, Registered. . & 4 & Nov. 1,1956 & 92.71 & 4.40 \\
\hline 100,000 & 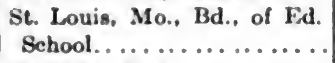 & 4 & July $\quad 1,1939$ & 94.75 & 4.40 \\
\hline 34,000 & Bayonne, N. J............... & 5 & Nov. 1,1928 & 103.75 & 4.50 \\
\hline 20,000 & California, State Highway... & 4 & July 3,1933 & 94.92 & 4.50 \\
\hline 10.000 & Cook County Forest Reserve & 4 & Feb. 1,1920 & 89.75 & 4.50 \\
\hline 90,000 & Ogden, Utah, School........ & $4 \%$ & Oct. 29,1939 & 100.99 & 4.62 \\
\hline 50,000 & Fremont, Neb., Refunding. . & 5 & Oct. 24, 1939 & 101.30 & 4.70 \\
\hline 100,000 & Pocatello, Idabo............. & 5 & Oct. 29, 1939 & 102.37 & 4.70 \\
\hline 10,000 & 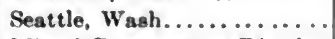 & 5 & July 1,1921 & 100.57 & 4.70 \\
\hline 40,000 & $\begin{array}{l}\text { Miami Conservancy District, } \\
\text { Ohio................ }\end{array}$ & 512 & Dec. 1,1931 & 105.86 & 4.85 \\
\hline 200,000 & Polk County, Texas, Road.. & 5 & Oct. 29,1959 & 101.00 & 4.87 \\
\hline 200,000 & Blount County, Tenn., Road & 5 & July 15,1949 & 100.00 & 5.00 \\
\hline 15,000 & Denton County, Texas, Road & 5 & Oct. 29,1949 & 100.00 & 5.00 \\
\hline 30,000 & $\begin{array}{c}\text { Hill County, Texas, Road } \\
\text { Dist................... }\end{array}$ & 5 & 1929 to 1941 & 100.00 & 5.00 \\
\hline
\end{tabular}

Contrast the following tables, so far as order of arrangement is concerned. 


\section{Tahex 4.-United Statea Chop Entishted Phodection Avoust 1, $1019^{1}$}

\begin{tabular}{|c|c|}
\hline \multirow[b]{2}{*}{ Crope } & I'roduetion \\
\hline & $\begin{array}{l}1919 \\
\text { indieations. } \\
\text { A we. I }\end{array}$ \\
\hline 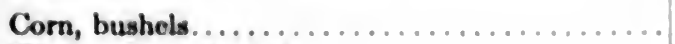 & $2,788,378,000$ \\
\hline Winter wheat, bushels. . . . . . . . . . . . . . . . . & $715,301,000$ \\
\hline 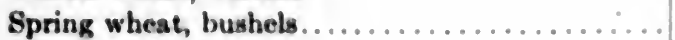 & $225,030,000$ \\
\hline 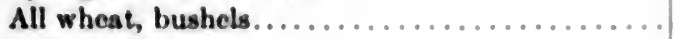 & $940,381,000$ \\
\hline 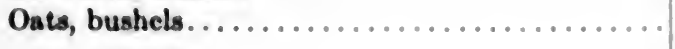 & $1,266,401,000$ \\
\hline Barley, bushels. & $203,525,000$ \\
\hline Rye, bushels. . . . . . . . . . . . . . . . . . . . & $84,552,000$ \\
\hline Buckwheat, bushels. . . . . . . . . . . . . . . . . & $16,103,000$ \\
\hline Potatoes, bushels...................... & $357,120,000$ \\
\hline Sweet potatoos, bushels. . . . . . . . . . . . . . . . . & $100,436,000$ \\
\hline Flaxseed, bushels. . & $10,239,000$ \\
\hline Rice, bushels. . . . . . . . . . . . . . . . . . . . . . . & $43,427,000$ \\
\hline 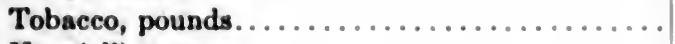 & $1,335,052,000$ \\
\hline Hay (all), tons . . . . . . . . . . . . . . . . . . . & $110,876,000$ \\
\hline 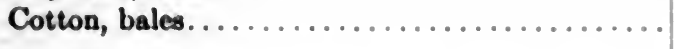 & $11,016,000$ \\
\hline Apples, total crop, bushels... & $155,004,000$ \\
\hline Peaches, bushels....................... & $49,793,000$ \\
\hline Pears, bushels...................... & $12,260,000$ \\
\hline Kafirs, etc., 6 states, bushels. . . . . . . . . . . & $130,153,000$ \\
\hline 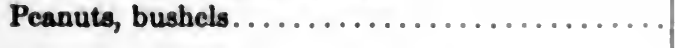 & $57,547,000$ \\
\hline Beans (dry), 6 states, bushels........ & $12,338,000$ \\
\hline Sugar bects, tons. . . . . . . . . . . . . . . . . . & $6,963,000$ \\
\hline 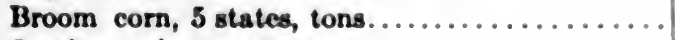 & 59,100 \\
\hline Sorghum, sirup, gallons. . . . . . . . . . . . . . & $33,757,000$ \\
\hline 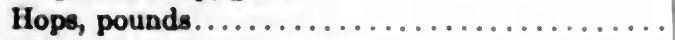 & $34,906,000$ \\
\hline
\end{tabular}

'Monthly Crop Report, United States Department of Agriculture, August, 1919. 
Table 5.-Production of Corn in the Leading Five States, 1916-1918:

(000 omitted)

\begin{tabular}{|c|c|c|c|c|c|c|c|c|}
\hline \multicolumn{3}{|c|}{1918} & \multicolumn{3}{|c|}{1917} & \multicolumn{3}{|c|}{1916} \\
\hline State & $\begin{array}{l}\text { Produc- } \\
\text { tion } \\
\text { Bushels }\end{array}$ & $\begin{array}{c}\text { Per } \\
\text { cent. } \\
\text { of } \\
\text { U.S. }\end{array}$ & State & $\begin{array}{l}\text { Produc- } \\
\text { tion } \\
\text { Bushels }\end{array}$ & $\begin{array}{c}\text { Per } \\
\text { cent. } \\
\text { of } \\
\text { U.S. }\end{array}$ & State & $\begin{array}{l}\text { Produc- } \\
\text { tion } \\
\text { Bushels }\end{array}$ & $\begin{array}{l}\text { Per } \\
\text { cent. } \\
\text { of } \\
\text { U.S. }\end{array}$ \\
\hline U. $\mathrm{S}$. & $2,582,814$ & 100.0 & U. s. & $3,065,233$ & 100.0 & U. $\mathbf{s}$. & $2,566,927$ & 100.0 \\
\hline Iоwa. & 375,624 & 14.5 & III... & 418,000 & 13.6 & Iowa & 366,825 & 14.3 \\
\hline Ill.... & 351.450 & 13.6 & Iowa ... & 410,700 & 13.4 & III. . & 300,900 & 11.7 \\
\hline Ind...... & 169,554 & 6.6 & Nebr... & 249,480 & 8.1 & Nebr... & 192,400 & 7.5 \\
\hline Mo....... & 133.860 & 5.2 & Mo..... & 241,500 & 7.9 & Ind..... & 174,658 & 6.8 \\
\hline Ohio...... & 133.200 & 5.2 & Ind .... & 196,776 & 6.4 & Mo..... & 132,112 & 5.1 \\
\hline 5 States & $\ldots$. & 45.1 & ¿ States & $\cdots$ & 49.4 & 5 States & .. & 45.4 \\
\hline
\end{tabular}

There is no particular sacredness about any order in tabulation, unless it is the alphabetical. The order should generally be chosen so as to emphasize the classification which is adopted. An unnatural or rule-of-thumb arrangement is never justified.

What seems to be the basis of arrangement of the details in Table 6 , showing the classification of statistics of corporate incomes in 1916, as published by the Commissioner of Internal Revenue?

Tables 2, above, and 7, following, illustrate what may, for convenience, be called "Progress" tables.

In the clearest way possible project onto a tabular form the message which is wished to be conveyed. Make the totals prominent by placing them first, and show the relative importance of the classification by the rulings and the spacings of major and

${ }^{1}$ Monthly Crop Reporl, United States Department of Agriculture 
Tanla 6.-Unitso States Conponate Income Stathotich, 1910"

1986 Claselfoation

\begin{tabular}{|c|c|}
\hline Clases & Niet liseome \\
\hline Total........... & $88,765,908,984$ \\
\hline 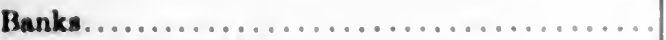 & $400,590,580$ \\
\hline Insurance cornpanies. . . . & $127,906,231$ \\
\hline Public utilities.......... & $1,541,076,130$ \\
\hline Extraction of minerals. . . . . . . . . . . . & $798,883,349$ \\
\hline Manufacturing and incehanical . . . . . . . . & $4,157,625,000$ \\
\hline 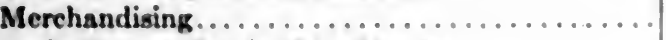 & $464,875,807$ \\
\hline Agriculture and animal husbandry ...... & $69,862,431$ \\
\hline 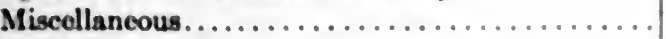 & $1,205,070,556$ \\
\hline
\end{tabular}

Tanl: 7.-Lvi Stock Changes dunsg July '

\begin{tabular}{|c|c|c|c|c|c|c|}
\hline \multirow[b]{2}{*}{7} & \multicolumn{2}{|c|}{ Cattle } & \multicolumn{2}{|c|}{ Swine } & \multicolumn{2}{|c|}{ Sheep } \\
\hline & 1919 & 1918 & 1919 & 1918 & 1919 & 1918 \\
\hline On farms July 1. & 100.00 & 100.00 & 100.00 & 100.00 & 100.00 & 100.00 \\
\hline Birthe in July........... & 2.78 & 3.19 & 7.88 & 9.86 & .38 & 38 \\
\hline Broucht on farms in July...... & 1.83 & 2.99 & 1.79 & 2.16 & .83 & 2.14 \\
\hline Moved of farms in July...... & 4.97 & 6.01 & 8.48 & 11.31 & 4.80 & 5.85 \\
\hline Farm olaughter in July........ & .29 & .49 & .30 & .45 & .44 & .60 \\
\hline Died on farms in July.... & .34 & .45 & 1.79 & 1.68 & .81 & .87 \\
\hline Remainine Aug $1 . . . \ldots \ldots$ & 98.71 & 90.23 & 99.10 & 98.88 & 04.86 & 95.20 \\
\hline
\end{tabular}

minor headings. Make tables attractive, concise, and emphatic. Fit them appropriately to standard sized pages; number the lines and columns when this will result in clarity; and above all give them suitable,

' American Economic Revicu, September, 1919, p. 512.

'Monthly Crop Report, United States Department of Agriculturo. 
brief, but explicit titles. A title should be a concise epitome of the contents of a table. It is not its purpose to include all of the facts which a table contains. It should be short, well punctuated, clearly phrased, and incapable of being misconstrued. Titles are generally faulty because of omissions and an inverted order in the characteristics which are named. The natural order is from superior to subordinate items.

Classification and tabulation generally require that the facts be grouped, or condensed. It is impossible to retain the individuality of each item. Abbreviation-a sort of telescoping - is necessary, but it is also dangerous, because it sacrifices accuracy. Conciseness and brevity are desirable in tables, but not at too great a sacrifice. How far grouping may go depends upon the problem in mind and the occasion for classification. What it involves, however must not be ignored.

Using the data in Table 3, the issues may be condensed as follows, but the detail which is necessary for viewing the issues individually is lost.

Table 8.-Municipal Issues Classified by Net Interest Rate

\begin{tabular}{|c|c|c|}
\hline Net interest rate, per cent. & $\begin{array}{c}\text { Number of } \\
\text { issues }\end{array}$ & $\underset{\text { issues }}{\text { Amount of }}$ \\
\hline Total... & 16 & $\$ 1,009,000$ \\
\hline 4.00 to 4.25 . & $\ldots$ & \\
\hline 4.25 to $4.50 \ldots$ & 4 & 210,000 \\
\hline 4.50 to $4.75 \ldots$ & 7 & 314,000 \\
\hline 4.75 to 5.00 . & 2 & 240,000 \\
\hline 5.00 and over......... & 3 & 245,000 \\
\hline
\end{tabular}


More serious for detailed analysis is the grouping shown in the following table.

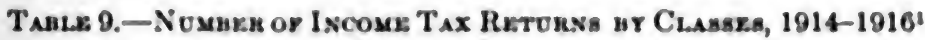

\begin{tabular}{|c|c|c|c|}
\hline \multirow{2}{*}{ Ineotses } & \multicolumn{3}{|c|}{ Total number of returne } \\
\hline & 1914 & 1913 & 1916 \\
\hline 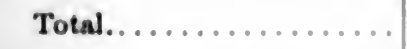 & 357,515 & 336,652 & 429,401 \\
\hline 83,000 & 82,754 & 69,045 & 85,122 \\
\hline 4,000 & 66,523 & 58,949 & 72,027 \\
\hline $10,000 \ldots \ldots \ldots$ & 127,448 & 120,402 & 150,551 \\
\hline $15,000 \ldots \ldots \ldots$ & 34,141 & 34,102 & 45,305 \\
\hline $20,000 \ldots \ldots \ldots$ & 15,790 & 16,475 & 22,621 \\
\hline $25,000 \ldots \ldots \ldots$ & 8,672 & 9,707 & 12,956 \\
\hline $30,000 \ldots \ldots \ldots$ & 5,483 & 6,196 & 8,055 \\
\hline $40,000 \ldots \ldots \ldots$ & 6,008 & 7,005 & 10,068 \\
\hline $40,000-\quad 50,000 \ldots \ldots \ldots$ & 3,185 & 4,100 & 5,611 \\
\hline $50,000-100,000 \ldots \ldots \ldots$ & 5,161 & 6,84 & 10,452 \\
\hline $100,000-150,000 \ldots \ldots \ldots$ & 1,189 & 1,793 & 2,900 \\
\hline $150,000-200,000 \ldots \ldots \ldots$ & 406 & 724 & 1,284 \\
\hline $200,000-250,000 \ldots \ldots \ldots$ & 233 & 386 & 726 \\
\hline $250,000-300,000 \ldots \ldots \ldots$ & 130 & 216 & 427 \\
\hline $300,000-400,000 \ldots \ldots \ldots$ & 147 & 254 & 469 \\
\hline $400,000-500,000 \ldots \ldots \ldots$ & 69 & 122 & 245 \\
\hline $500,000-1,000,000 \ldots \ldots \ldots$ & 114 & 209 & 376 \\
\hline $1,000,000$-and over......... & 60 & 120 & 206 \\
\hline
\end{tabular}

'American Economic Review, September, 1919, p. 503.

The distribution of the items within the groups is concealed. Whether the items are concentrated at the upper or the lower sides of the groups, or are distributed uniformly through them, is not known.

The contents of tables should unmistakably bear on the problems to which they relate. Extraneous matter should be removed. Tables should be explicit 
and contain a minimum of "unclassified," "not stated," and "miscellaneous" material. If this type predominates, it is either a suggestion of a desire to withhold some of the detail, or evidence that the basis of classification is faulty.

The scientific mind sees things in groups. It classifies according to common characteristics, heterogeneous and seemingly unrelated facts; traces out similarities, and looks for cause and effect. It seeks underlying principles through analysis. "Classification is indispensable to, and accompanies every scientific inference," and tabulation involves far more than drawing lines and inserting numerical symbols. It is a means of recording classification and analysis.

But how is a business to study its problems by means of tabulating the facts which it currently receives? For most businesses it is unnecessary to create an elaborate organization for this purpose. Every business should provide some specialized machinery to scrutinize currently the records which are received, and to test by experiment the relation which they have to current problems. This can be done by tabulating the facts and by observing the underlying principles which seem to determine them. If the records do not contain all the facts which are necessary either to explain a problem, or to furnish a continuing picture of a business operation, it is necessary to seek new data through additional records, or through schedules sent to the various operating divisions, or the groups concerned with operation, sales, etc. If additional information on sales, on office methods, on production costs, are required, this can be secured by means of schedules, if they are properly 
framed so as to enlist the support and cooperation of those to whom they are sent.

The problems of classifying and grouping dissimilar facts, of separating large aggregates into their several parts, and of building up totals from details are intimately related to the methods by which facts are collected. Every step in the collection process involves some sort of tabulation. Indeed, collection and tabulation of facts are but two steps in one general process of classification.

There is a technique in the method of collecting facts which is important, and which business should seek to apply. In every industry, departmental jealousies are common, sectional points of view maintain, and it is frequently difficult to overcome them and to secure the united coopperation of all in matters of common interest. Personal interviews will help to pave the way for securing information, and the tone in which inquiries are made will serve to establish confidence. Coöperation is indispensable, and anything which will contribute toward it must be capitalized. Above all, suspicion must be allayed, and sectional and narrow personal interests dispelled.

The preparation of schedules is simple, but fundamental principles should be observed.

First.-Assurance should be given, either within the schedule itself or preparatory to its being sent, that the inquiries are made for the good of the business as a whole, and that it is mutually advantageous that the questions be answered fully and accurately. Coopperation must be solicited. The collection of full and satisfactory information depends upon the existence of good-will and mutual understanding. 
Second.-Schedules, or inquiries, should be as brief as is consistent with the purposes for which they are intended, and the questions unmistakably addressed to the problem involved. So far as is possible, the relation of each question to the part of the inquiry with which it is concerned, and to the problem as a whole, should be evident.

Third. - The schedule form itself should be simple and consistent with the type of records which exist, so that supplying the information desired will not involve an undue amount of labor and occasion error, because of the necessity for reinterpreting the customary units of measurement.

Fourth.-The questions should be simple, and incapable of being misunderstood; and, so far as is possible, answerable by "yes" or "no," or by number. They should not allow of evasive answers, and should not be unduly inquisitorial. The order in which they are asked should be convenient for the person addressed, and not involve unnecessary duplication, or arouse a suspicion that the informant is to be in any way tricked by his answer.

Information obtained directly from business records, or from schedules based on records, should be subjected to a thorough editing before the tabulation process begins. Evident errors due to omissions, additions, false interpretations, or misunderstandings, should be corrected at once. Undue tampering with the facts, however, is to be guarded against, and alterations made only in case of unmistakable error. In all cases, alterations should be made evident through the use of some distinctive mark or ink device. It is an easy matter materially to change the nature of 
a fact, and to distort the truth by the interchange of a few items, or by entrusting the editing to an inexperienced person. So far as possible, the returns should be made consistent with the facts, and complete. This may necessitate the return of the schedule. If it does, full explanation should be made of the reasons for returning it, and coöperation solicited.

As soon as data are properly edited, tabulation may at once proceed. This should be begun, however, only after a definite plan of classification has been worked out, and the nature of the problem upon which the classification is to throw light, clearly sensed. All of the considerations noted above in this respect are of primary significance. Indeed, in many instances the nature of the tabulation wanted determines the type of the data which is collected. The order of procedure in periodic studies, for instance, where comparisons are currently made, is first to decide upon the tabulations which are wanted, and afterward to collect the data in such a way that the purpose will be realized. In analyses of a trial character, when the nature of the data is not known, the form of tabulation must be largely experimental. The form which it takes, even in such cases, simply serves to put in tangible form a scheme of classification already made.

The actual tabulating process may be done either by machine or hand methods. Where the problem is simple, and the data relatively few, hand tabulation will suffice. Where the problem is complex, and the data numerous, some sort of machine tabulation must be employed. There are on the market two standard mechanical tabulating machines, the Hollerith and the 
Powers. Either of them may be used to advantage in large establishments where continuous and elaborate use is made of statistical data. The process by which tabulation by machine methods is carried on is comparatively simple, and need not be described here.

In selecting statistical data from secondary sources such as the Reports of the United States Census on Manufactures or Occupations, or from such widely used journals as Bradstreet's, care should be used to see that the facts are comparable. Simply to take prepared figures from different but complementary sources, good in themselves, and to fit them into tables, in order to substantiate a belief, or to see the implication of your problems from a new angle, without at the same time subjecting them to rigid tests of accuracy, content, and application, is to confuse the mechanics of tabulation, with logical analysis. Tabular outlines, neatly filled with figures which prove, and with percentages which seem to show relations, suggest so much care in preparation that they often carry a conviction which is unwarranted. Their neatness and form seem to guarantee the nature of their contents. Tabulation is always a means, and not an end, in statistical studies. The business concern which consents consciously, or unconsciously, to allow elaborate tabulations of facts currently to be made, without continually subjecting them to tests of validity, and application to particular problems and issues, is not only wasting money but also violating the fundamental consideration which should control every business; namely, the scientific point of view. 


\section{CHAPTER V}

\section{PRESENTING THE FACTS-GRAPHICS}

Classified facts may also be expressed graphically. There is a psychology about graphic presentation which is significant and which business can not afford to ignore. Through tabulation, facts are only imperfectly visualized. Relations do not stand out; they remain abstract. It is difficult to compare more or less, to see differences, and to appraise the amounts. Graphically, however, relations are seen; there is an appeal to the eye, as well as to the intellect. A fact is emphatic in proportion to the number of avenues through which it makes its appeal.

But graphic presentation alone will not suffice. Through classification and tabulation, facts are reduced to logical order; through graphic forms they are illustrated according to this order. Graphic presentation adds to the meaning of facts by throwing it into relief. It does not replace tabulation; it complements it.

In selecting diagrams or other graphic forms serviceability, simplicity and truthful representation of the facts should be the aim. There is always a best form in graphics as there is in tabulation. The same requirements as to order of arrangement of details, spacing, size of the figure, and methods of making the relations between facts emphatic, apply here as they do in tabulation. The physical work of charting 
may be assigned to the relatively inexperienced; the choice of the forms to use must be made by one who not only understands precisely what is to be shown, the psychology of the persons to whom it is addressed, but also appreciates the peculiar appeal of the different illustrations that are available.

In choosing graphic figures certain elementary but at the same time fundamental principles should be followed.

First.-Avoid figures which must be read in two or more dimensions.

Second.-Guard against confusing the apparent with the real. In this connection, lines or bars are superior to surfaces and solids.

Third.-Accompany graphic forms with the concrete data which they represent.

Fourth.-See that the fact and the form of its presentation agree.

Where areas are involved, choose some form of statistical map as a means of illustration. Maps show both position and magnitude. Data may be spread out on them and studied in relation to space. Strive for that degree of accuracy in map making which your problems require, and remember that maps, like all types of diagrams, are serviceable, primarily, in the power of suggestion, rather than in their truthful portrayal of precise facts. (See Figs. 21, 22, 23 and 24.) Suit the graphic device to the problem to be solved. Use the same discrimination here that you use in the preparation of the data for illustration; choose the means in conformity with the ends.

Some forms of data may be shown to advantage in 
graphs or curves. When a continuous picture is desired, either as a means of describing a variable fact at one time, or a constant fact over a period of time, a graph or curve has distinct advantages over a column of figures. If, for instance, wage-rates or earnings are to be studied, reduce them to graphic form. Choose scales which will throw them into relief, but which will neither exaggerate the exceptionally large, nor lose sight of the exceptionally small units. Study the direction and shape of the distribution and try to see the facts in relation to each other, and to the whole.

Along the horizontal scale, plot the measurements, and on the vertical scale list the frequency with which each measurement occurs. Make the steps on both scales equal units (see Figs. 4 and 20). Under no circumstances should there be doubt as to the meaning of the units or the spaces by which they are represented. Let the illustration be a faithful representation of the fact. Do not attempt to give an arbitrary direction to the curve, nor smooth it unless the imperfections of the data suggest it, or the character of the samples makes it necessary. The classification which precedes the graphic presentation is the means of analyzing it; the graphic figure chosen is the device for illustrating it.

When the facts which are studied are historical, i.e., extend over a period of time, an historical curve may be used to illustrate them. Scientific method in the classification must remove the uncertainties of such an analysis. Periods which have nothing in common, and units of measurements which have changed during the periods, cannot be compared. An historical curve will rarely, if ever, reveal incon- 
sistencies. All that can be expected of it, is faithfully to record the changes from time to time. If these are fictitious, the curve is not to blame; the error is in subjecting them to this treatment. The analysis is fundamental; the curve only suggestive.

Business executives cannot afford to ignore the merits of graphic presentation, but they must not be deluded into the belief that it carries with it a magic which makes it unnecessary to look behind it. Reasoning from graphic figures alone, where the conditions of the measurements which they represent are not known, violates every canon of scientific method. The superficial is confused with the fundamental.

Business problems and business facts must be taken apart and scrutinized. Classification is the firststep in this process, and graphic presentation the means by which the classification is expressed. No business is too small to profit by this approach, and none is too large to ignore its possibilities. The requirements of scientific method furnish the conditions under which analysis is applied.

It is impossible in a brief statement adequately to discuss the technique of graphic presentation. For a more complete discussion reference should be made to the author's "Introduction to Statistical Methods," and to Brinton, W. C., Graphic Methods for Presenting Facts. It may be helpful, however, partly in emphasis of what has been said, and partly for the sake of convenience, to summarize in the form of general rules, the salient points to be remembered in the use of graphic figures. ${ }^{1}$

1"Rules for Graphic Presentation of Statistical Data," by DAY, REed and Secrist. Weekly Statistical News, Central Division of Planning and Statistics, Washington, D. C., No. 5, Oct. 10, 1918. 


\section{A. General Make-up of Diagrame}

1. Data to Accompany Diagrams. - The data shown graphically in a diagram should be given in tabular form either beside or within the diagram, or in close proximity in the text. Care should be exercised, however, to place figures so as not to disturb or distort the visual impression conveyed by the chart. (See Fig. 1 where this rule is followed, and Figs. 2 and 3 , where it is violated. In Fig. 1, for instance, the inclusion of the concrete data makes it possible to verify the percentages upon which the diagram is drawn. In Fig. 2, this is impossible.)

2. Scale Units.-In general, in the laying off of scales, the scale intervals on any single diagram should be exactly proportionate to the gradation of number, size, or time represented (the logarithmic scale constitutes an exception to this rule). (See Fig. 4, where this rule is seriously violated. The scale units on the horizontal axis are not proportional to the sizes of the groups into which the capital data are divided. Had the rule been followed, the direction of the curves would have been distinctly less vertical and the visual impression different. See also Fig. 20 where the rule is violated on the horizontal axis. If the space units were proportional to the amounts, the curves would be drawn out much farther to the right.)

3. Scale Figures.-Figures for the scales of diagrams should be placed at the left and at the bottom, or along the respective axes.

4. Base Lines. - It is well to distinguish-as by heavier inking-lines which represent standards of attainment or bases of measurement or comparison. 
(See Figs. 5 and 6. In the first, the rule is violated; in the second, it is followed. In Fig. 6, the base line for both series is presumably 100 , and constitutes -although this is not stated on the diagram-the average for the year, the monthly prices being computed and plotted as differences, more or less from this amount. In Fig. 5, both prices and quantities are measured from zero, and the line representing it should have been inked heavier than the other lines.)

5. Arrangement of Items. - Items should be grouped so as to facilitate the comparison of those most significantly related. Within groups, some systematic order should be adopted. The most serviceable arrangements are according to $(a)$ the sequence of the items in time, with the earliest at the left; $(b)$ the size of the items, with the largest at the top or at the left; or $(c)$ the favorableness of the items, with the most favorable at the top or at the left. (See Figs. 7, 8, and 9. In Fig. 7, the amount controls the order of the states, the largest amount coming first. In Fig. 8, the order of the states is determined by the geographical position which they have in passage across the country from East to West. In Fig. 9, the order from top to bottom seems to be haphazard. Frequency would have suggested itself as the natural order.)

6. Position of Titles.-So far as practical, all printing upon a diagram should be placed so as to be read with ease from the bottom of the sheet. (This is pretty much a matter of preference. In the originals of the following figures the practice was about 
equally divided. So far as the writer is concerned, the position of the title is not a relatively important matter.)

7. Use of Colors.-Where a need for duplicates may arise, charts should be made entirely in black and white. The use of colors is not recommended except for large wall charts.

8. Size of Sheet.-Avoid irregular sizes of paper. As far as practical, the established correspondence sizes $(8 \times 101 / 2$ or $81 / 2 \times 11)$ should be used.

\section{B. Choice of Graphic Forms}

1. For Simple Comparisons of Size.-(See Figs. 10 and 11 , where surfaces and bars are used as alternatives for illustrating size. In all of the figures, bars or single dimension illustrations are clearly preferable. Avoid such an illustration as Fig. 12. In Fig. 13, the illustrations are suggestive but confusing since the scale is not given and two dimensions are used.)

(a) Bars.-Bars are the most satisfactory graphic device for this purpose. In general, all the bars used in the diagram of a single study should be of uniform width.

(b) Lines.-When a large number of separate items have to be shown in a single diagram, lines may be employed in place of bars.

(c) Position.-Bars (or lines) are best placed horizontally.

2. For Comparisons of Component Parts.-(See Figs. 14, 15, and 16. In Fig. 14, cross-hatched 
columns are placed vertically, and in Figs. 15 and 16, horizontally. The vertical columns are more readily compared than are those which are horizontal. In Fig. 15, the more recent year is placed at the bottom, while in Fig. 16, the order of the years is reversed. These figures should be contrasted with the pie-diagrams shown in Figs. 1, 2, and 3, as means of illustrating component parts.)

(a) Subdivided Bars.-Subdivided bars are the most satisfactory form for this case.

(b) Cross-hatching.-Cross-hatching is the best way in which to distinguish component parts.

(c) Position.-Horizontal bars are to be preferred to vertical, except when the items are separated by intervals of time, in which case vertical bars should be used.

3. For Displaying Frequency Distributions.

(a) Vertical Column.-In general, the vertical bar (or column) form is to be used. The straight-line histogram, however, is a satisfactory alternative. (See Fig. 20, where the histogram is used.)

(b) Position of Scales.-The scale for the variable is to be placed along the horizontal axis; the scale for the frequencies along the vertical axis.

4. For Showing Geographic Variations.

(a) Dot Maps.-Where the variable takes the form of varying numbers of a given item, the situation is best represented by a dot map, in which each dot represents a fixed number of cases. All of the dots should be of uniform size. (Figs. 21, 22, 23, and 24, show four types of dot maps. Fig. 21 gives only an impressionistic view of frequency, but is well 
fitted for this purpose. Places of "high" and "low" density are brought out in a remarkable manner. Fig. 22 fails of its purpose, because the size of the dots cannot be readily compared. The exact amount could be better illustrated by a cross-hatched surface as in Fig. 24. Fig. 23, likewise, illustrates an unsatisfactory map device for much the same reasons as those noted concerning Fig. 22.)

(b) Shaded Maps. - Where a continuous variable is to be shown, solid black and white, and graded cross-hatched areas constitute the most satisfactory form. Care should be exercised to secure gradations of intensity of black and white corresponding closely to the gradations of the variable.

\section{b. For Showing Time Variations.}

(a) Straight-line Graph.-In general, the use of the straight-line graph between plotted points, is to be recommended. (Fig. 25 shows typical straightline historical graphs. In this case, two vertical scales are employed, and care must be used in interpreting the lines. In Figs. 18 and 26, vertical bars, and in Fig. 19, horizontal bars, rather than connected lines, are used to show data historically. Where the increase or decrease over a period is continuous and uninterrupted, this form of illustration is satisfactory. Where the tendency is irregular, continuous lines should be used. Care, however, should be employed, so as not to assign meaning to the direction of the lines connecting the points when they are unrelated, and to confuse absolute with relative changes. In this connection, see Fig. 27 and the discussion relating to it.) 
(b) Position of Scales. - Intervals of time should be scaled invariably along the horizontal axis. (See Figs. 13 and 19, where this rule is violated.)

(c) Zero of Vertical Scale.-There is a strong presumption in favor of the appearance of the zero on the vertical scale on the chart. (On the logarithmic or "ratio" chart there is no zero line.)

(d) Logarithmic Scale.-The vertical logarithmic scale is to be used when rates of change or proportionate increases and decreases are to be emphasized. When the logarithmic scale is employed, the limits of the scale should be at some power of ten. (See Figs. 28 and 29, and the discussion accompanying them.)

These rules are general, and should, so far as is possible, be applied to all graphic forms. Each business, however, must meet its problems in the light of their peculiarities, and adjust the graphic illustrations to the most appropriate ends. The making of diagrams and curves is never an end. Diagrams should be considered as a means of throwing light on current and basic problems, and should constantly be adjusted to the individual for whom they are prepared, and the problems which they illustrate. A diagram designed to furnish an executive with a concise picture of an operation, or a series of operations, will, of course, be different from one which is designed for the public at large. Graphic forms are significant primarily because of what they suggest, and the psychology and intelligence of the group for which they are prepared should constantly be kept in mind. 
Graphic presentation is an art, and too much attention cannot be given to it on the part of the modern executive who desires to apply to his business the scientific point of view.

Fio. 1.-Pie-diagram showing the distribution of total stock of hams, bacon and shoulders, reported August 31, 1917.

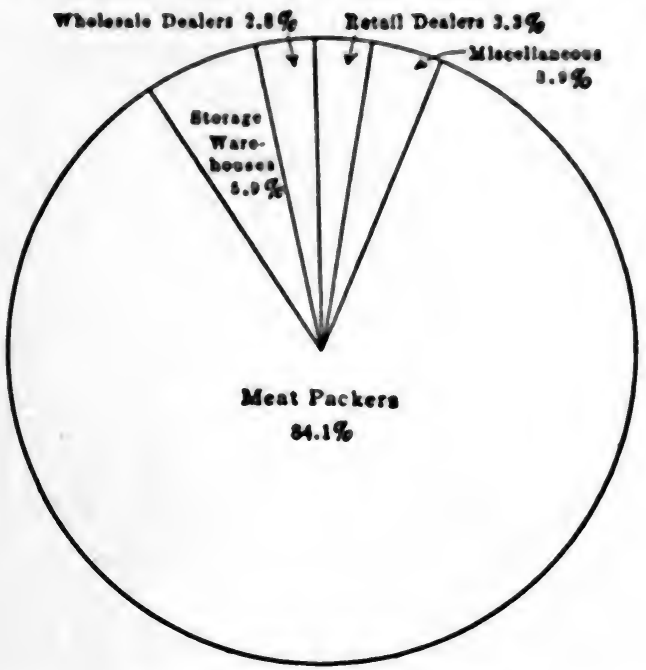

Stock Reported (Pounds).

Meat packers. .................... 361,932,276

Storage warehouses. . . . . . . . . . . . . . . 25,512,057

Wholesale dealers. . . . . . . . . . . . . . . . . . . . 11,940,169

Retail dealers. .................... 14,368,359

Miscellaneous..................... 16,651,367

Total......................430,407,228

The above figure and those following illustrate different forms of graphic presentation. Some of them follow and some violate the rules given above-with what consequence, the reader must in large part determine for himself. Some of the more outstanding 
virtues and limitations of the figures are given in the comments which accompany them.

In Fig. 1, the surface of the circle constitutes 100 per cent. or the entire amount of stocks reported, as shown in the table below the figure. An alternative and generally more satisfactory way of showing component parts is by using bars the lengths of which are

Frc. 2.-Pie-diagram showing the percentage distribution of the world's mill supply of cotton contributed by each country; 1917.

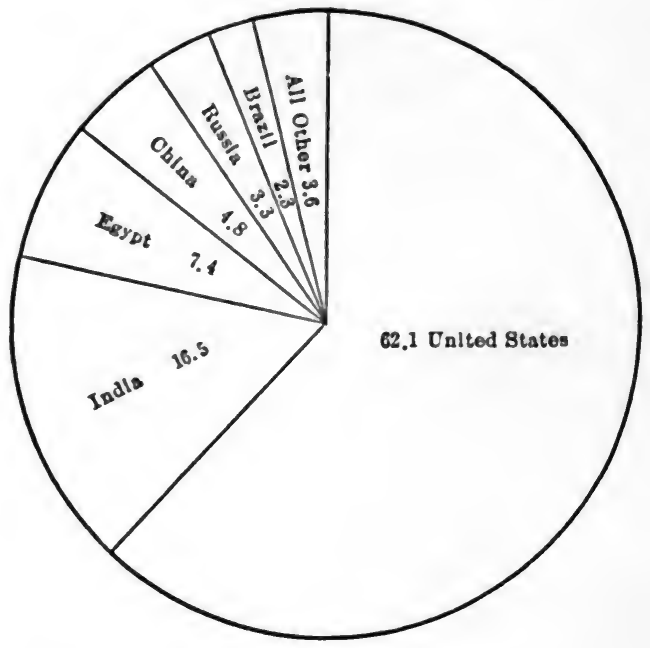

proportionate to the amounts (see Figs. 14, 15, and 16.) The table beneath the illustration would have been more complete had it contained the percentage figures illustrated in the diagram.

Fig. 2 is faulty in not containing the concrete data on the basis of which the percentages are computed. Moreover, the relations between the per- 
centages are not as clearly illustrated as they would have been had bar-diagrams been used. (See Figs. 14, 15, and 16.)

The pie-diagrams below are presumably drawn in proportion to the amount of the goods produced, but there is nothing in the illustrations to show this, nor

F1G. 3.-Pie-diagrams showing the percentage distribution of the production of boots and shoes, and of textiles, by states.

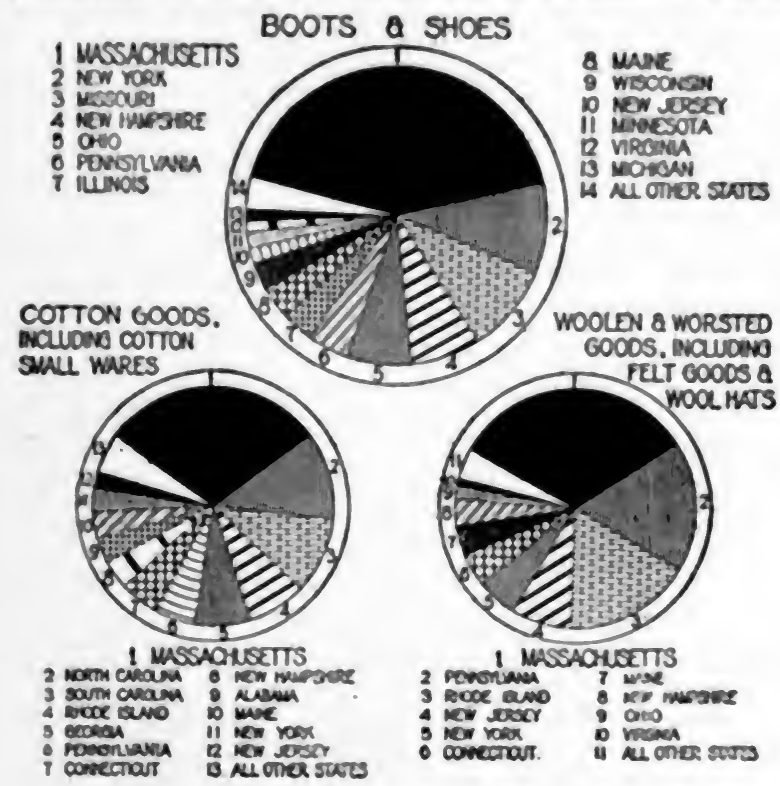

is the scale given in which the measurements are made. Moreover, the concrete data are missing - both the amounts and the relationships have to be taken on faith. The use of bar-diagrams would have been preferable here, as in Figs. 1 and 2.

Fig. 4 is reproduced exactly as it appears in the 
original. It is defective in several respects. The vertical scale contains the unit 9000 instead of 900 . The horizontal scale is divided into uniform spaces, but these are related to varying amounts. The in-

Fig. 4.-Curves showing the relation of farm capital to labor income on 260 general farms in Monmouth County, New Jersey.

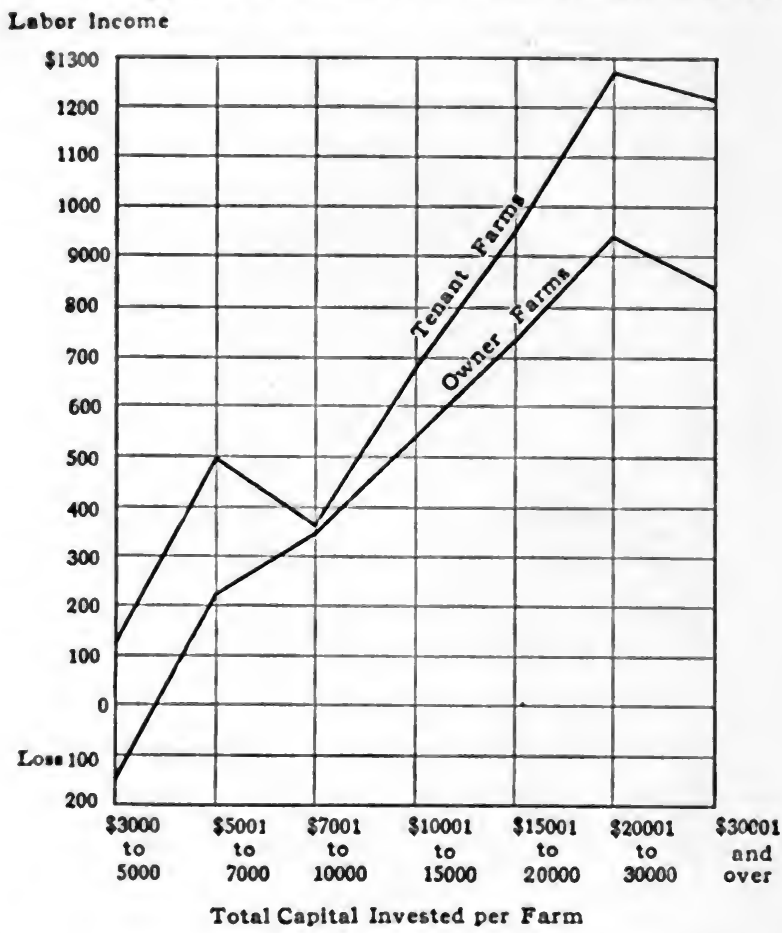

terval, presumably, is $\$ 2000$ between $\$ 3000$ and $\$ 7000$ (but, see the different ways of recording the lower sides of the first two groups). The intervals above $\$ 7000$ are in order, $\$ 3000, \$ 5000, \$ 5000, \$ 10,000$, and an indefinite amount, but the scale is drawn as though 
they were identical. The result of this error is to give a false direction to the curves.

The base or zero line in Fig. 5, should have been more heavily inked than the other lines. The spaces assigned to the months represent in fact a series of rectangles the heights of which are indicated by the positions of the curves at the middle points. The lines connecting the points on the production curve

Fic. 5. - Graphs showing the price and production of eggs by months on selected farms, Washington Co., Ohio, 1912-1916.

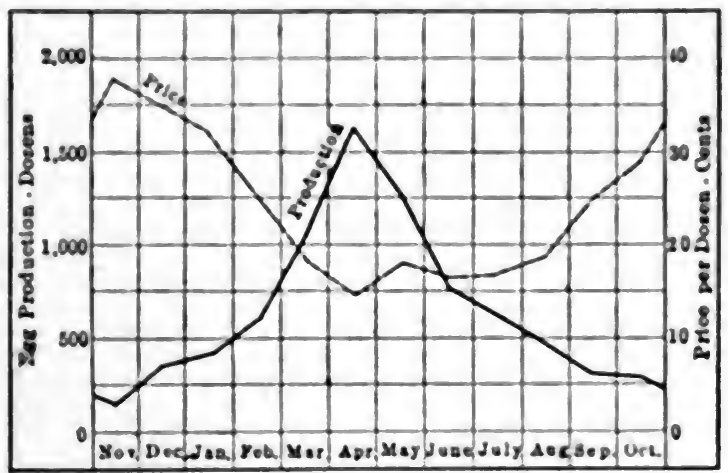

have no other purpose than to aid the eye in interpreting the increase or decrease from month to month, and in noting the general contour of the curve. The points on the price curve for the months presumably represent averages so that no significance should be attached to the lines connecting these points. It is not clear from the curves why the beginning and stopping points are not the middle of the month spaces. The curves clearly show the inverse relationship between production and price.

The base or 100 per cent. line in Fig. 6 is rightly 
more heavily inked than the other lines so that supply and price in excess and in defect of it are clearly shown.

FIG. 6.-Curves showing by months the relative supply and price of Wisconsin butter, 1914.

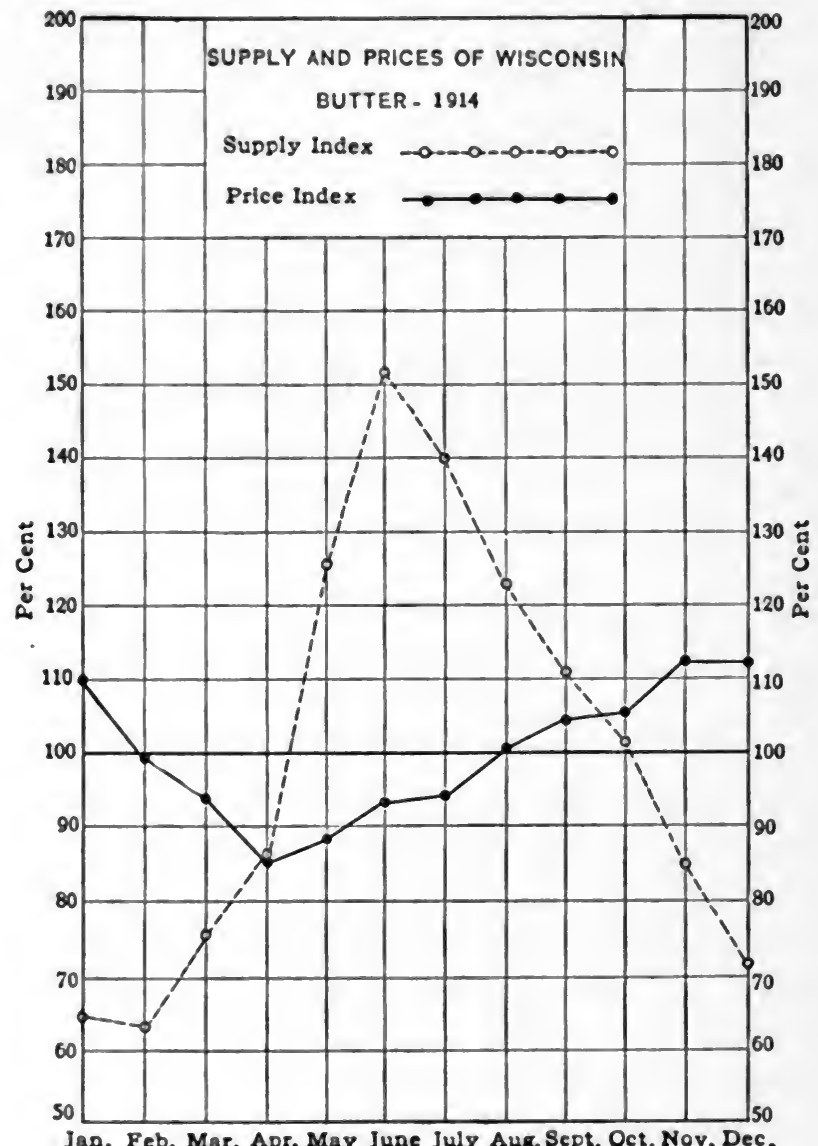

It will be noticed that the 100 per cent. line bisects the areas inclosed within both curves - that is, the excesses 
are equal to the deficiencies. In this figure, the months or horizontal units are indicated by a line rather than by a space as in Fig. 5. There are eleven spaces in this figure; in Fig. 5, there are twelve spaces for the year. There is no question in this figure about the points at which these curves should begin and end as there is in the preceding one.

From the curves it may be deduced that the supply and the price are relative, rather than absolute numbers, but the value of the illustration would have been increased had this fact been stated in some such form as follows:

Average monthly price for the year $=100$ per cent.

Average monthly supply for the year $=100$ per cent. Moreover, the concrete data should have been included in the chart. The figure clearly shows that the price of butter is much more stable than is the supply.

The bar-diagram, (Fig. 7), illustrates the stocks of sugar held by retail dealers by states in the order of amounts. The largest is put first and is therefore given emphasis, but the reverse order would have been equally good. An alphabetical arrangement of the states would have been meaningless for the purpose of the illustration. The bars are placed horizontally and are disconnected. Because of the regularity of the decline from the greatest to the smallest amount, little advantage would have accrued from connecting the ends of the bars by straight lines. The diagram suggests the relative amounts and that is all that it is intended to do. The concrete data are made a part of the diagram, and there is no occasion in studying 
Fig. 7.-Bar-diagram showing stocks of sugar reported by retail dealers, by states, August 31, 1917.

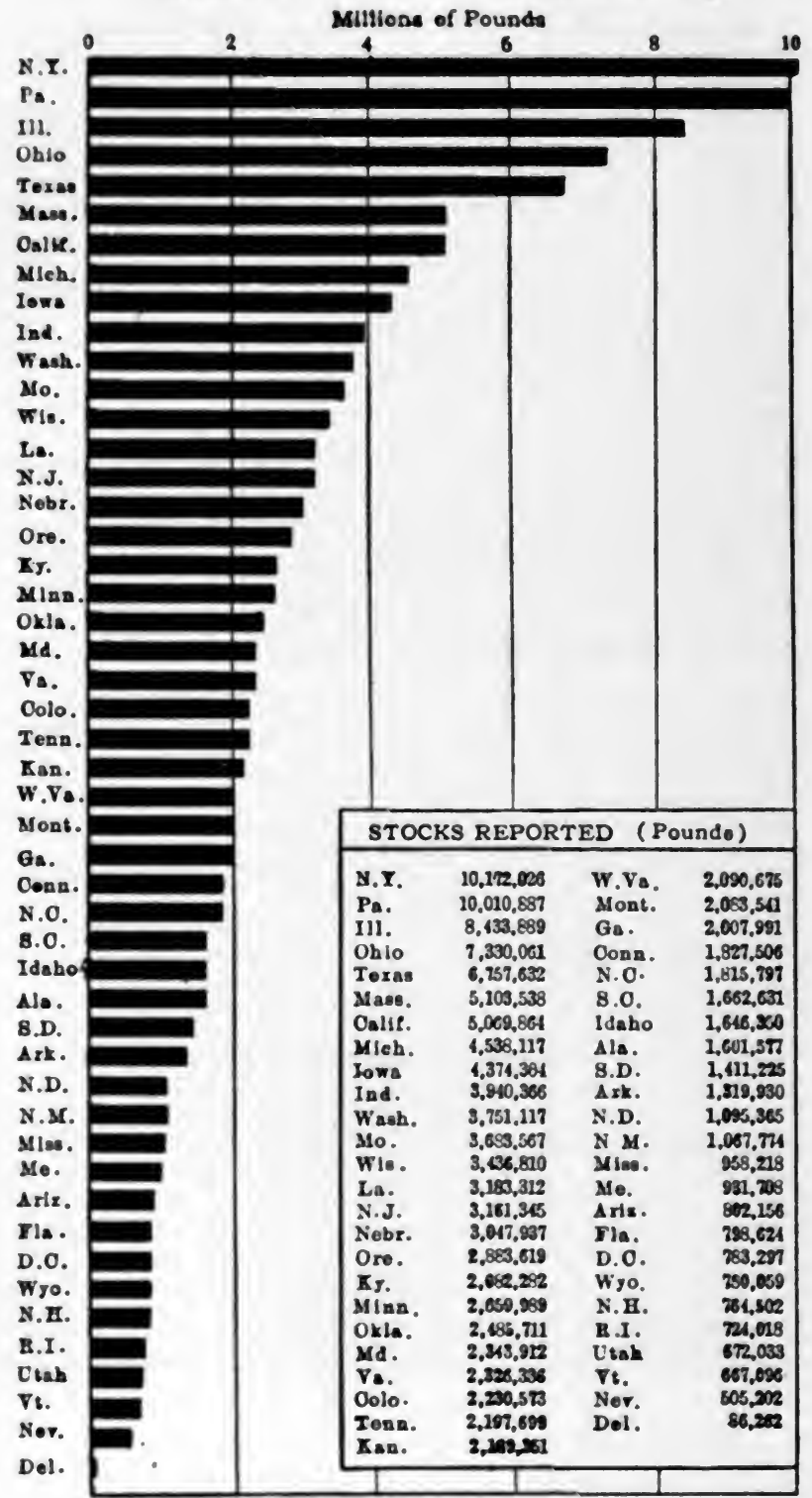


Fic. 8. - Bar-diagram showing, by states, and for farm mortgages the percentage of business on which commission is paid.

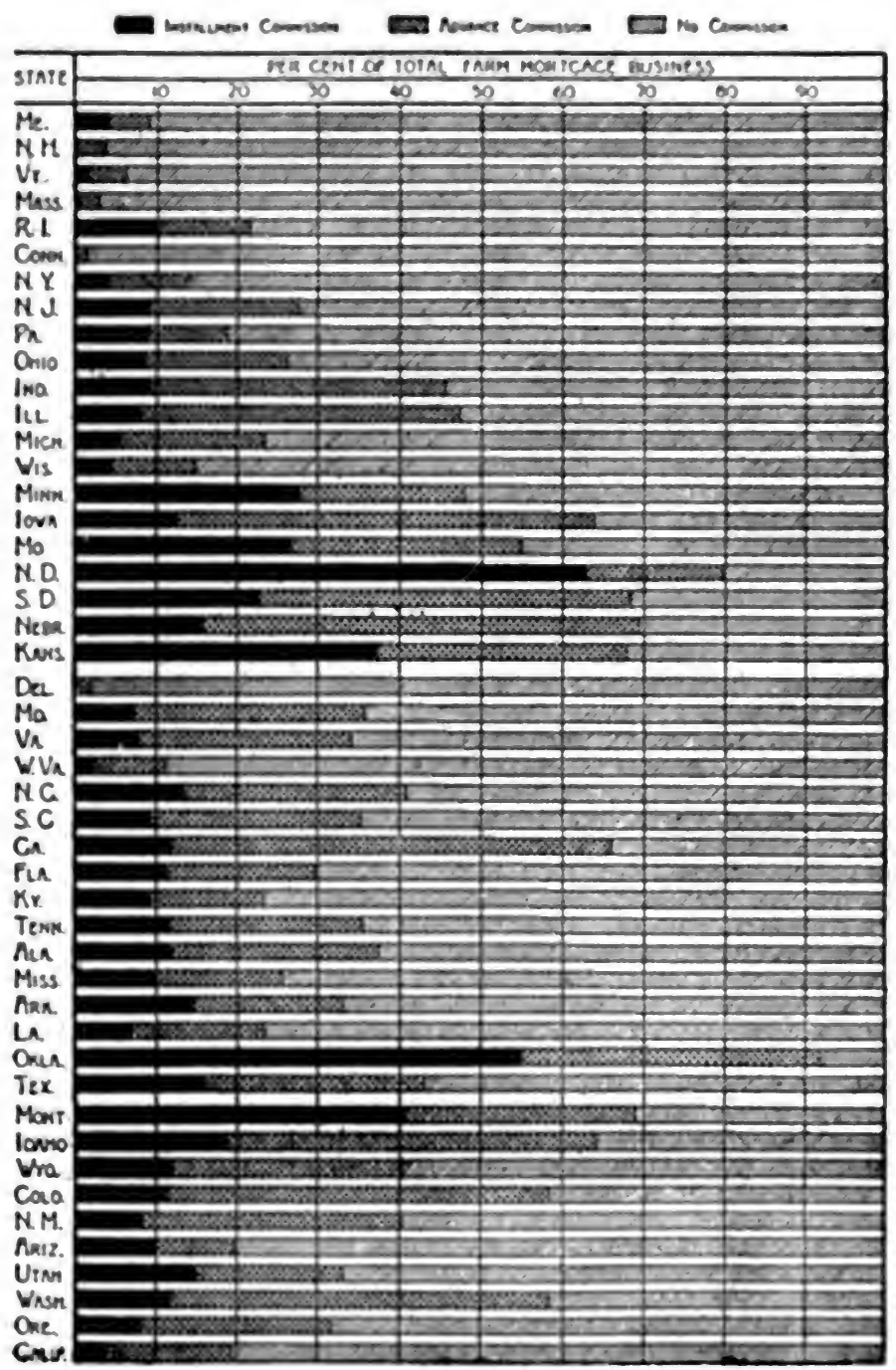


the illustration to determine the exact amounts for the individual states.

The bar-diagram, (Fig. 8), illustrates for each of the states the percentage distribution of commissions on farm mortgages. The order of the states is geographical and the illustration not convincing because of this fact. If the size of "Installment commission," for

Fig. 9.-Bar-diagram showing the per cent. distribution of reasons for workmen leaving their positions.

WHY MEN LEFT

REASONS FOR LEAVING

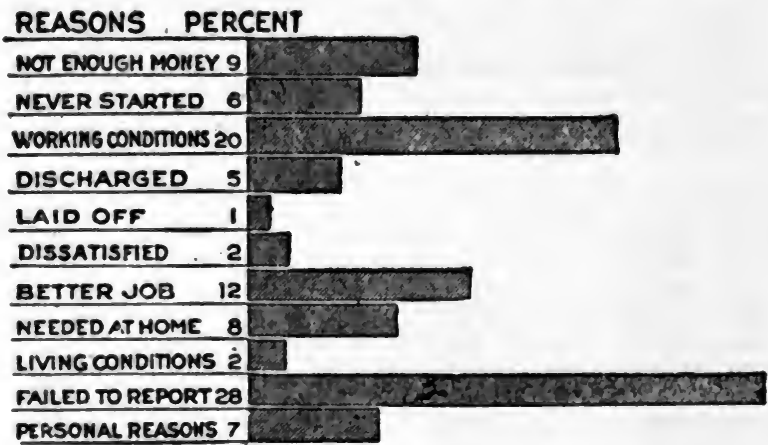

instance, had been made the controlling factor, the dominant element in the illustration, as indicated by the shades, would have been made emphatic. There is always a best order to follow, and it should govern in the make-up of a diagram.

This figure shows relative rather than absolute amounts, and should have been accompanied by the concrete data on which the percentages are computed. 
The bar-diagram, (Fig. 9), is defective in the following particulars: (1) It is not provided with a scale. (2) The order in which the reasons are given is without significance: it is not emphatic. (3) The conerete

Fra. 10. - Surfaces and bar-diagrams showing for specified years, the arnount of whent in bushels purchaseable for $\$ 100.00$.

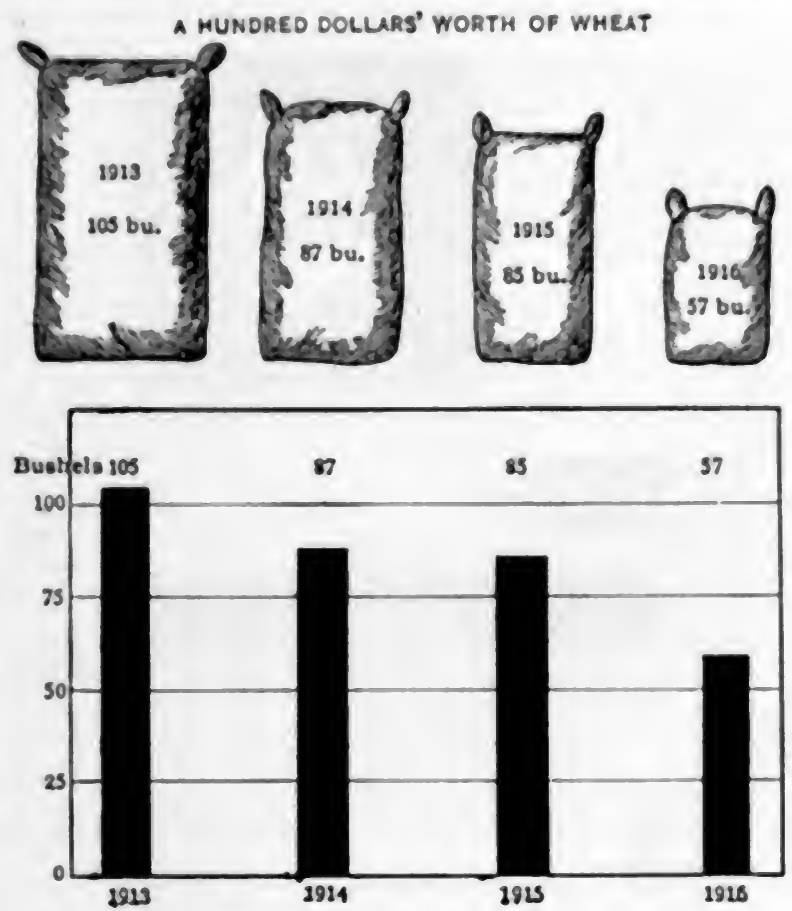

data upon which the percentages are calculated are not given.

In Fig. 10 surfaces and bars are used as alternative illustrations. The "sacks" vary both in length and width, and the question is raised immedi- 
ately: Are they drawn to scale? They are not so drawn. The amounts and the illustrations may be contrasted as follows, if 1913 is taken as 100 .

Amounts: $\mid 1913=100 ; 1914=83 ; 1915=81 ; 1916$ $=54$.

Fic. 11. - Surfaces and bar-diagrams showing the relationship between the areas of Russia in Europe and the Russian Empire.
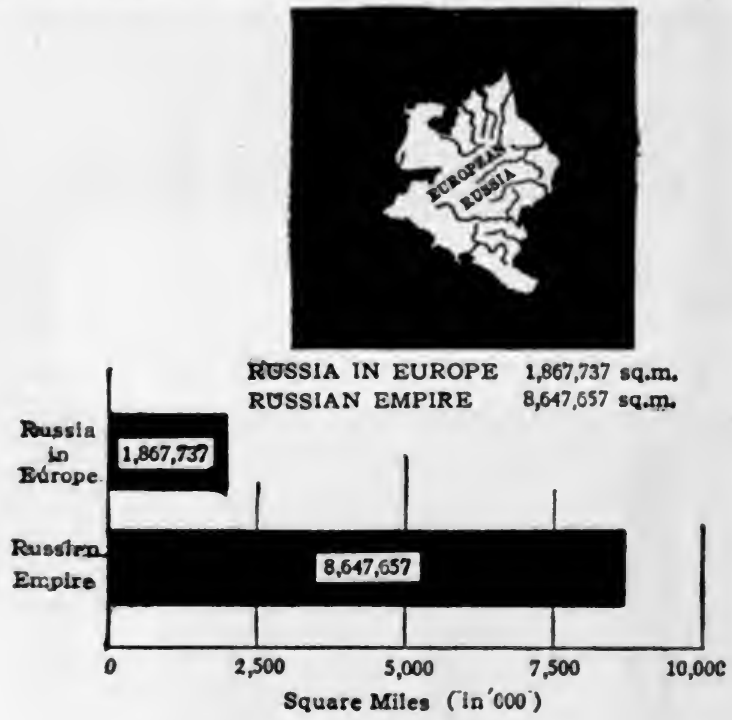

Illustrations: $1913=100 ; 1914=67 ; \quad 1915=54$; $1916=30$.

If the "sacks" are thought of as solids, then the discrepancy between the fact and the illustration is much greater. The drawings were presumably made with the length only in mind, but they are deceptive because both the length and the width vary. For surfaces, the dimensions vary as the square roots 
of the areas; and for solids, as the cube roots of the contents.

The amounts are accurately and better illustrated by the bars. There is nothing deceptive about them;

Frg. 12. - Surfaces showing the relationship between total coal production and savings in ooal consumption resulting from curtailing light.

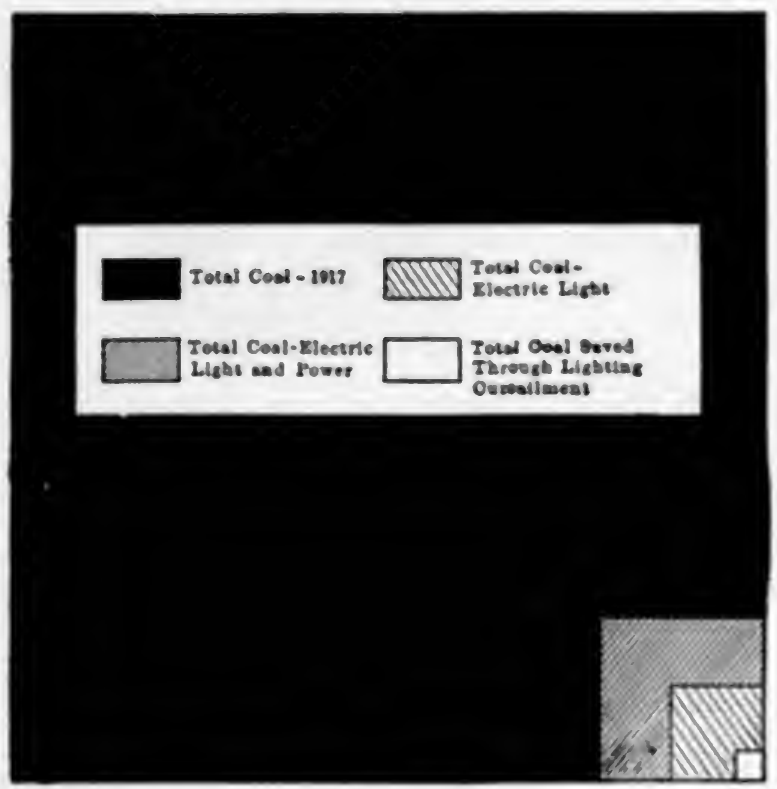

their accuracy is at once confirmed by the scale according to which they are drawn.

In Fig. 11, surfaces and bars are used as alternative illustrations. Contrast the effect. Which method seems to you preferable as an illustration?

In Fig. 12, surfaces or areas within areas are used. Because, in such figures, the dimensions vary 
as the square roots of the areas, comparison is very difficult, if not impossible to visualize. Such illustrations ought not to be used.

Fig. 13.- Surfaces and bar-diagrams showing gross tonnage of vessels registered in Canada and Great Britain, engaged on the Great Lakes and connecting waters west of Montreal.

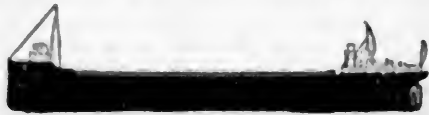

1899-1900

\begin{tabular}{|c|c|c|}
\hline Plecal Year & $\begin{array}{l}\text { No. of } \\
\text { Veseale }\end{array}$ & $\begin{array}{c}\text { Oross } \\
\text { Tranere }\end{array}$ \\
\hline & $\begin{array}{l}212 \\
210\end{array}$ & $\begin{array}{r}00,984 \\
157,026\end{array}$ \\
\hline ivis: & 206 & $\mathbf{n o , 2 8}$ \\
\hline
\end{tabular}

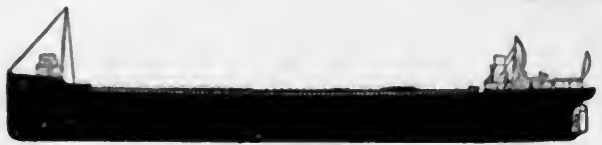

$1905-1906$

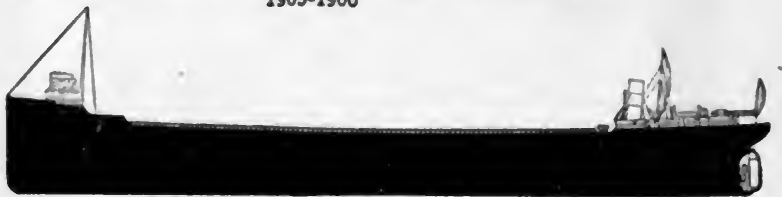

$1913-1914$

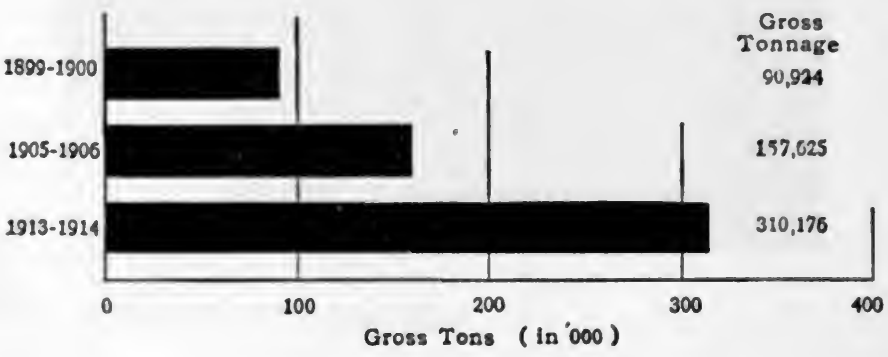

In Fig. 13, surfaces and bars are used as alternative illustrations. The areas of the ships are significant while the lengths of the bars are all that need to be considered. Both illustrations are drawn on absolute scales. The use of figures of ships is 
suggestive, but the illustration is inconclusive because of the absence of a scale and the use of two dimensions.

Notice the optical illusions in Fig. 14: the bars seem to be constricted at the black areas. The scale is unfortunately placed at the right rather than at the left of

Fro. 14.-Cross-hatched bars showng the distribution of the gross income of selected farmers in Wisconsin.

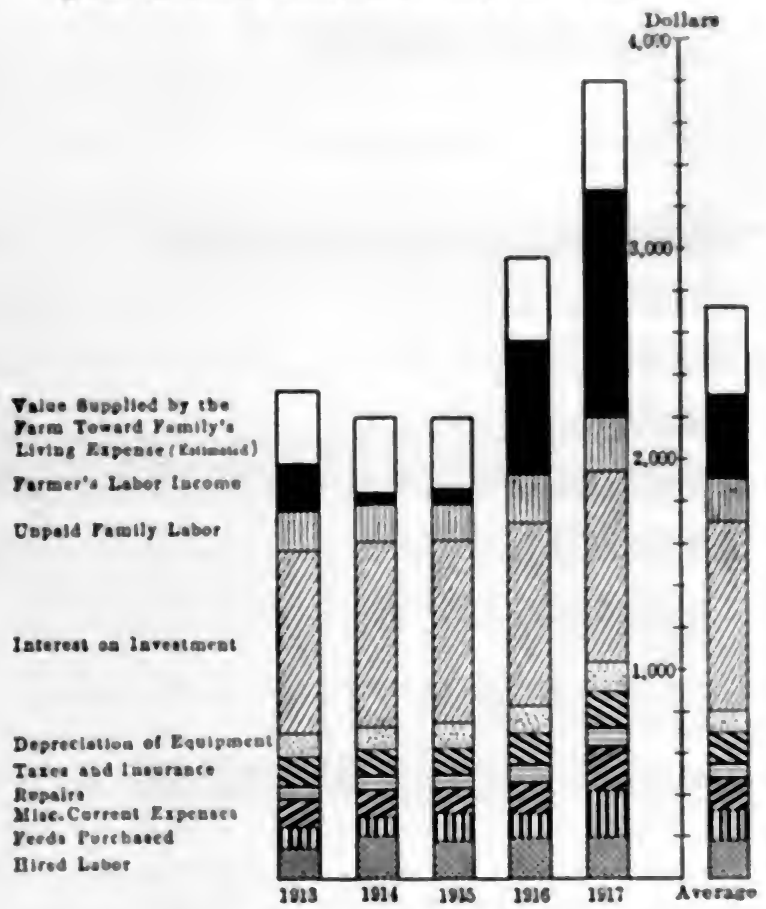

the figure. If faint guide lines were drawn across the surface of the diagram, it would be easier to make comparisons of the total and relative amounts.

Fig. 15 shows the percentage relationship between the areas but does not give the concrete data upon 
which the distribution is made. The cross-hatching is distinctive. The bars, however, should have been placed vertically.

Fig. 16 is distinctive in having both the concrete data and the percentage relationships component parts of the diagram. The order of the years is the reverse of that followed in Figs. 14 and 15.

Fig. 15.-Cross-hatched bars showing the distribution of areas on selected farms in Washington County, Ohio, 19121916.

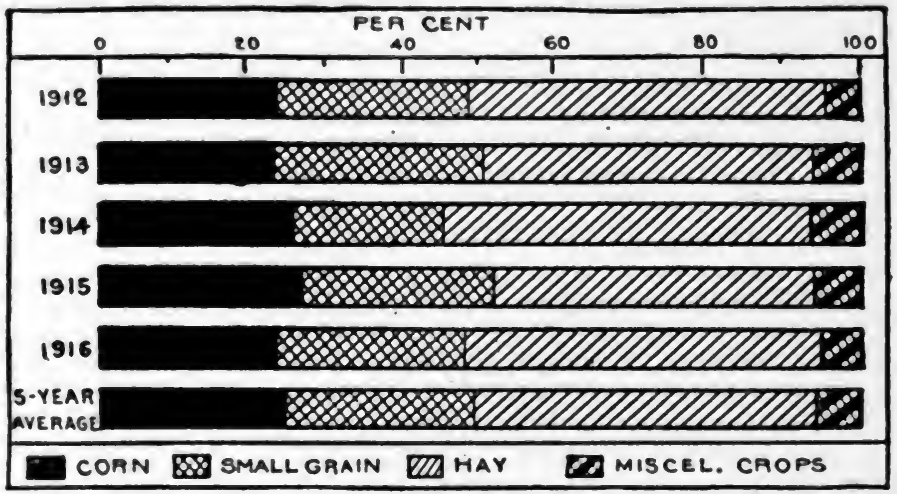

In Fig. 17, a double percentage scale is used. The shipments for each month of the year are shown by the height of a rectangle. The 'rectangles are distinct, uniform in width, and broad enough to be emphatic. Undoubtedly, the most evident thing from the diagram is not the percentage amounts for the months individually, but the general distribution throughout the year. It would have been helpful in the interpretation of the diagram, if the absolute amount which is distributed on a percentage basis throughout the year had been made a part of the illus- 
tration. The accuracy of the distribution by months, if not the exact amount shipped during the year, could then have been proved.

Fta. 16.-Cross-hatched bars showing the per cent. distribution of stocks of sugar reported for August 31, 1917 and August 31, 1916 for important groups of firms.

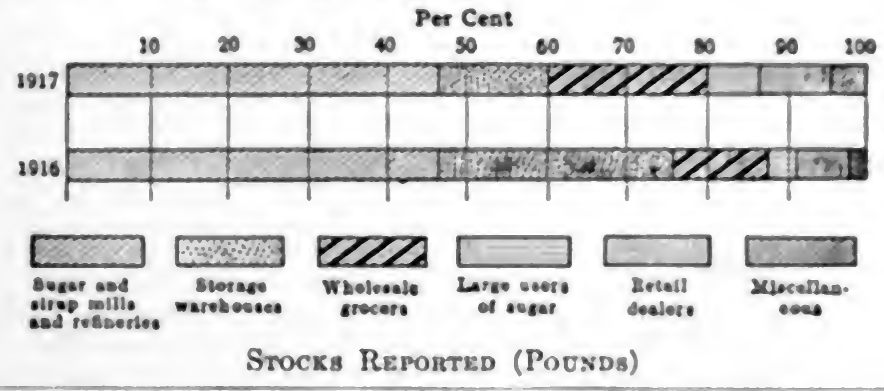

\begin{tabular}{|c|c|c|c|c|}
\hline \multirow{2}{*}{ Group } & \multicolumn{2}{|l|}{1917} & \multicolumn{2}{|c|}{1916} \\
\hline & Quantity & Per cent. & Quantity & Per cent. \\
\hline Total.... & $1,039,279,301$ & 100.0 & $1,430,660,470$ & 100.0 \\
\hline $\begin{array}{l}\text { Sugar and sirup mills } \\
\text { and refineries....... }\end{array}$ & $450,767,457$ & 46.3 & $660,301,064$ & 46.2 \\
\hline Storage warchouses... & $146,728,359$ & 14.1 & $428,077,562$ & 29.9 \\
\hline Wholesale grocers..... & $207,398,679$ & 20.0 & $166,961,829$ & 11.7 \\
\hline Large users of sugar. .. & $66,581,728$ & 6.4 & $49,856,325$ & 3.5 \\
\hline Retail dealers......... & $90,429,732$ & 8.7 & $96,855,176$ & 6.8 \\
\hline Miscellaneous......... & $47,373,346$ & 4.6 & $28,608,511$ & 2.0 \\
\hline
\end{tabular}

In Fig. 18, the bars are placed vertically and are spaced on the horizontal axis in proportion to the time. The figure is defective in not having a common scale.

In Fig. 19, the horizontal rectangular bars are 6 
joined together thus giving a connected, step-like curve covering the entire period. The widths of the bars, moreover are proportionate to the periods between successive censuses. Contrast this illustration and Fig. 18, which also depicts a fact historically. Which do you prefer, a vertical or horizontal position for the bars?

Fig. 17.-Bars showing per cent distribution by months of Cheddar cheese shipments from Wisconsin to Chicago, in 1911.

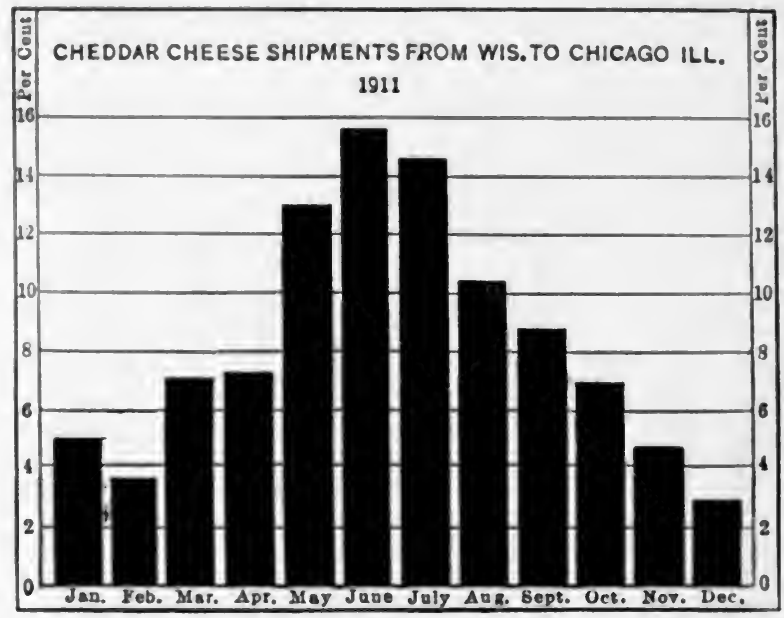

In Fig. 20, the wage groups for each class of wage earners are represented on the horizontal axis by vertical lines, uniformily spaced throughout the diagrams. It should be noted, however, that the rule which requires the spaces to be proportionate to the size of the groups is violated for the group "Under $\$ 3.00$," and for all groups above $\$ 16.00$. The effect of widening the spaces so as to make them proportionate to the size of the groups both at the beginning 
and the end of the curves would be to give them a flatter and more dispersed appearance.

The concrete data, here, as in so many diagrams, unfortunately are missing.

Fro. 18. - Bar-diagram showing values of products in leading industries, 1579-1913. (Values in millions of dollars.)
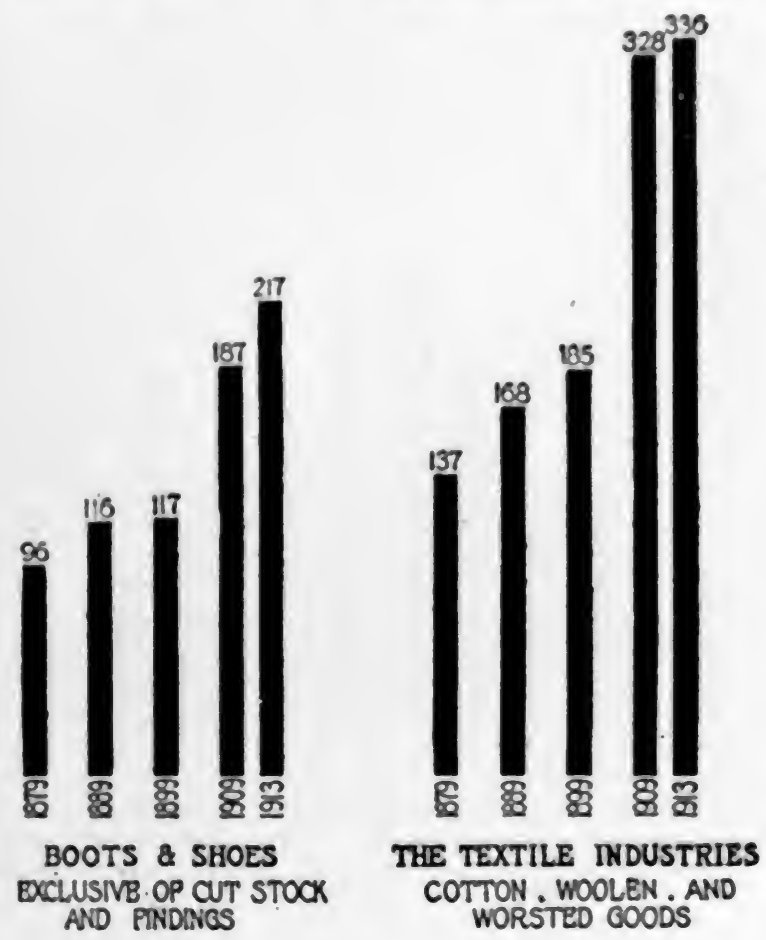

The value of a frequency dot map, as illustrated in Fig. 21, is that it gives a clear idea of density and distribution, and change from "highs" to "lows." It is easy from such a map to visualize places of con- 
centration and "scatteration." The value of each dot is of little consequence in reading exact frequency, since the chief purpose of the map is only to give an impressionistic view.

Fig. 19.-Cross-hatched bars showing by census years, the proportion of urban population to total population in Massachusetts, $1790-1910$.

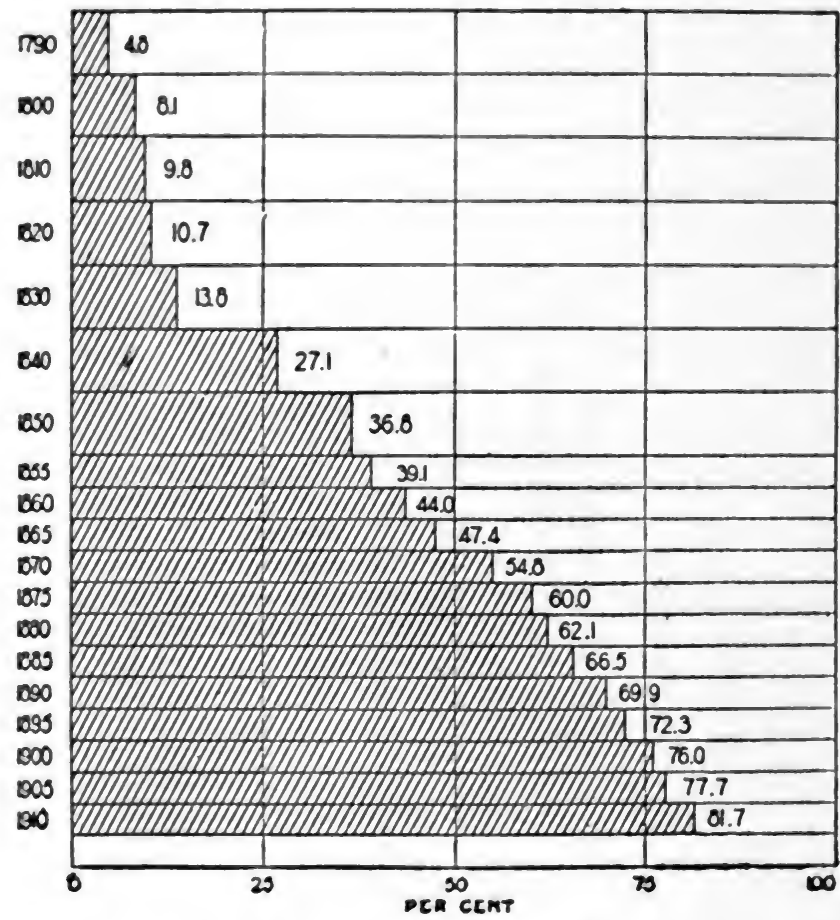

The type of map illustrated in Fig. 22, is unsatisfactory because the sizes of the dots are not readily comparable. If it is not desired to show exact amounts, then the scale is useless; if it is so desired, the illustration fails of its purpose. 
Such a map as that shown in Fig. 23, is unsatisfactory; neither the size nor the shading of the dots being readily comparable.

Fia. 20.-Frequency graphs showing the percentage wage distr.bution of classified wage-enrners by wage groups.
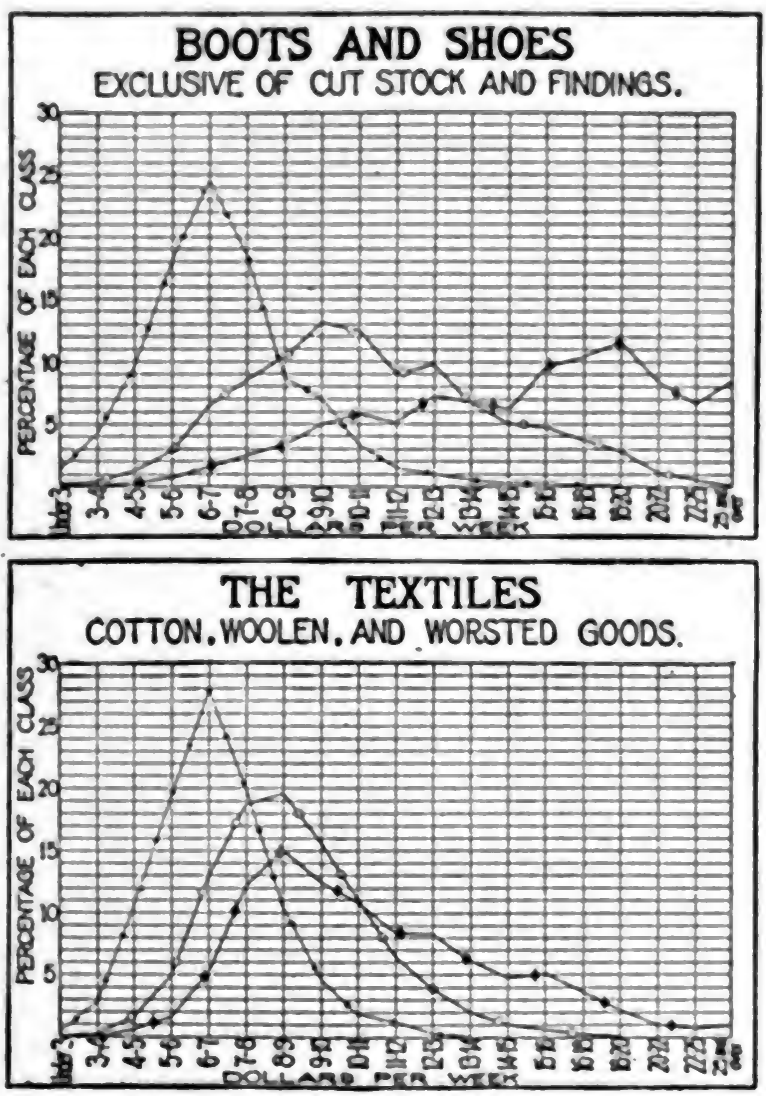

In Fig. 27, the "bars are placed vertically . . . . and the so-called 'curve' is formed by introducing the line connecting the points at the end of the bars. 

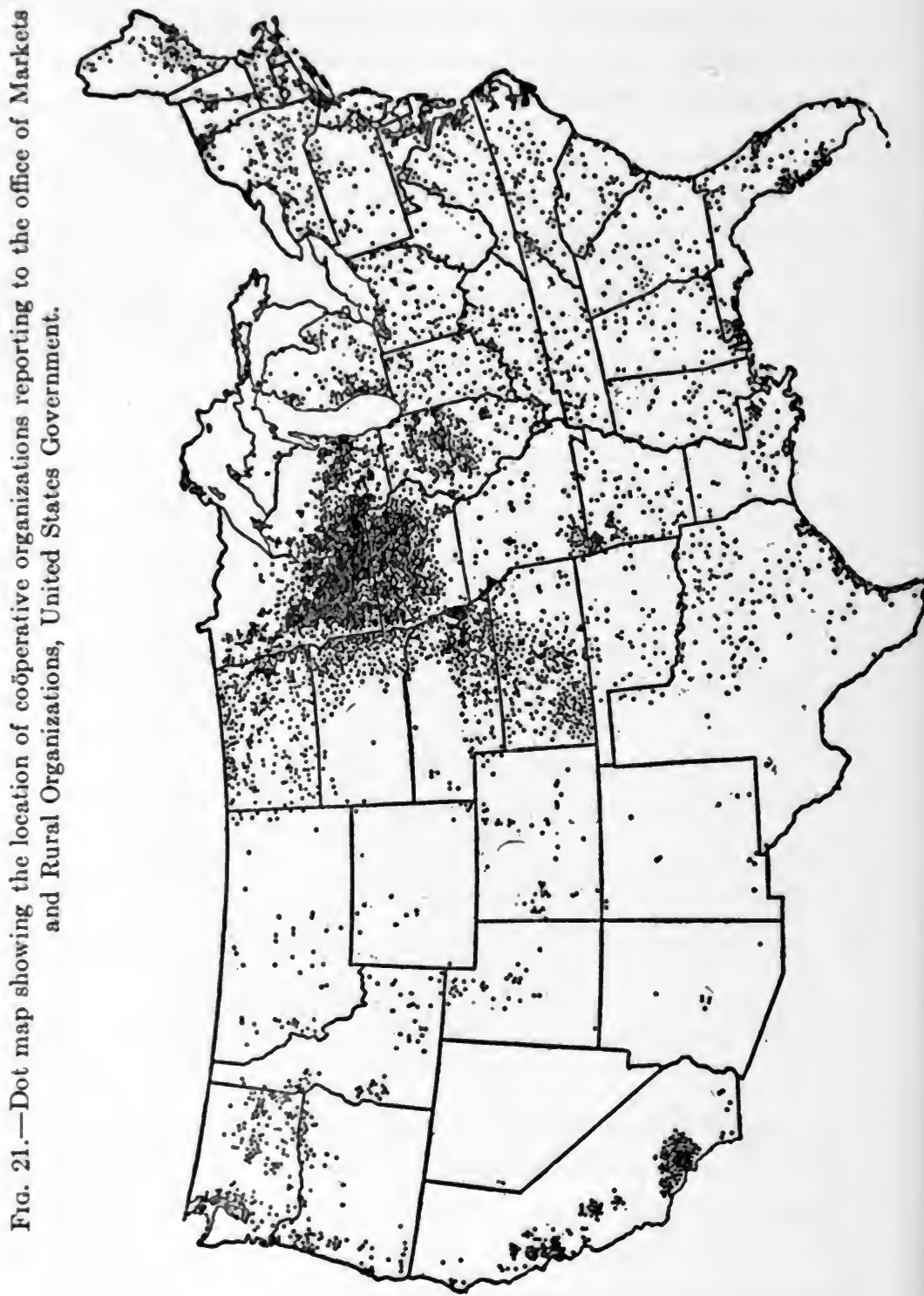
"Now it is evident that the only things properly comparable in such a chart are the distances from the base line to the points determined - in other words, the length of the bans. The introduction of the distinctive connecting line at once diverts attention from the proper comparison to the line itself. If, as is usually the case, the bars be not introduced the gradient or steepness of the line becomes then inevitably the basis of judgment and all notion of the distances as the real subject of comparison is lost. Unconsciously the line is erroneously interpreted as expressing rate of change. But rate of change .... can only be accurately re-

Fra. 22.-Varying-size dot map showing amounts of primary shipments of American Cheese from Wisconsin, 1911.

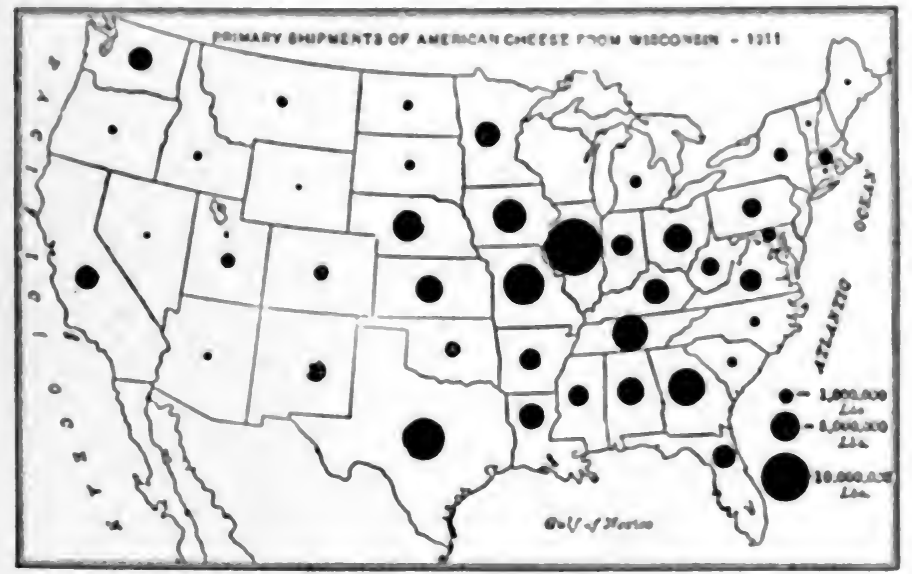

presented by a ratio chart in which percentage differences and not arithmetic differences are plotted.

"Moreover, it often happens that a large part of the scale has no points assigned to it. In that case it is common practice to ornit the lower portion of the scale. This at once and completely renders impossible the only significant comparison. Suppose the smallest magnitude in a given group be 75 and a larger magnitude be 100. It would then be in accord with common practice to cut away the lower portion of the seale to, $8 a y, 70$. The ocular comparison of the two magnitudes will now, of necessity, bo that 
between 5 and 30 and not between 75 and 100. The chart then becomes not only useless but positively deceptive. Furthermore, when the series of magnitudes or number of lines becomes increased beyond two it becomes difficult, if not impossible, to compare the

Fig. 23.-Varying-shade dot map showing the amount of dairy butter, in pounds, produced, sold, and consumed, in Wisconsin Counties, 1909.

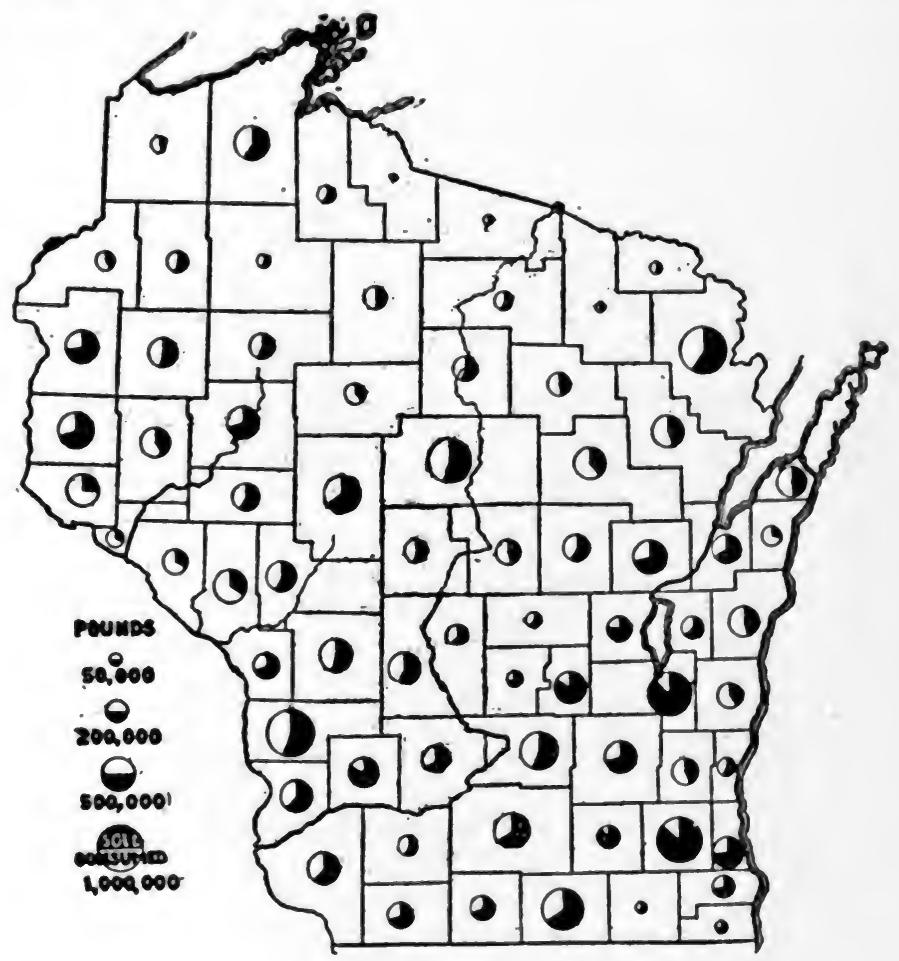

distances even though the entire scale be given. If this is further complicated by an abbreviated scale the situation becomes one of obscurity multiplied by deception."

Frequently, it is desired to show graphically per- 


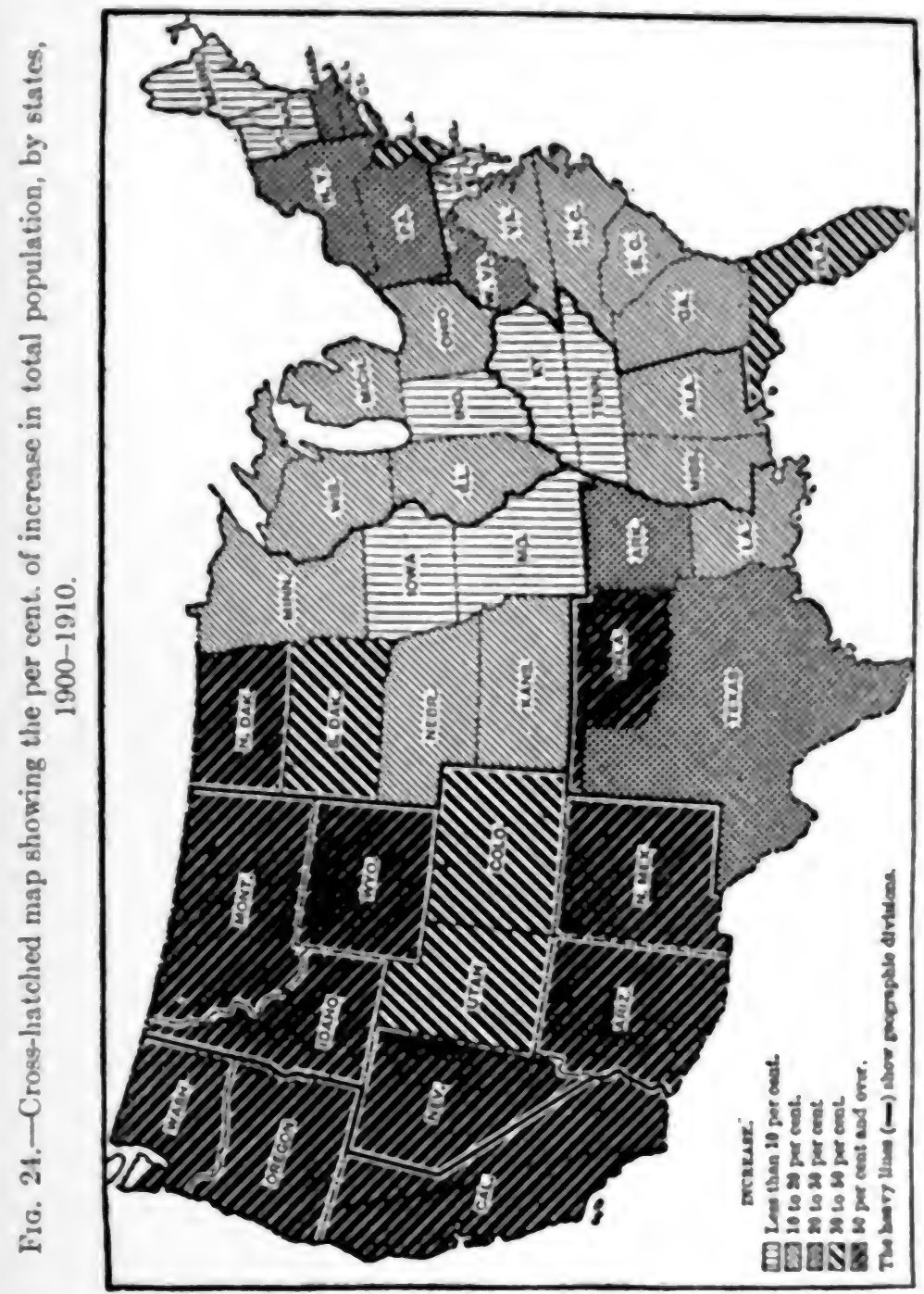




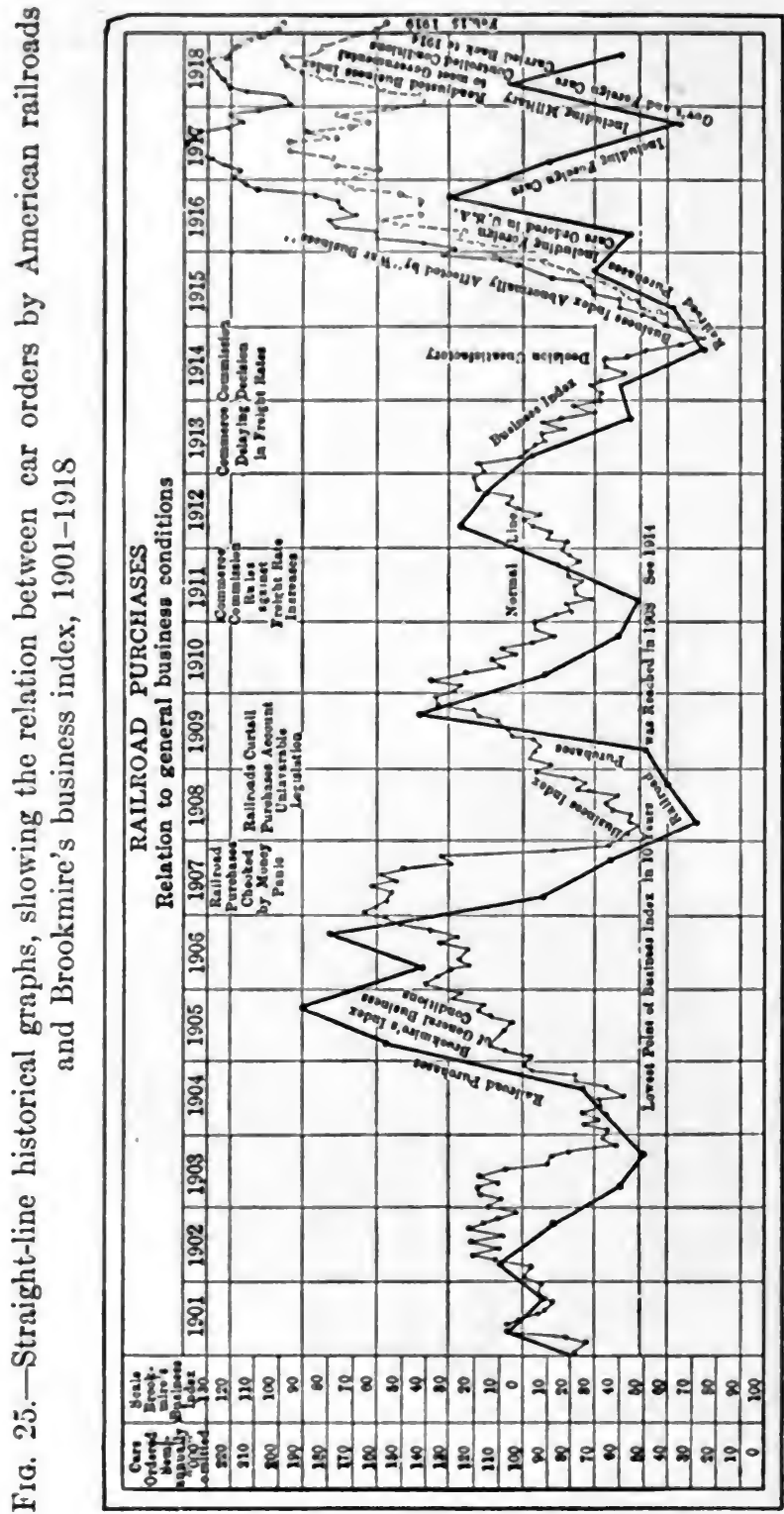


F1G. 26. - Bar-diagram showing the relative growth in investment and in electricity sold in kilowatt houn, for years, 1896-1913.

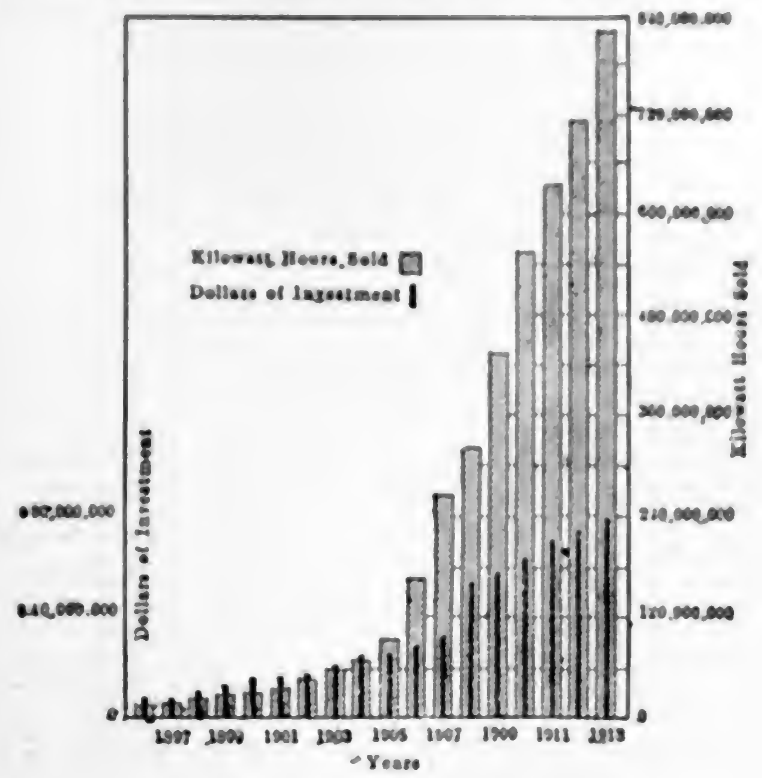

Frc. 27.-Combination bar-diagram and line chart.

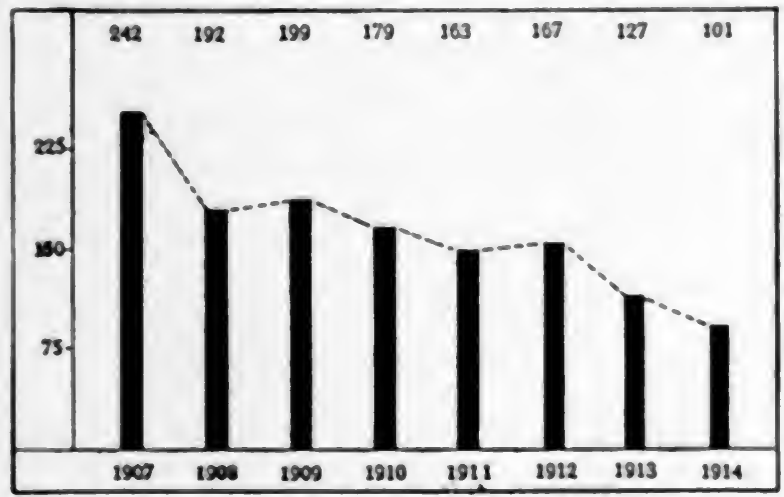


centage rather than absolute changes. The ordinary graphs, such as those above, show absolute changes or differences. When percentages are to be shown, a "ratio," or logarithmic scale, must be used. Arithmetic or difference scales and percentage or ratio scales are illustrated and described immediately below in an article prepared by Lucian W. Chaney.

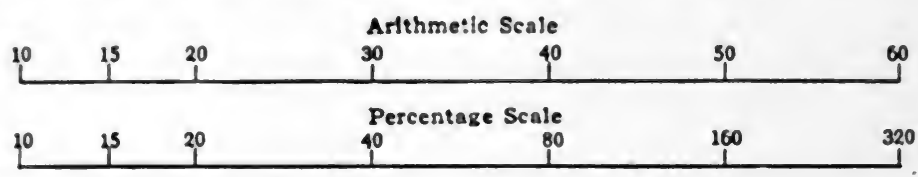

"It will be noted that in the arithmetic scale equal linear distances represent equal arithmetic differences, whereas in the percentage scale equal linear distances express equal percentage differences. In the case of the arithmetic scale one space represents 10 units; in the percentage scale one space represents 100 per cent. difference.

"If it is desired to introduce intermediate numbers in the above arithmetic scale, the space between any two of these will be divided into 10 equal parts. Eleven would then be one unit from 10 , while 15 would be midway between 10 and 20 , since points having equal arithmetic differences are always equidistant. The construction of a complete percentage scale, on the other hand, is more complicated because the relation of any magnitude as compared with an ascending or descending series of magnitudes is a constantly changing percentage. To illustrate: From 100 to 110 is a 10 per cent. increase, whereas from 200 to 210 the increase is only 5 per cent. Therefore, on a percentage scale the linear distance from 200 to 210 will be less than that from 100 to 110 . Thus it is seen that in passing up the percentage scale numbers separated by the same difference as regards magnitude will be represented as drawing closer together on account of the decreasing percentage of difference.

"Suppose it is desired to locate the intermediate number 15 on the percentage scale given above. In order to do this the fundamental method is to find from logarithmic tables the logarithms 


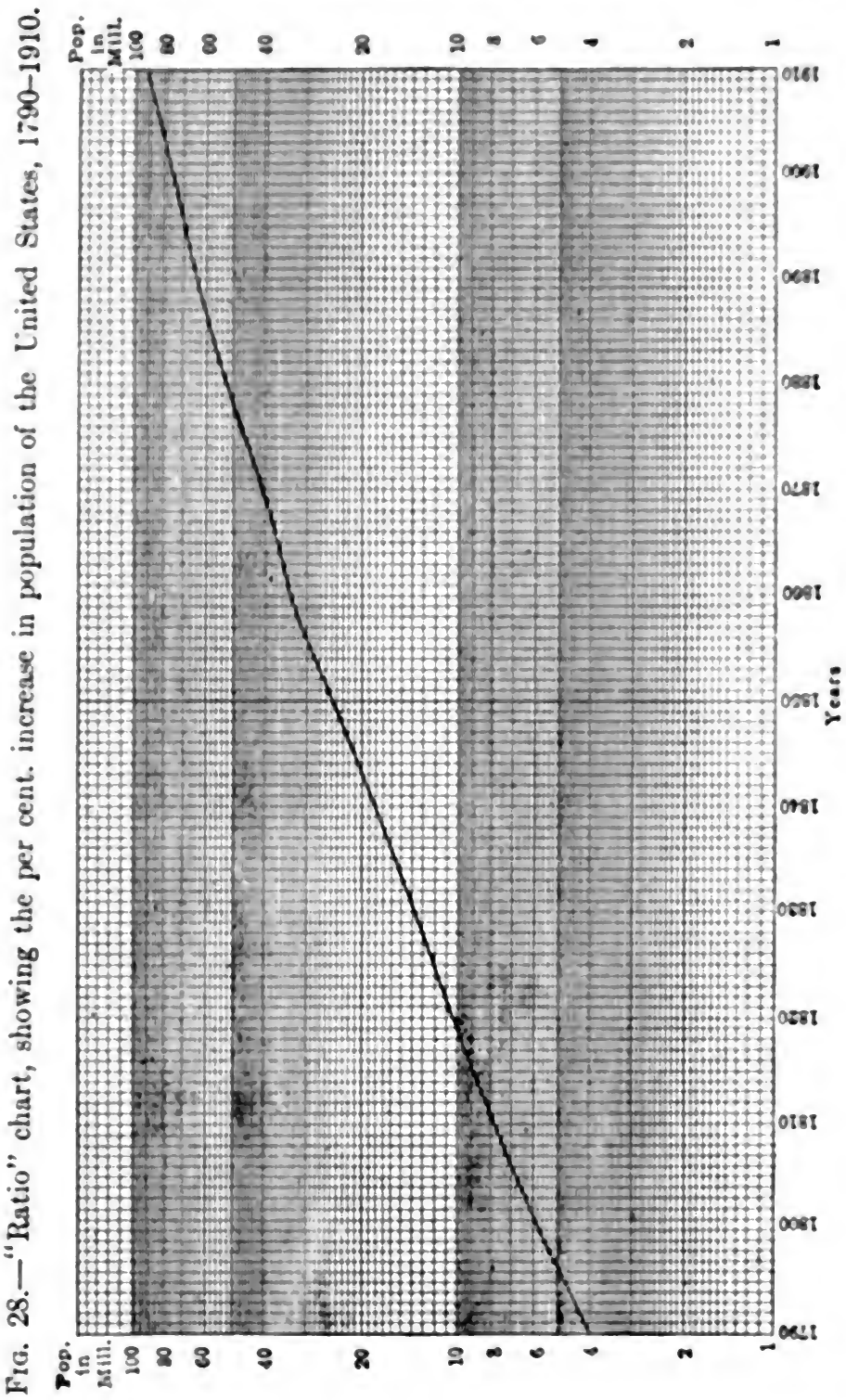


of 10,15 , and 20 and then place 15 in a position representing the relation between its logarithm and those of 10 and 20 . When this is done it will be found that 15 is not equally distant from 10 and 20 as in the arithmetic scale, but is nearer to 20 , as shown. This accords with the fact already shown by illustration that the relation of a given value to an increasing series is a constantly decreasing percentage."

It is, of course, unnecessary to prepare your own ratio paper, since various types may be secured in the trade. Figs. 28 and 29, respectively, taken from Fisher, "The 'Ratio' Chart," show the population of the United States plotted on a ratio and on a difference basis.

Professor Chaney has the following to say concerning the characteristics and functions of the "ratio" chart.

" 1 . In a ratio chart a given linear distance on the scale always represents the same percentage difference.

"2. The gradient or steepness of the lines always and inevitably expresses the exact rate of change in any series of statistical facts. Consequently, equal rates of change or equal percentages of difference will have the same gradients. If two magnitudes vary 10 per cent. upward their curves will run parallel however far separated they may be on the chart. For example, if one magnitude increases from 10 to 11 while another increases from 100 to 110 the curves corresponding to the change will be parallel, indicating the same rate of change. It is evident that plotting the same magnitudes on an arithmetic scale would show ten times the amount of difference in the second case although the percentage difference is identical.

" 3 . The percentage scale in the ratio chart has no zero. A moment's consideration will show that this must necessarily be true. As long as there are magnitudes to be plotted, no matter how small, the percentage decrease can never be 100 and thus can never theoretically reach the zero point. . . . The absence of the zero in the ratio chart is sometimes misapprehended as a 
disadvantage. On the contrary, the particular value of the seale is related to this fact. Because of the absence of the zero, atten-

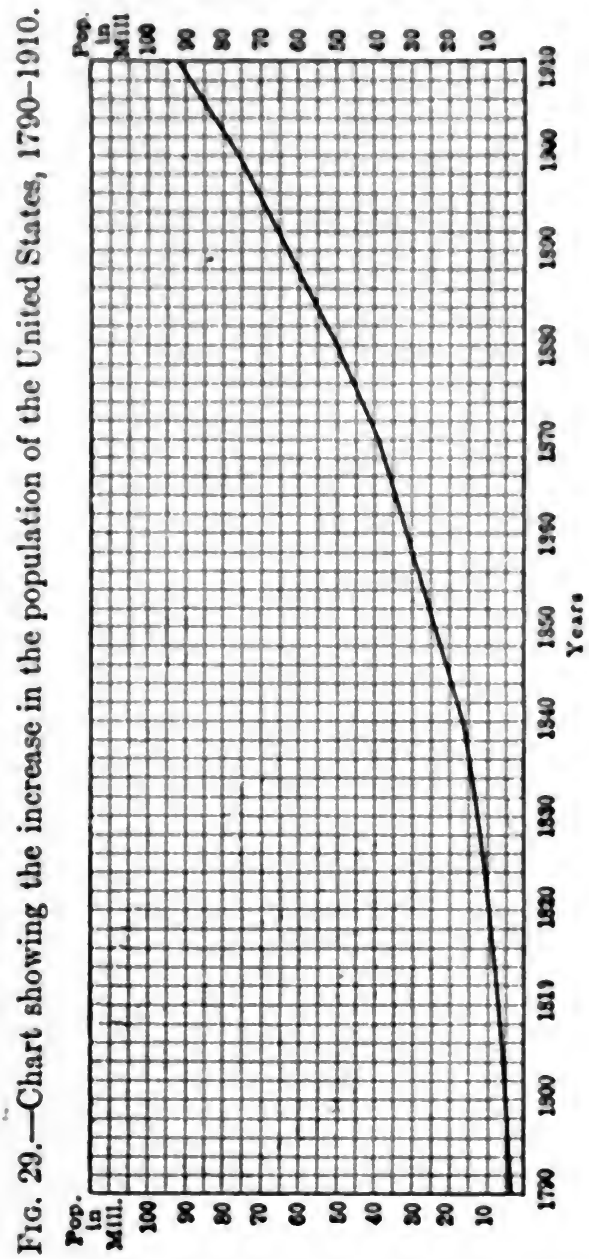

tion is necessaruy ana properly centered upon the relations of the various magnitudes to each other and particularly upon the rates of change. 
" 4 . The ratio chart makes possible a direct and correct comparison of increases and declines. The usual method of expressing changes up or down is to say, for example, that a rise of 50 per cent. was followed by a decline of 30 per cent. This mode of expression is used without realization that it involves expressions which cannot be compared one with the other. Comparatively few persons at once recognize that an increase of 100 percent. is exactly balanced by a decline of 50 per cent. Percentages of increase can be properly compared with other percentages of the same sort and percentages of decline are similarly comparable, but no direct comparison can be made between a percentage of increase and a percentage of decline." 


\section{CHAPTER VI}

\section{SUMMARIZING THE FACTS-AVERAGES AND OTHER MEANS}

The viewpoint of the business man who is willing to act on the basis of facts is, What does the analysis show? To what conclusions does it lead? The demand is for some form of a summarized statement. The details must be shortened, or crowded together into a single expression. Not that they are of no significance, but as details they are impossible of being readily handled. A total which summarizes the different parts, or an average which seems to characterize the detail, and which can be compared with similar figures over a period, or for different conditions, is what is wanted.

Men of action are sometimes impatient with details and treat them as though they were identical and uniform, and could be ignored. They are inclined to look upon them as "details," which will take care of themselves. This attitude is suggestive of the state of mind which looks upon business as simple, and its processes as capable of being reduced to a few underlying principles, which can better be felt than stated; better expressed as axioms than as relative truths. The point of view is what may be termed absolute rather than relative. It looks with suspicion upon diagnosis, and is rather content with generalization. It tends to ignore the fundamental truth that busi- 
ness is diverse and the situations with which it deals ever changing, and to accept the dogma of status. It is impatient, for instance, with the idea that labor is more than a commodity, that the market cannot be stated in single terms of "demand and supply," and that a protective tariff, competition, or free trade have limitations depending upon the type of national industry, necessity for state control, and the interests of classes.

Now, this type of mind has both its strength and limitations. There are a comparatively few fundamental underlying business truths resting on human psychology, the extent of industrial development, etc., but they are relative for time and place, and are not absolute. They are discovered not by intuition, but by analysis. Neither can they be divorced entirely from the detail of business operation, trade relation, and human conduct. Average market conditions may be accurately stated. Likewise the response of the average individual to a type of advertising, for instance, may be calculated. Business, while it can not overlook these underlying truths, cannot always be sure that a particular unit will benefit or suffer from them. All of the conditions which give rise to them may not be experienced in every business. There are some which are above and some which are below the norm established for business as a whole. For instance, it may be true that costs vary with industrial output, but the rate is different for different producing establishments. The business which is built on a general cost basis, will have difficulty, under certain conditions, in financing its opera- 
tions; and, under other conditions, will be realizing enormous profits.

The point which it is desired to emphasize is that there are variations, among individual businesses, from the norm established by business as a whole, and these should not be lost sight of in the daily conditions of operation. A business unit, large or small, must shape its policy on its past experience and on the experience of business as a whole, but it cannot be blind to the fact that most, if not all, of these are relative only, and that new conditions and new problems are always suggesting and making necessary changes and readjustments.

What has been said has particular application to the subject of this chapter. Averages, in the terms of which business is wont to express its condition and to compare its operations, should not be regarded as "a secret something which determines events After calculating a certain average, business is likely to conclude that some secret fate is at work and to expect a faithful and continuous repetition of this average. Every average is a sort of fictitious substitute for the details which it replaces, serviceable when the conditions for which it stands are known, but deceptive when they are ignored.

The truth of this contention should be seen more concretely. Business profits may be stated as averages. In this form they are convenient. A statement of the average wage which is paid to a diverse labor force may carry some meaning to the business executive. Likewise, costs over a period of time may be averaged in order to detect improvement, or the reverse. But profits are different on different goods. On 
one the mark-up is 20 per cent.; on another 50 per cent. On one the turn-over per year is ten; on the other, two. Can these differences be ignored in the single expression "average profits?" Likewise, the average wage paid may, for comparative purposes, be a satisfactory way of stating the wage bill; but is it significant in meeting the demands, on the part of labor representatives, for increased wages, or satisfactory to the employer in contrasting amounts paid and services secured? Similarly, average costs are deceptive unless the conditions of their measurement are identical.

The burden of what has just been said is that general impressions, whether expressed as averages or otherwise, will not suffice in business. Averages constitute norms with which experience may be compared, but comparison is valid only when conditions are identical. It is a legitimate endeavor of business to set up for different types of enterprises norms or average conditions which will serve as guides in testing operations. However, these standards must be precise, and the conditions to which they apply, uniform. For many purposes, the differences from the average are far more significant than the norm itself, since they measure the relative degree with which it is experienced.

Let us apply what has been said to the different types of averages which should be used in the analysis of business problems.

First, there is the generally known arithmetic mean, or average. It is on the tongue of every business man, and is probably the most generally used summary expression. What does it mean? It is 
that amount which results from dividing the sum of a series of numbers by the number in the series. Specifically, the average sale from the following experience- $\$ 1.00, \$ 5.00, \$ 3.28, \$ .60, \$ 2.22, \$ 4.81, \$ .10$ - is \$2.43. What is this average? Plainly, it is the center of gravity, or balancing point in the series, the numbers larger than it being exactly balanced by those smaller than it. It is clearly not represented in the series at all. In this sense, it is purely fictitious. It is unreal. In another series, however, this average may be represented in every number, as in the series \$2.43, $\$ 2.43, \$ 2.43$, \$2.43; average \$2.43. In still another, it may be closely approached by some of the items and widely separated from others, as in the series, $\$ 2.39, \$ 2.41, \$ 2.45, \$ 2.46, \$ .10, \$ .15$, \$9.62, \$.26, $\$ 2.03$; average $\$ 2.43$.

What are its characteristics? First, all of the items have to be included in the computation. Second, all of the items, though different, are treated as identical in the divisor. Third, it is not of necessity, though it may be, represented in a series. Fourth, in giving the result, each item is significant according to its size.

The average (arithmetic mean) as such, tells one nothing concerning the series out of which it is made. The differences from it may be large or small; how large or how small is not known. It ignores the detail. It groups different conditions together, and reduces them to a hypothetical common denominator by an arbitrary process of division.

Are business operations, or experience, or groups of them, capable for practical purposes of being so described? What is needed is not a purely hypo- 
thetical center of gravity, which the average gives, but a deseription of the differences from the average, and the manner in which they are distributed about it. Take, for example, wages or transportation costs. What is needed adequately to express either, so as to set them in their true light for business planning and the solution of the problems to which they give rise, is some measure of their distribution for the same or for different classes. What are the extremes; what is the most common wage or cost; above or below what figure do the bulk of the instances fall? What is the average difference from the average, and to what are the wide differences due?

When doubt arises as to details, appeal is made to averages. They have been called the business man's excuse for laziness. They might also be called the device par excellence, for dealing in glittering generalities. As averages are often used, both indictments are, without doubt, largely true. The scientific point of view does not require that averages be repudiated, but it does provide that they shall be used with intelligence and discrimination.

However, there are many significant uses of the average (arithmetic mean). Statistics has been called by some the "science of averages," and appeal is often made to the "law of averages." What is this law? Business and other experiences tell us that it is unnecessary in many problems to measure all of a series or to count all of the instances with which we deal. Not all butter is sampled when purchased, nor all cotton scrutinized when graded. In an analysis of markets, appeal may be made to the law of averages. In keeping with the general principle that 
the average height of a number of people may be secured by studying the heights of a few thousand drawn at random from a larger body, the response to a selling or advertising campaign, for instance, may be established from an analysis of a well selected group of samples. It is unnecessary to include everybody, but it is essential that each characteristic of the group shall be represented in the samples taken. Realizing this fact, business enterprises are appealing to the law of averages in studying markets and in testing advertising media. How truly samples may be representative, however, is often times difficult to establish. Scientific observation may be difficult. The peculiarities of a group may not be revealed from the samples taken, and serious error result from generalizing broadly from samples which can be measured.

The value of sampling as a method is conditioned by the degree to which a part represents a whole. Too frequently samples are employed with the belief that "other things will remain equal." In measuring physical phenomena, the most accurate result may be secured by averaging all measurements, if there is no bias in the unit of measurement, if allowance is made for the personal equation, and if measurements are made under similar conditions. Business phenomena, however, are constantly changing. Samples which will suffice in one period will be inadequate at another. Conditions of time, place and income, as well as the psychology of the groups to which the measurements apply, are constantly in a state of flux, and one should not place too much reliance in the compensation of errors. Business conditions change with 
the temper of the people, with political practices and principles, with labor unrest, etc. Blindly, to take an average in the hope that the law of compensating errors will always give a perfect picture from imperfect detail is economically suicidal.

The peculiarities of the arithmetic mean, as an average, cannot be removed. All of the items which enter into it are given equal weight; they are all treated the same in the divisor, and the product of the division is almost invariably hypothetical. As a single summary figure, it is often unsatisfactory. In time comparisons, it is generally misleading if the data out of which it grows are not homogeneous. The same is equally true when it is applied to geographical or frequency data. An average of this type may not only be unrepresentative but deceptive. The average daily output of a factory over a period may remain constant and yet the production in various departments change radically. Similarly, the average wage paid may remain constant and the wage scale seriously slump or rise at the lower, middle or upper groups.

But there are, of course, other averages. These, however, are less commonly used, although for many purposes they are superior to the arithmetic mean. They are averages, however, and are subject to many of the limitations which are characteristic of the arithmetic mean.

Probably the most familiar of the other ways of characterizing complex details, is to use the median. The median is the middle item in a series arranged in the order of size, and divides the group, therefore, into two parts. In this sense, undoubtedly, it is 
more accurately described as a partition expression or division mark, although it serves the purpose of an average. Similarly, it is possible to divide a series into more than two parts. In case the division is into four parts, the partition expressions are known as quartiles.

What are the characteristics of the median?

First.-In its computation, all of the data are required, but the frequencies only are important and not the size of the items, except at or near the middle.

Second.-It is uncertain and indefinite in a series which is not essentially homogeneous. That is, a series may be uniform throughout, as, for instance, in the case of the wage-rates of a group of 100 individuals. The median of such a series would be the characteristic wage-rate; as would also the arithmetic mean. However, if a few poorly paid individuals were introduced at the lower side, and a few highly paid persons at the upper side, the median would remain the same, but the arithmetic mean would be different.

Third.-The median may be computed when the size of the items at the extremes is unknown, provided the frequencies are given. This is of distinct advantage when the measurements are imperfect, or incapable of being known.

Fourth.-The median may be indeterminate. It may fall between two measurements in a series. In such a case, it is, like the arithmetic mean, a purely fietitious number.

If business men, in their attempt to summarize the detailed facts of their business, would use both the arithmetic mean and the median, there would be 
less tendency for their generalizations to be loose and indefinite, since the two figures would supplement each other. However, the median, because of its peculiar meaning, is frequently unconsciously used. Wage earners, for instance, are ranked according to their honesty, integrity, and industry; and standards are set which apply not to the exceptionally good man, nor to the exceptionally poor man, but rather to the middle man, thought of in comparative terms. Psychologists, in the selection of employees by mental tests, or by other means, frequently employ the median, and relate individuals in a series to this middle man. Wherever the ranking device is employed, the median concept is used.

Moreover, the arithmetic mean and the median of details which are not too erratic and dissimilar tend closely to agree. The arithmetic mean, because of its being affected by the extremes as well as by the frequencies, tends to be less than the median when the small items predominate, and larger than the median when large ones are more frequent.

If the arithmetic mean wage, or cost, is compared not only with the median, but also with the quarter measures, or quartiles, then as a summary expression, it becomes more significant than when it stands alone. The point was made in the discussion of the arithmetic mean, that it lacks definiteness, and is often used loosely to describe a situation which cannot be summarized in a single figure. If it is compared with the median and quartiles, as averages, then a part at least of this criticism no longer applies. If the business executive keeps in mind the purposes which averages serve, and the necessity for business facts to be sum- 
marized in brief form, he should be anxious to employ not only one but several devices which serve his purpose.

The use of the median in connection with an ordinary payroll may be illustrated, the purpose of the average (the median) being to characterize the hourly wage-rates which are paid. The number of men and the wage-rates per hour are given below:

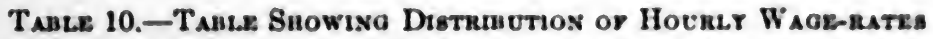

\begin{tabular}{c|c||c|c}
\hline Number of met & $\begin{array}{c}\text { Wage-rates per } \\
\text { hour, conts }\end{array}$ & Number of men & $\begin{array}{c}\text { Woce-rates per } \\
\text { hour, cente }\end{array}$ \\
\hline 12 & 60 & 9 & 82 \\
16 & 70 & 4 & 90 \\
25 & 75 & 2 & 95 \\
\hline
\end{tabular}

The arithmetic wage-rate is 73.6 cents and the median 75 cents. It will be noticed that the order of arrangement is consecutive, and that the median rate is 1.4 cents more than the average. The wage-rate of the individual one-quarter of the way up the series is 70 cents and that of the individual three-quarters of the way up the series is 75 cents. In the median and two quartiles, therefore, we have three summarizing expressions of this series. The arithmetic mean, on the other hand, gives us but one.

There is still another average, which is in current use, and which should be employed in business. It is what is called the mode. It is that item in a series which is most characteristic, or common. It is the typical fact. and being typical, is representative. It is in no sense hypothetical or unreal. It is that position where most of the instances fall, and which may 
be said to be characteristic. In the above series showing the wage-rates for men, more individuals were shown to have been receiving 75 cents than any other amount; 75 cents is, therefore, the mode. Of course, there were people receiving more and others receiving less than this amount, but these, for the purpose of this particular summarizing expression are ignored.

What are the characteristics of the mode as an average?

First.-Only a part of the data is required for its computation. In the series above, the mode would have been no different had the two people who are shown to have received 95 cents, received $\$ 2.00$. Similarly, it would have remained the same had the twelve people, who are shown to have received 60 cents. per hour, received purely a nominal sum.

Second.-The mode as an average is invariably represented in a series.

Third.-In the calculation of the mode, the frequencies, or number of instances, are primary, and the units to which the frequencies occur, only secondary.

In the discussion of business success and failure, labor force, cost, etc., when these are summarized in a single expression, undoubtedly, the mode is the average which is most commonly in mind. The modal idea is expressed in the "average" clerk, the "average" bank clearing, the "average" day's sale, the "average" man on the street. That is, the thing which is the rule, or which is characteristic, is expressed in this way. It is the prevailing rate, or individual, which is in mind.

Fourth.-Extreme items are ignored. 
Fifth.-Its location is sometimes indeterminate. There may be more than one mode, in case the series is complex.

The mode, like the median, is different from the arithmetic mean, inasmuch as extreme items, or instances, are ignored. The mode tends to remain fixed, is less erratic than the median, and far less subject to change than the arithmetic mean. When taken together, these three averages serve rather fully to describe the detail concerning any business fact. Taken alone, either of them is indefinite and a poor substitute for the detail which they replace.

There is no reason why business should not become as familiar with the use both of the median and the mode, as it is with the arithmetic mean; and there is far greater justification in many instances for the use of the mode as a single expression, than there is for the use of the arithmetic mean. The business executive should not "rush headlong," as it were, into the use of any of these averages, without an appreciation of the relationship which they have to his precise problems, and without a keen appreciation of the characteristics which each possesses. Each of them is designed to put into brief form, for the purpose of comparison, the essence of the detail to which it relates. They should be used to give expression to a conclusion arrived at from the study of details, and this cannot be done unless the precise nature of each one is thoroughly understood. To employ averages to express the result of a process of thought or analysis, is always legitimate when they are used discriminatingly.

No single average is good for all purposes. Each is affected differently by the arrangement, frequencies, 
and the character of the details, and should be employed with a full knowledge of its peculiarities. The use of an average is always a function of the purpose which one has in mind. The form of the average and its use cannot be divorced. Caution and foresight are necessary at every step in the use of averages; caution as to those which are to be employed; foresight as to the significance which they have, and analysis as to the possibility of details to be characterized in such a manner. To use them blindly, and without discrimination, is in violation of the underlying principles of scientific method as applied to business problems. The executive, no matter how large or how small the business he controls may be, or in whatever fields he may be working, cannot afford to base his judgment on averages without a keen appreciation of what is implied in doing so.

In the use of averages for business purposes, the following questions should be raised and answered. Is it possible to employ a single expression to depict the details which are essential so as to view data in all their bearings? In the problem considered, is the greatest interest in the characteristic or modal feature, in the median or half-way position or in that mathematical position at which the average (arithmetic mean) falls? Is it necessary and wise to employ all of these descriptive units, to compare their differences and to determine their similarities? No single answer to these questions can be given. To employ an average may be legitimate, and still the question be indeterminate as to the most appropriate average to use. Data must be analyzed and the functions of averages in general and in particular be clearly per- 
ceived before answers can be given. As caution and analysis are necessary in the use of averages, so discrimination and judgment are essential in assigning importance to them when used.

In no other aspect of business is the employment of an average so common and at the same time its use so little understood, as in summarizing prices. Summaries are wanted for prices of labor, money, materials, securities, etc. To know the market condition and trend is imperative for business operation and planning. But prices differ for different goods or services, different conditions of demand and supply, different markets, different conditions of sale and purchase. The meaning of price change is different for differently situated producers, consumers, and middlemen. For instance, an economist may use stock prices "to measure change in the purchasing power of money over stocks; a speculator may wish to forecast the probable future course of the market; a public commission may be interested in the terms on which corporations can raise new capital; a publicist may investigate the claim that government regulation has brought loss upon investors; a financial historian may wish to mark off periods of expansion and contraction; a trustee may inquire whether the fluctuations of his security holdings have compared favorably with the average course of the market; an insurance company may seek light on the probable future of interest rates; a student may wish to compare stock speculations with the price fluctuations of commodities at wholesale or retail, of labor, of bonds, of farm lands, of securities in other countries, etc. Now, each of these people will have use for a stock 
index. But the more carefully these various uses are analyzed, the clearer it becomes that their requirements differ." The prices of commodities, wholesale and retail, are wanted for as varied uses, as are also those of the prices of labor. How are prices to be summarized and interpreted for these different purposes?

Business men and students of economies are familiar with the currently compiled indexes of prices. They at least know by name Bradstreet's, Dun's, The Annalist's and the Bureau of Labor's index numbers. But do they know what they contain, what they mean, and are they consistent in their use of them in connection with price problems? Is their attitude toward them scientific, or rule-of-thumb? How discriminating are they in quoting authorities, and how consistent in using them as a basis for business policies and conclusions?

Index numbers in the simplest form may be defined as relative or percentage numbers in which data for one year or other similar period, or an average for a year or such period, are taken as a base, generally indicated by 100 , and upon which data for subsequent years or periods are computed as percentages. The method by which a simple index number of prices may be calculated is illustrated below.

What has been the movement of the prices of building material during the war? In this illustration, only a few quotations are taken, and the index numbers would not suffice for too broad a generalization. However, it is the principle of index number making which is now being discussed and these prices will suffice for this purpose. 


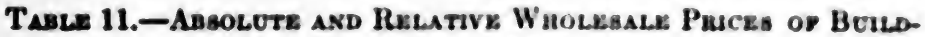
ino Matrmals, 1913 to 1919 !

Actual. Packa

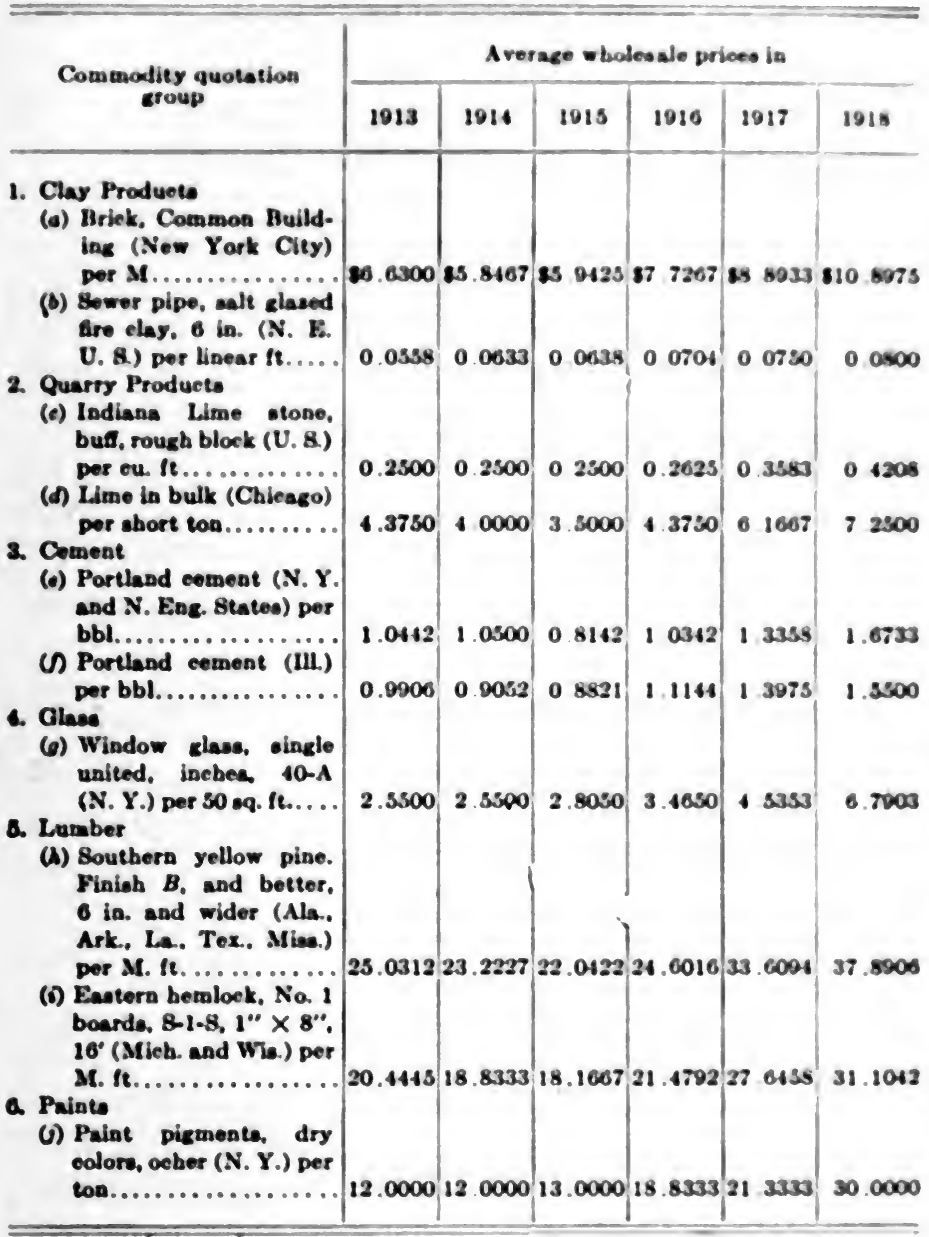

' Price Bulletin (various) War Industries Board, Washington, D. C., 1919. 
Relative Prices

$1913=100$

\begin{tabular}{|c|c|c|c|c|c|c|}
\hline Total of relatives...... & 1000.0 & 960.9 & 046.2 & 1155.4 & 1447.1 & 1778.4 \\
\hline $\begin{array}{l}\text { Index numbers as averagee of } \\
\text { relative prices............ }\end{array}$ & 100.0 & 97.0 & 94.6 & 115.5 & 144.7 & 177.8 \\
\hline 1-a as above.. & 100.0 & 83.2 & 89.6 & 116.5 & 134.1 & 164.4 \\
\hline $1 \longrightarrow b$ as above... & 100.0 & 113.5 & 114.3 & 126.2 & 134.5 & 143.4 \\
\hline 2 -c as above..... & 100.0 & 100.0 & 100.0 & 105.0 & 143.3 & 168.3 \\
\hline $2-d$ as above... & 100.0 & 91.4 & 80.0 & 100.0 & 141.0 & 165.7 \\
\hline $3-1$ as above.... & 100.0 & 100.5 & 78.0 & 99.0 & 127.9 & 160.2 \\
\hline $3-f$ as above..... & 100.0 & 91.4 & 89.0 & 112.5 & 141.1 & 156.5 \\
\hline 40 as above.... & 100.0 & 100.0 & 110.0 & 135.9 & 177.9 & 266.3 \\
\hline $5-h$ as above..... & 100.0 & 92.8 & 88.1 & 98.3 & 134.3 & 151.4 \\
\hline 5-i as above.... & 100.0 & 92.1 & 88.9 & 105.1 & 135.2 & 152.2 \\
\hline $6-j$ as above..... & 100.0 & 100.0 & 108.3 & 156.9 & 177.8 & 250.0 \\
\hline
\end{tabular}

According to this calculation, prices of building materials for the years 1913 to 1918 inclusive, advanced as follows:

\begin{tabular}{|c|c|c|c|}
\hline \multirow{2}{*}{ Year } & \multirow{2}{*}{ Index number } & \multicolumn{2}{|c|}{ Per cent. increase } \\
\hline & & Over 1913 & Over preceding year \\
\hline $1913 \ldots \ldots \ldots$ & 100.0 & & \\
\hline $1914 \ldots \ldots \ldots$ & 97.0 & $3.0^{*}$ & $3.0^{*}$ \\
\hline 1915. & 94.6 & $5.4^{*}$ & $2.5^{*}$ \\
\hline $1916 \ldots \ldots \ldots$ & 115.5 & 15.5 & 22.1 \\
\hline $1917 \ldots$ & 144.7 & 44.7 & 25.3 \\
\hline 1918. & 177.8 & 77.8 & 22.9 \\
\hline
\end{tabular}

* Decrease.

This simple example contains the essential steps in the calculation of an average of relative prices type of index number. More important than the arithmetical calculation is the selection of prices or other data to be compared. Indeed, this is the major consideration in making index numbers. After all, the purpose in 
calculating them is to make a comparison, and the validity of the inference drawn from them is determined not only by the method in which they are combined, but also by the fact of their inherent likeness. The truth that like can be compared only with like applies here with especial emphasis.

In calculating and using an index number, business executives should have in mind:

First.-The purpose for which the results are to be used.

Second.-The number and kind of commodities that are to be included, the form in which their prices are stated, and the markets from which the quotations are secured.

Third.-The questions as to whether all commodities are to be treated as equal, or are to be given different weights.

Fourth.-The test to be used in assigning different weights.

Fifth.-The base period against which comparisons are to be made.

Sixth.-If averages of relative prices are used, the average which should be chosen.

These conditions are important since not all index numbers are equally well suited for all purposes. If an executive wishes to calculate the effect on his employees of the increased cost of living, he ought not to choose wholesale prices as a basis for an index series. Moreover, the number of commodities which enter into the index numbers and the importance assigned to them, for this purpose, are important. Prices of a half-dozen commodities purchased in large quantities by consumers are far more important than several 
times this number which enter only insignificantly into living costs. The same consideration is equally true in the construction of a wholesale series, a cost of production series, and a securities series.

Moreover, the collection of prices and use of index numbers are difficult in another way. There are producers' and consumers' prices, jobbers' and mill prices, wholesale and retail prices. There are prices in large markets under conditions of world competition, and prices in isolated communities where monopoly essentially rules. The selection of prices raises such questions as the following:

What is meant by price; is the price retail or wholesale; under what condition is price named; to what grade of commodity or service does it apply; on what market is it quoted; are "prices" contract, import or freely competitive in character?

Now, there are various ways in which index numbers may be computed. A simple form is illustrated on pages 113-114. In this case, 1913 is taken as a base. The prices are calculated as relatives or percentages on this year and the percentages averaged. But neither a base nor an average is necessary. Actual prices may be reduced to a common denominator, as so much per pound, and simply added together. The result is a series of amounts in dollars and cents. It is in this form in which Bradstreet's number is calculated. Bradstreet's numbers for recent years are given in Table 12.

The Annalist index number is different. It is a weekly number made from the wholesale prices of twenty-five commodities chosen in such a way as to represent the principal items in a family budget. It 
Table 12-Table Grvina Bradstuxet' Commodity Puck Index Numakm, Jaxuakr, 1903 to Julr, 1919

\begin{tabular}{|c|c|c|c|c|}
\hline \multirow{2}{*}{ Yoar } & \multicolumn{4}{|c|}{ Index number: fret of the month } \\
\hline & Jesunary & April & July & Oetobes \\
\hline 1003. & 88.0789 & 88.1247 & $\$ 7.8708$ & 87.9083 \\
\hline 1004 . & 7.9885 & 7.0600 & 7.6318 & 7.9213 \\
\hline $1905 . .$. & 8.0827 & 7.9996 & 7.9160 & 8.2298 \\
\hline 1800. & 8.3289 & 8.2987 & 8.2835 & 8.5380 \\
\hline 1007. & 8.9172 & 8.9640 & 9.0409 & 8.8503 \\
\hline 1908. & 8.2049 & 8.0050 & 7.8224 & 8.0139 \\
\hline 1909. & 8.2031 & 8.3157 & 8.4573 & 8.7478 \\
\hline 1910. & 9.2310 & 9.1998 & 8.9246 & 8.9267 \\
\hline 1911. & 8.8361 & 8.3223 & 8.5933 & 8.8065 \\
\hline 1912. & 8.9403 & 9.0978 & 9.1119 & 9.4515 \\
\hline 1913. & 9.4935 & 9.2976 & 8.9521 & 0.1526 \\
\hline 1914. & 8.8857 & 8.7562 & 8.6560 & 9.2416 \\
\hline $1915 \ldots$ & 9.1431 & 9.7753 & 9.8698 & 9.9774 \\
\hline 1916. & 10.9163 & 11.7598 & 11.5294 & 12.0399 \\
\hline 1917. & 13.7277 & 14.5769 & 16.0880 & 16.9135 \\
\hline 1918. & 17.9436 & 18.4431 & 19.1624 & 18.9942 \\
\hline 1919. & 18.5348 & 17.2795 & 18.8964 & 19.5215 \\
\hline
\end{tabular}

Talle 13.-Table Giving the Ansalist's Yearly Commodity Price Index Nombers, 1890 to Beptrember, 1919

(Base period 1890 to $1899=100$ )

\begin{tabular}{|c|c|c|c|c|c|}
\hline Yoar & $\begin{array}{c}\text { Index } \\
\text { number }\end{array}$ & Year & $\begin{array}{c}\text { Index } \\
\text { nutmber }\end{array}$ & Year & $\begin{array}{c}\text { Index } \\
\text { number }\end{array}$ \\
\hline 90 & 109.252 & 1900 & 99.388 & 1910. & 137.172 \\
\hline 18 & 119 & 190 & 104. & 1911. & 131.068 \\
\hline 1892. & 108.624 & 1902. & 116.204 & 1912. & 143.254 \\
\hline 1893. & 116.100 & 1803. & 107.516 & 1913. & 139.980 \\
\hline 1894. & 102.076 & 1804. & 108.664 & 1914. & 146.069 \\
\hline 1895. & 94.604 & 1805. & 110.652 & 1915. & 148.055 \\
\hline 1896 & 80.096 & 1900 & 114.364 & 1916 & 175.720 \\
\hline 189 & 84.092 & 1907 & 117.940 & 1917 & 261.796 \\
\hline 188 & 92.208 & 1808 & 125.756 & 1918. & 257.050 \\
\hline 189 & 93.348 & 1800 & 133.952 & 1910 to Sept. 1 & 301.904 \\
\hline
\end{tabular}




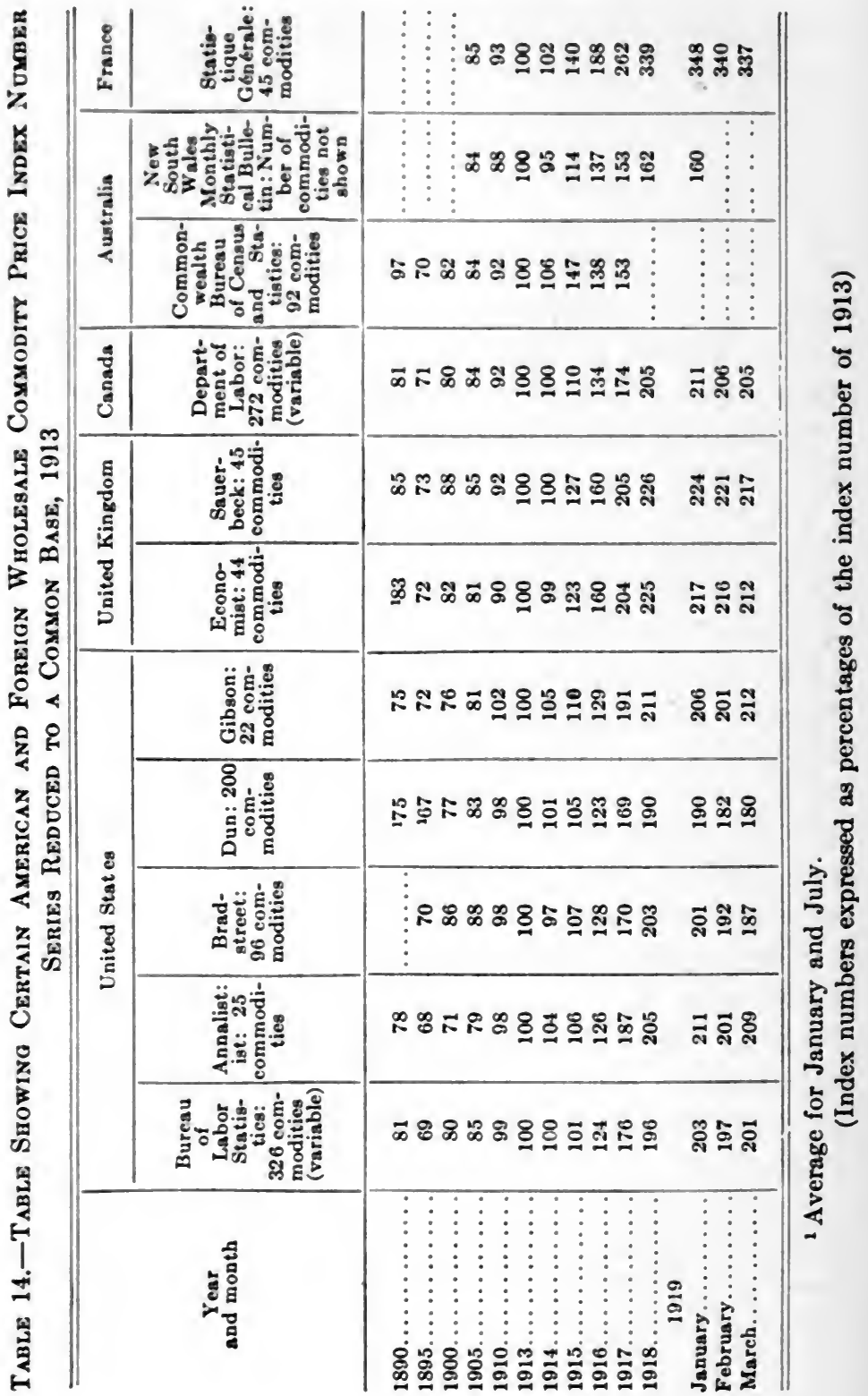


is ealculated as an average of relatives, as is the example on pp. 113-114, but uses as a base the average of the prices, 1890-1899. The yearly numbers for the years since 1890 appear in Table 13.

In Table 14 a number of American and foreign wholesale price index series have been reduced to a common base by dividing the index in each series for 1913, on the original base, into the index for each year or month on that base. For some of the series this process gives only approximately correct results, but these are sufficiently accurate for general purpose comparisons.

The most satisfactory index number of retail prices for the measurement of the changing prices of foods is that compiled by the United States Bureau of Labor Statistics. This series is shown in the following ratio chart for the years 1913-1919.

The principal peculiarities of index or relative numbers of prices may be summarized as follows:

First. - ". . . . . No index number corresponds to a real thing. . . . . An index number points to no single fact. It gives. . . . . only an indication of a general trend. People often think and speak loosely on this topic, as if an index number told the whole story once for all. There is no one change in prices. There is a medley of changes, different in direction and degree. All that we can hope to secure by averaging and summarizing is some concise statement of the general drift."

Second.-Index numbers of wholesale and retail commodities should be distinguished. The conditions under which wholessle and retail prices are deter- 

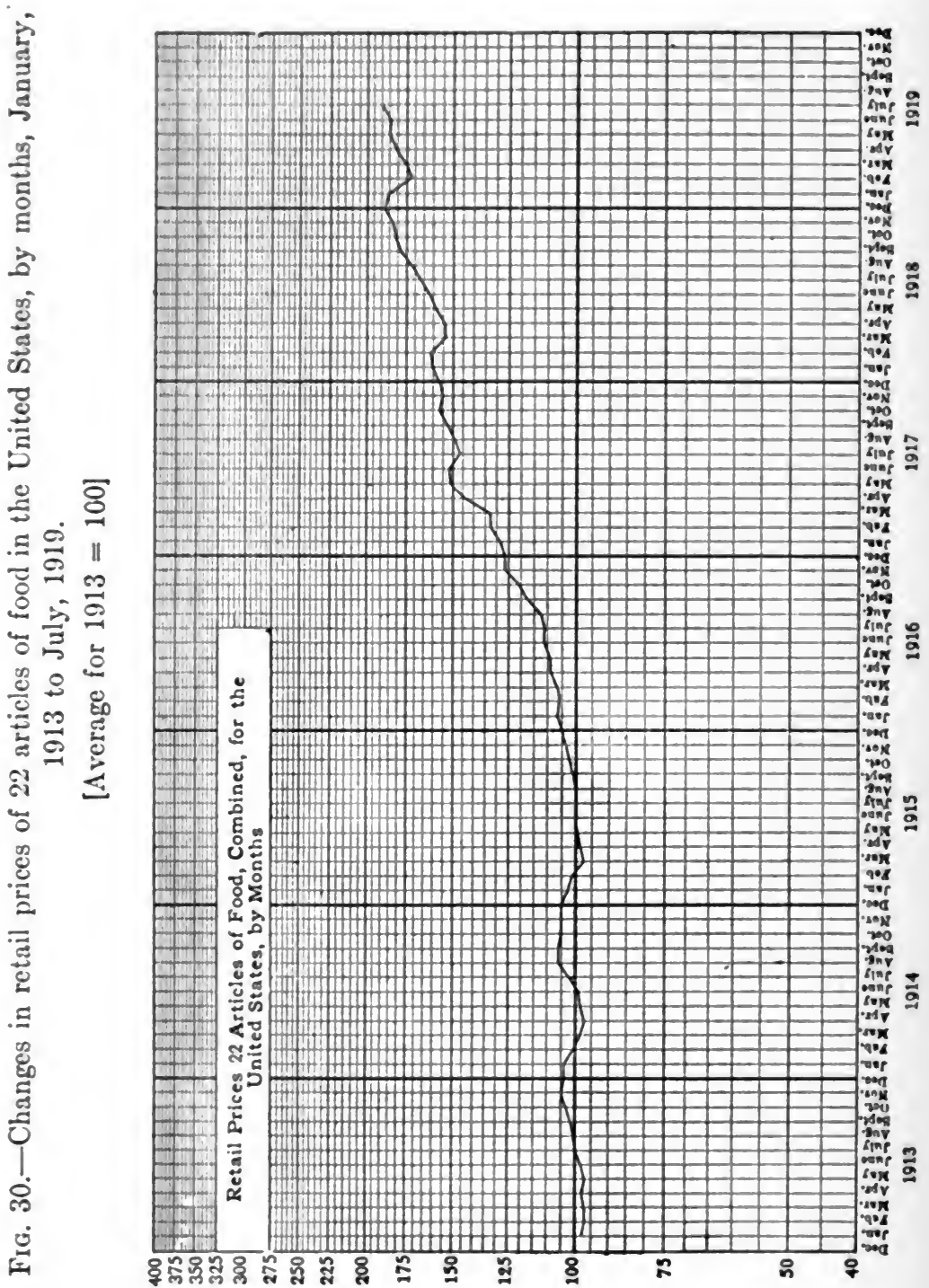
mined are different, as are also the uses to which they should be put.

Third.-For any index number the types of the commodities which are used are significant. Distinction should be made, for instance, in wholesale index series, between producers' and consumers' goods; between raw and manufactured commodities; between mineral, animal, and farm products. All of these respond differently to conditions of scarcity and surplus, and time and place.

Fourth.-In using index numbers consideration should be given to the number of commodities used, the places from which quotations are taken, and the frequency with which they are included.

Fifth.-Index numbers of prices should be sonsidered from the point of view of the method by which they are computed. In this respect the following are important.

(a) Are the numbers average prices or actual prices? If average prices, what average is used and with what effect?

(b) Are the commodities taken as of equal importance, or are some commodities assigned greater importance than others?

(c) If weights are assigned to indicate relative importance, upon what basis are they chosen?

(d) If a base year is used, what, if any, significance is there in the period chosen?

Sixth-General purpose should not be confused with special purpose index numbers of prices.

Other phases of index numbers of prices are important to the business executive, but they cannot be treated here. For a fuller discussion of them, the 
reader may consult the author's Introduction to Statistical Methods.

Now, what are some of the inconsistencies of which the business man and others are guilty in the use of price index summaries? There are many, but only a few will be suggested here.

First.-The demand for wage increase is brought to a head in a strike, and justification is sought by labor in the increased cost of living. The business man consults a price index series, but unfortunately, he chooses the wrong one. It may be Bradstreet's, or the Bureau of Labor Wholesale series to which he refers, and from which he develops his argument. $\mathrm{He}$ is in error, (a), in choosing a wholesale series; (b), in construing the change of prices as indicated as equivalent to cost of living changes; $(c)$, in choosing a general purpose series and using it for a particular use; $(d)$, in failing to see that the weights assigned to commodities have nothing to do with the scale in which the commodities enter into consumers' budgets.

Second.-Need arises for some measure of the wholesale prices of manufactured producers' goods, such, for instance, as farm or other machinery. The Annalist index number is used, notwithstanding the fact that 68 per cent. of the manufactured commodities contained in this number are consumers' rather than producers' goods, and that 32 per cent. of the commodities are, in fact, raw rather than manufactured materials.

Third.-Similarly, an index number is wanted which will serve as a general barometer of business, and Dun's is chosen, notwithstanding the fact that it is given as the amount in dollars and cents which is 
required to purchase a year's supply of goods for an individual at a given time, and is not as susceptible to market changes in prices as is Bradstreet's or the Bureau of Labor's wholesale number.

It is unnecessary to give further examples of the unscientific use of summarized price data. The above illustrations undoubtedly, are of daily occurrence. Here, fact analysis is ignored, and the scientific method has no place.

Business facts must be summarized and digested, and averages are useful in the process, whether applied to prices, wages, costs, sales, or what not. The process of summarization, however, is fundamental, and the spirit in which it is done, exacting. The technique is important here as it is in tabulation and graphies, and it is hoped that what has been said will at least serve the purpose of emphasizing the scientific attitude in which the technique should be applied, and of describing briefly the ways in which detail may be summarized. 


\section{CHAPTER VII}

\section{COMPARISON AND THE ESTABLISHMENT OF BUSINESS PRINCIPLES AND STANDARDS}

The modern business executive must see business facts and relations in their larger aspects. Business is intensely human. It deals in the last instance with individuals and with groups, and the psychology of both must be understood. Moreover, the fact must be appreciated that the time, place, and condition under which business is carried on, are vital in the comparisons which are made, the standards which are set up, and the principles which are established. Business is controlled by customary and statutory law, as well as by its legal interpretation. The institutions of property, custom, and contract also affect business at every turn, and its plans must be interpreted in the light of them. Similarly, political ideals are potent in shaping the sphere which business assumes, and in controlling its development. Competition is also an important factor and the exercise of personal initiative important. These larger facts and relationships cannot be ignored.

Just how these larger aspects of business are significant must be determined upon an analysis of each type of enterprise, and the nature of its immediate problems. Custom may control in the determination of the prices of goods and services, and in the wages which are paid. Statutory law may control the 124 
form of business and the expenses under which it operates. In the latter aspect, taxes and other payments imposed by governments are instances in point. Concerning them, business must take an enlightened and positive attitude and provide for them in the accounts which are kept and the plans which are made. Of these facts, business, of course, is fully aware in a general way when problems arise, but it does not always see their full import from day to day and make provision for them.

The point which is being stressed is that business must be considered in its relative aspects, and that those who are in control must not be unmindful of its relationship to the underlying forces of economic, political, and social life. It is necessary, of course, to see one's individual problems, and to settle them with regard to the effect which the solution will have on profits, on public approval, and on the interests of those who are instrumental in bringing success. But for a business executive solely to see them as his problems, and to treat them as if they were unrelated to the larger political, economic, and social currents of the times, is, of course, to lose sight of the factors which at bottom make them problems at all. If this is done, the solutions offered may be temporary and bring with them later more serious and fundamental problems, the solution of which lies outside of the ken and the experience of the individual establishment. Tampering with the labor problem-putting of facing the real problems by refusing to meet the real issues, or by ignoring that they exist-for instance, is a case in point. This problem is far larger than any establishment, and its issues more fundamental than those 
which are the subject of controversy within a given industrial concern. How this problem, like others, is related to group psychology, to political and social ideas, and how it may be constructively met, must be determined by business if it is to function smoothly and the coopperation upon which it rests is to endure.

Although the problems of business are relative to time, place, and condition, and are intimately related to such institutions as custom, property, and contract, and to problems of psychology, many of them may be stated in definite terms and the facts which define and measure them be determined. What these facts are, the conditions which must be established in order to measure them, and the ways in which they may be summarized have been suggested in the preceding pages. What must now be emphasized are the conditions which make comparisons and the establishment of standards and principles valid for business uses. How are the results of the application of scientific methods to business to be realized and made to contribute to business success?

The establishment of business standards and principles results from comparison. For things to be compared, they must possess points in common, and to determine common qualities, uniform standards of measurements must be applied. A business fact, however, is not a uniform thing; it does not always exhibit itself in the same way. It cannot always be treated uniformly and subjected to one foot-rule. It is complex and varied and requires that the units of measurements applied to it shall be adjusted according to the form in which it reveals itself. Hence, comparisons of business facts are never perfect; they are 
experimental and approximate. The standards must constantly be changed and adapted to time, place, and condition. Because of change in circumstances, what is true today, under a given condition, may not be true tomorrow.

If comparisons are difficult to make and are often misleading, then the establishment of cause and effect relations in a narrow and absolute sense is virtually impossible. It is a tempting thing for a business executive to reason, that if $A$ happens, $B$ will result. He would like to be sure, for instance, that if prices are lowered, sales will be stimulated; that if he puts more money into advertising, larger sales will be experienced; that if he grants the increase of wages demanded, labor will be satisfied. Unfortunately, peace of mind does not come in this way; a quantitative cause does not necessarily bring with it an equal quantitative effect. The result is not absolute, but relative. Business does not go on repeating itself in a round of sameness, nor do the effects of certain causes always remain identical. Variation is always present.

To illustrate, stimulation of business is shown in increased bank clearings and in expanding loans, but not all banks are equally affected, nor is business uniformly speeded up. Surplus reserves of banks are related to interest rates on call loans, but will an $X$ reserve always give a $Y$ rate? A change in wholesale prices causes the retail prices to fluctuate, but will a change of 20 per cent., for instance, in the wholesale price of hides always bring 20 per cent. change in the price of shoes? To ask such questions is to answer them; and yet, is it not customary in business 
for plans to be made and policies pursued as if there were, underlying the whole business structure, some automatic and perfectly certain cause and effect machinery?

Business phenomena are related; they do stand in the relationship of cause and effect to each other, but this is not so simple and so predictable as it is sometimes indicated to be. What the relationship is can rarely if ever be guessed; but it can be measured, and it is the function of scientific method to determine it.

There is a Science of Business. The method by which it is discovered and stated is the same as that which is employed in the natural sciences; but the difficulties of applying it are vastly more serious. Experimentation is not so easy; the factors which are dealt with are far more complex, and the conditions under which they operate more diverse and difficult of standardization. But the problem of understanding it is not insuperable. The absolutely indispensable conditions upon which it rests are first, a wholesome respect and an unconditional demand for the truth; second, scientific observation and measurement of business facts; third, the application of facts to business problems upon the basis of working hypotheses, with the purpose of determining their relative truths; and fourth, the formulation of standards and principles as rules for business guidance.

A business synthesis is sadly needed, not alone of the activities of individual business establishments, but of industries as well. Such a synthesis lies within the power of every concern and of industries too, the moment that it is seriously wanted. Fact analysis supplies the method. What is most needed is a 
disposition seriously to employ it on the requisite scale. Business rivalry and diminished profits require that business be scientific, and the new competition suggests the ways in which savings and economies may be introduced. What is needed among competitors is common statistical activity and exchange of information. More analysis of business facts and equal sharing in the results are necessary. The old dogma, "the gain of one is the loss of another," needs to be abandoned. Bureaus of research, or research departments, must become a component part of every business establishment, and the scientific method the point of view of every business executive.

What the scientific method is has been fully described. What the facts of business are which should be analyzed have been suggested, and the ways indicated in which complex data may be summarized. Having caught the spirit of fact analysis, and understanding what it implies, it is the indispensable function of an executive to apply it to his problems. Moreover, it is essential for employers' organizations, business clubs, and managers' associations, to study scientific method in relation to business problems and to install machinery whereby the experiences of all may be put at the service of each.

When businesses have done this, either individually or coöperatively, industry will be seen in a new light. The principles and rules for guidance then will not be formulated out of prejudice nor arrived at in an occult or rule-of-thumb manner, but will be established on the basis of facts scientifically analyzed and properly interpreted. They will not be accepted blindly, but with discrimination, and the conditions will be 
established for making business scientific. Fact analysis will become the rule, and industry will prosper as a result of its application. The standards of fact analysis are severe, its methods are exact, but the results worth while. Business must be conducted on a scientific basis.

There are, therefore, in summary, two phases to scientific method, as applied to business or other phenomena: first, scientific observation, and second, logical inference. In the application of these standards, a science of business is to be developed. 


\section{INDEX}

A

Accidents, 16; compensation for, 16; how measured statistically, 28; statistics of, and comparability, 28.

Accounting and Statimica, 3.

Accuracy, meaning and standards of, 34-35.

Advertising and custom, 36.

Analysis, busines, requirements of, 3-4, 10, 12; relation of comparinon to, 30 .

Annalist's index number, 112; 1890 to 1919, 117; how calculated, 116-117, 119; peculiarities of, 122.

Average, average measure the best measure, 103; the arithmetic mean, 100-104; (arithmetic mean), characteristica of, 101, 104; (arithmetic mean), how computed, 101; relationship of (arithmetic mean) to the mode, 109; concept of, 97-99; the medisn (sec Median); the mode (see Mode).

Averages, as summaries of details, 123; choice of, for business analyxis, 109-110; relation of, to business problems, 99-100, 102; sampling and, 102-104; use of, to summarize prices, 111-112.

B

Babson service, 22-23.

Bank clearings, as measure of trade buoyancy, 29.

Banking, 21.

Bar-diagrams, component parts and (illustrated), 73; order of detail and (illustrated), $72,73,74$.

Bars, component parts and (illustrated), 74, 79, 80, 81 ; constrasted with surfaces (illustrated), 75, 78; cross-hatching in (illustrated), 79; position of, 62; use of, as contrasted with lines connecting bars in historical series, S6-SS; use of, for comparisons of size, 61; use of subdivided, for presenting component parts, 62 ; use of vertical, in frequency distributions, 62.

Base lines in diagrams, 59.

Bias, 31.

Bradstreet's index number, 112; how calculated, 116; 1903 to 1919 , 117 ; peculiarities of, 122. 
Brinton, W. C., Graphic Methods for Presenting Facts, 58.

Brookmire Service, 22-23.

Buildings, 23.

Bureau of Labor price index number, 112.

Business, a "going" concern, 36; cause and effect relations in, 127-128; competition and, 2 ; facts of, classified, 5 ; meaning of, 1 ; modern, contrasted with ancient, 2; seen by different interests, 1-2; seen through averages, 99-100; the science of, 128; uses of index numbers in, 115-116.

Business advertising and custom, 36.

Business analysis, coöperatively undertaken, 129-130; misuse of index numbers in, 122-123; questions which it will answer, 30-37; scientific method and, 38-40; scientific method in, 129-130; scope of, 125-126; short- and long-time influences and, 34; standards and, 128; steps in, 128; use of averages in, 109-110; use of tables in, 54; what it requires, 3-4, 8, 10, 12 .

Business barometer, Bradstreet's index number $\mathrm{a}, 123$.

Business, coöperative, 12; custom and, 124-125; law and, 124-125; political ideals and, 124-125; property relations and, 124-125.

Business facts, capital, 8-9; character of, 27; classified, 13; commensurable, 26; credit, 9-10; depreciation rate, 11-12; frequency of measurement of, 34 ; investments, 9 ; labor, 8; land, 11; land, classified, 14 ; law and policy, 14 ; market, 7 ; market, classified, 14 ; meaning and use of, 29 ; production, 6 ; production, classified, 13; profits, 10, 11; sales, 7; taxes, 11 ; transportation, classified, 14.

Business judgments, crude data and, 30; facts and, 2; general, and 'statistical facts, 29.

Business operations, the measurement of facts and, 36 .

Business policy, shaped through analysis, 37-38.

Business problems, relative aspects of, 126.

Business research, 36

Business records, custom and, 36.

Business standards, statistical analysis and, 37.

Business synthesis, how realized, 128-129.

Capital facts, 8-9, 18-19; classified, 13; earnings, 18-19; resources, 18. Capitalization vs. capital, 18.

Cause and effect, business relations in the order of, 128.

Census, 20.

Circle diagrams to represent component parts (illustrated), 65-67.

Classification, relation to tabulation, 41 . 
Classification of facts, 41; meaning of, $11-12$.

Collection of data, schedules and, 81 ; relation of, to tabulation, 81.

Color diagrams, 61.

Cotmparison, eancence of, 126-127; what it involves, 30 .

Comparison in business analynis, 126-127.

Competition, business analyxis and, 37 .

Component parts, choice of graphies for expresexing, 61-62.

Cooperation in business, 12.

Cost tacts, 12.

Cost of living, ampling and, 32; choice of index numbers to meanure, 115-116; measurement of, 32.

Costs, busines analyais and, 36; meaning of average, 99-100.

Credit, 21.

Credit facts, 9-10, 14.

Crops, 19.

Crose-hatching, for presenting component parts, 62.

Curves, historiesl, 57-58; scales for, 57; smoothing of, 57; use of, 57 .

Depreciation, rate of, 11-12.

Diagrams, arrangement of items and, 60 ; base lines in, 59 ; form of, and the person for whom designed, 64; position of titles in, 60-61; rules for general make up of, 59-61; scale units and, 59; size of sheets and, 61; surfaces within surfaces and (illustrated), 76-77; to include the data represented, 59; use of colors and, 61.

Dot Map, frequency (illustrated), 86; use of frequency, 83; varying shades of dots in, 85; (illustraled), 88; varying size dots in, 84; (illustrated), 87.

Dun's index number, 112; peculiarities of, 122-123.

E

Earnings, 15, 18-19.

Editing of schedules, 52-53.

Executive, attitude of, toward problems, 27.

Exports, as measure of trade buoyancy, 29.

\section{$\mathbf{F}$}

Fact analysis, meaning, 3-4, 10, 12.

Facts of business, characteristic of, 5 ; classified. 5 .

Failures, 22.

Forecsoting, 22-23. 
Graphic forms, choice of, 61-64; use of, for comparisons of size, 61; use of, for comparison of component parts, 61-62; use of, in frequency distributions, 62 ; use of, in presenting geographic variations, 62-63; for presenting time variations, 63-64.

Graphics, 55-96; application of, to business analysis, 58; contrasted with tabulation, 55 ; position of titles on graphs, $60-61$; principles covering use of, 56; rules for selection of, 55-56; use of bars in, for comparisons of size, 61 ; use of lines in, for comparisons of size, 61 . Graphs, form of, and the person for whom designed, 64 ; historical, $57-58,63$; historical, use of straight lines in, 63 ; historical, and vertical zero, 64; position of scales in historical, 64; rules for general make up of, 59-61; scales for, 57; size of, and sheet, 61; smoothing of, 57 ; use of, 57 .

H

Harvard Committee on Economic Research, 23.

Hollerith tabulating machines, 53.

Income tax, returns, 49.

Immigration, 17-18.

Imports, as measure of trade buoyancy, 29.

Index number, Annalist's, 112; Bradstreet's, 112; Bureau of Labor, 112; Dun's, 112.

Index numbers, calculation of, 116; certain American and foreign, compared, 118; defined, 112; method of calculation of, illustrated, 112-114; misuse of, in business, 122-123; points to be considered in use of, 115-116; principles governing construction and use of, 119-121.

Index number of food prices, graph of, 120 .

Investment facts, $9,14$.

$\mathbf{L}$

Labor facts, 8; accidents, 16; classified, 13, 15-18; compensation for accidents, 16; immigration, 17-18; strikes and lockouts, 16; turn-over, 17; unemployment, 16-17; union membership, 15-16; wage-rates and earnings, 15 .

Labor turn-over, comparability of statistics on, 28. 
Land facts, 11, 23; clansified, 14.

Law and Policy facts, 14, 24-25.

Lines, use of, for comparisona of nize, 61.

Logarithmic charta, mealo units and, 89; (sece "Ratio" chart).

\section{M}

Maps, use of, 56; une of dot, 62; use of shaded, 63.

Market, conditions affecting, 30-31; how to measure the, 30-81.

Market analyris by sampling, 31-32.

Market extension through business analysis, 36-37.

Market facts, 7, 21-23; classified, 14; banking, 21; commodity prices, 22; credit, 21; failures, 22; forecasting, 22-23; land and building. 23 ; money, 21 ; security prices, 22; trade, 21-22.

Median, characteristice of the, 104-107; relation of the, to the arithmetic mean, 106; how to calculate the, 107.

Mode, characteristics of the, 108-109; defined, 107; relationship of the, to the median, 109; to the arithmetic mean, 109; une of the, in business analysis, 109.

Moncy, facts of, 21.

Moody service, 22-23.

Occupations, accuracy of data on, 35.

Office records, use of, 36.

\section{$\mathbf{P}$}

Pio-diagrams, to represent component parts (illustrated), 65-67.

Population, distribution of, 20-21.

Population facts, 13, 20-21; classified, 12.

Powers tabulating machines, 54.

Price index number, Annalist's, 112; Bradstreet's, 112; Bureau of Labor, 112; Dun's, 112.

Price indexes and special use, 112.

Prices, commodity, 22; meaning of, 111, 116; methods and problerns of mensurement of, 111-123; security, 22; uses of summaries of, 111-112.

Production facts, 6, 19-20; classified, 13; costs, 12; crops, 19; manufcetures, 20; raw materials, 10-20.

Production records, use of, 36.

Profite, facts on, 10, 11; moaning of average, 92-100; measurement of, 34. 
Quartiles, mesning of the, 105.

Questionnaires, editing of, 52-53; principles in preparing, 51-52.

\section{$\mathbf{R}$}

"Ratio" chart (illustrated), 93; characteristics of the, 94-96.

"Ratio" charts, contrast of, with difference charts, 92-96.

Raw materials, mineral, 10-20.

Research and business, 36 .

\section{$\mathbf{S}$}

Sales campaigns, population characteristics in developing, 30 .

Sales facts, 7.

Sales records, use of, 36 .

Salesmen, reports of, 37.

Salesmanship, standards of, 37 .

Sampling, "law of averages" and, 102-104; principles of, 31-32.

Samples, requirements of good, 103.

Scale, horizontal, in graphics, 57; logarithmic, to measure ratio changes, 64; vertical, in graphics, 57 ; vertical, in logarithmic charts, 64; figures, 59; units, and logarithmic charts, 59; position of, in frequency distributions, 62 .

Scales, spacings on vertical and horizontal (illustrated), 68; use of, in graphs (illustrated), 69.

Scientific method, business analysis and, 38-40; classification and, 50 ; fact analysis and, 36 ; meaning of, $3-4,8,12$; phases of, in business analysis, 129-130.

Schedules, editing of, 52-53; principles in making, 51-52.

Secondary sources, use of data from, 54 .

Secrist, Horace, An Introduction to Statistical Methods, 58, 122.

Selling costs, business analysis and, 36 .

Standardization, meaning of, in business statistics, 29.

Statistical facts, must be accurate, 34-35; must be comparable, 34; must fit, 33 ; must be homogeneous, $30-31$; must be representative, 31-33; must be stable, 33-34.

Stock prices, measurement of, 33 .

Strike, how measured statistically, 28; as a statistical fact, 27-28.

Surfaces and bars contrasted (illustrated), 75, 
Tables, preparation of unelem, is businems operations, $\boldsymbol{s}$.

Tabulation, advantages of, 41-42; a mean not and end, 54 ; butioess analysis through, 50; condensed detail and, 48; contrurted with graphics, 55; grouping in, 49; hand and machine, 33-54; order of detail in, 43-46; position of totals in. 46; principlen to be followed in, 43-48; relation of, to the collection of data, 51, 83; relation of, to elaseification, 41, 53; tilles to tables and, 47-48; unclasxified material and, $\mathbf{5 0}$.

Tax facte, 11, 14.

Trade facts, 21-22.

Transportation facts, 23-24; clansified, 14.

Turn-over, meaning of average, 100; of goods, comparison of, 31; of labor, 17; of labor, comparisons of, 31 .

$\mathbf{U}$

Unemployment, 16-17.

Union membership, 15-16.

$\mathbf{W}$

Wage, meaning of average, 99.

Wage-rates, 15.

Wages, accuracy of, 35.

Wholesale prices, measurement of, 32-33.

Z

Zero line, marking of (illustrated), 69-70; vertical scale and, 86-88. 
$\because$ 



\section{,}

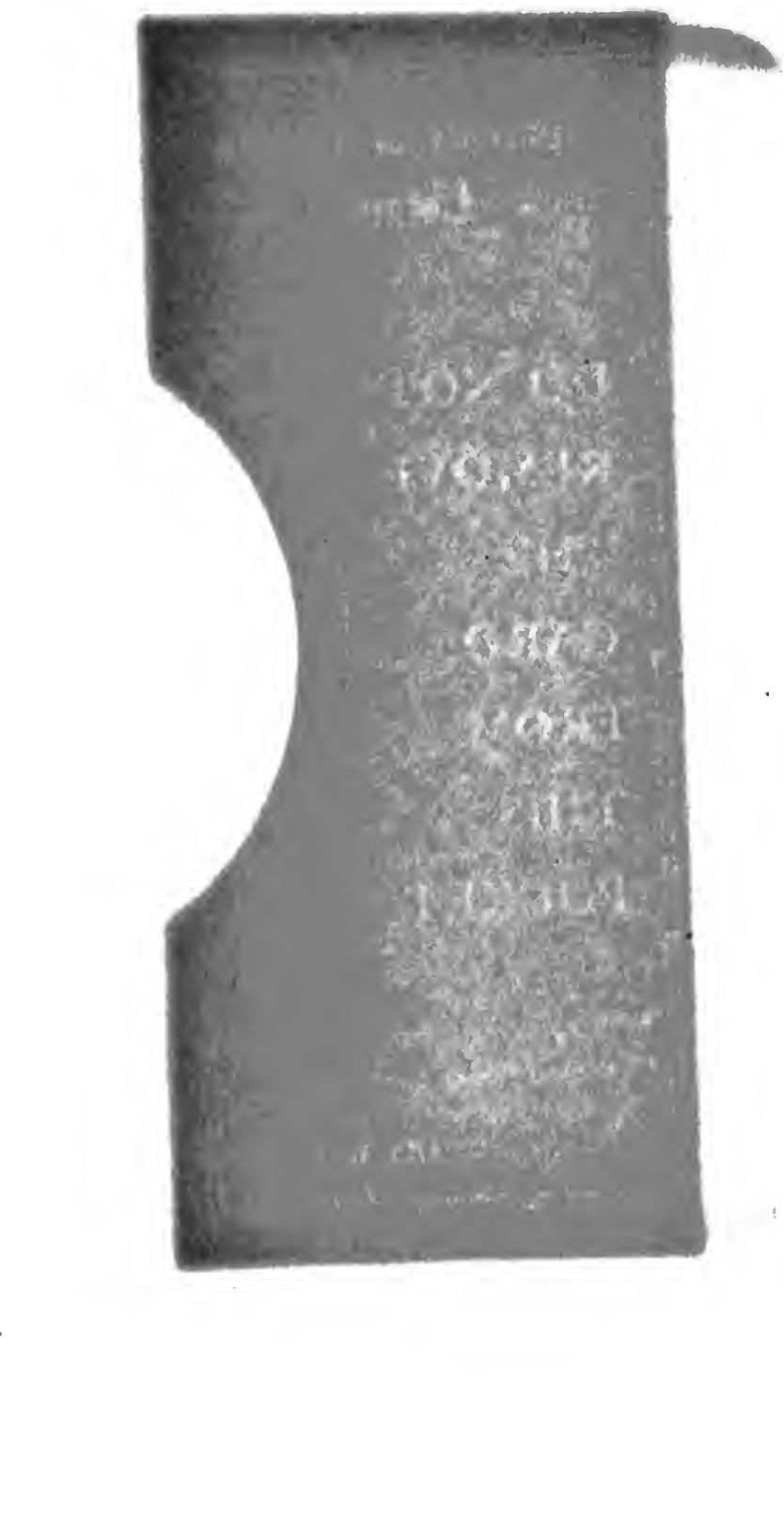




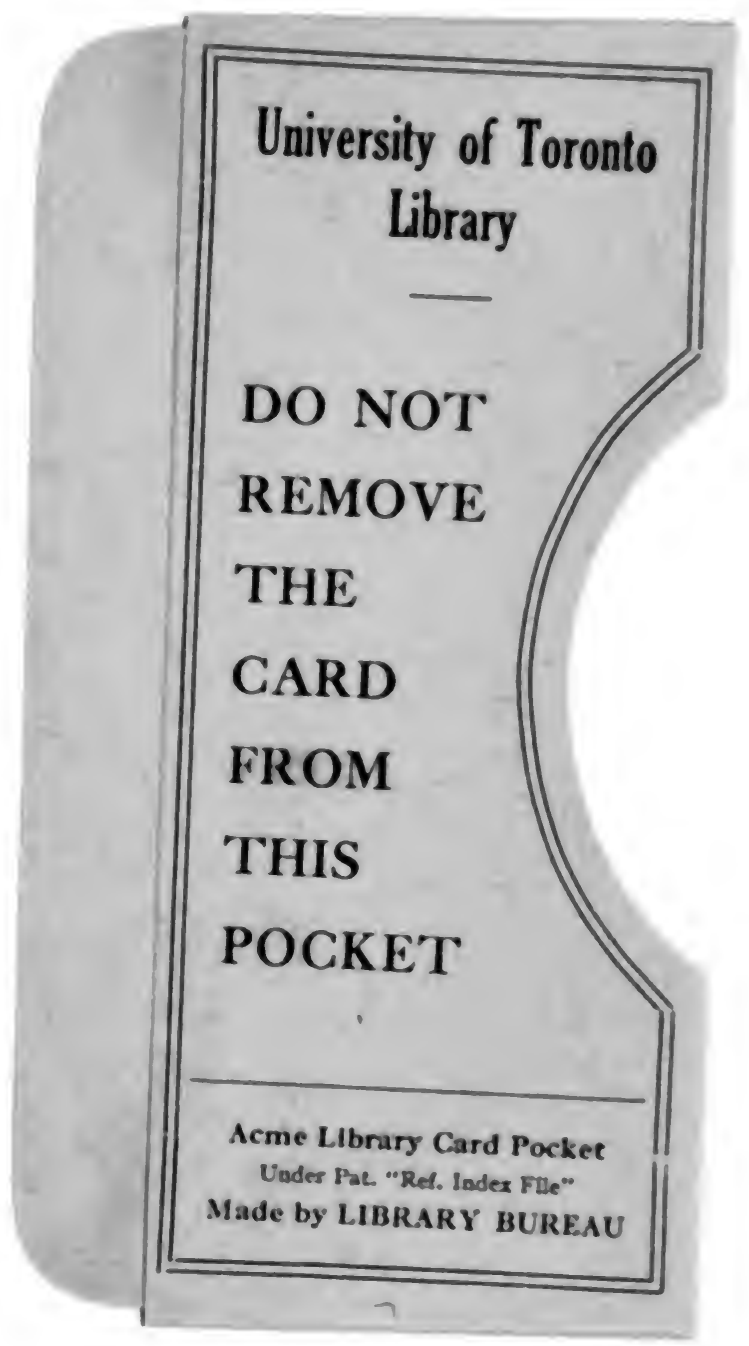


